Development of Packed Bed Membrane Reactor for the Oxidative Dehydrogenation of Propane 


\section{Development of packed bed membrane reactor for the oxidative dehydrogenation of propane}


Samenstelling promotiecommissie:

Prof. dr. ir. L. Lefferts, voorzitter

Prof. dr. ir. J. A. M. Kuipers, promotor

Dr. ir. M. van Sint Annaland, assistent-promotor

Dr. ir. H. J. M. Bouwmeester

Prof. dr. ir. Th. H. van der Meer

Prof. dr. J. G. E. Gardeniers

Prof. dr. ir. J. C. Schouten

Prof. Dr.-Ing. habil. S. Heinrich
Universiteit Twente

Universiteit Twente

Universiteit Twente

Universiteit Twente

Universiteit Twente

Universiteit Twente

Technische Universiteit Eindhoven

Technische Universität Hamburg-Harburg

Publisher:

Gildeprint B.V., Enschede, The Netherlands

Copyright (C) 2009 by Ž. Kotanjac

All rights reserved. No part of this book may be reproduced or transmitted in any form, or by any means, including, but not limited to electronic, mechanical, photocopying, recording, or otherwise, without the prior permission of the author. 


\title{
DEVELOPMENT OF PACKED BED MEMBRANE REACTOR FOR THE OXIDATIVE DEHYDROGENATION OF PROPANE
}

\author{
PROEFSCHRIFT
}

ter verkrijging van

de graad van doctor aan de Universiteit Twente,

op gezag van de rector magnificus,

Prof. dr. H. Brinksma,

volgens besluit van het College van Promoties,

in het openbaar te verdedigen

op vrijdag 4 december 2009 om 13.15 uur

door

\section{Željko Kotanjac}

geboren op 25 september 1977

te Kraljevo (Servië) 
Dit proefschrift is goedgekeurd door de promotor:

Prof. dr. ir. J. A. M. Kuipers

en de assistent-promotor

Dr. ir. M. van Sint Annaland 
Оиу Светиславу, за испунене давног обећана 



\section{Preface}

An increasing and long lasting demand for lower olefins, especially propylene, gave a strong motivation to scientists all over the globe to search for an alternative production route. One of the most promising ones was oxidative dehydrogenation of propane, often referred as ODHP, which, compared to thermodynamically unfavored non-oxidative dehydrogenation, could bring larger yields of desired propylene. This was one of the reasons why The Netherlands Organization for Scientific Research (NWO) decided to support financially a project on the development of a reactor concept for the selective oxidation of propane for olefin production, which result, in the form of this thesis, is in front of you.

To achieve the goals set in the project proposal, prof. dr. ir. Hans Kuipers decided to give me an opportunity to start this long, but rather interesting trip into a world of engineering science. Thus, a big and special thanks goes to him, for all what he has done for me in the past few years. It is impossible to express how much freedom he gave me in my research: so many brainstorming discussions, extremely intelligent remarks and excellent explanations for all the problems I had encountered in my work and his bird-eye view on a subject have helped that this thesis comes to the light. As this was a joint project of two research groups, I would also like to express my gratitude to prof. dr. ir. Geert Versteeg, who offered me to start working on this project in his group and whom I am deeply indebted for my coming to The Netherlands. His scientific support and supervision were much more than a graduate student can expect from his professor!

My daily supervisors, dr. ir. John Niederer and dr. ir. Martin van Sint Annaland I am very grateful for creating just the right hue of relaxed and productive work environment that I had the privilege of enjoying the past years. Their ideas, their help, and especially their unique brand of enthusiasm form the bedrock on which much of this thesis was built.

Experimental work definitely couldn't be performed without the best technicians I've ever met - special thanks goes to Benno, Wim, Johan, Erik and Gerrit not only for constructing my experimental setup, but also for their smart technical advices, without which I would never have my setup working properly. They were always willing to leave all their work and help me when something went wrong, thus, once more - thank you. Secretaries Irene and Nicole I am grateful for handling all administrative work for me in the past years and for being a friendly-ear for all my complaints. My colleagues from both, OOIP and FCRE group, I would like to thank for creating a good and stimulating atmosphere. 
Moving towards more personal acknowledgments, I would like to thank all my friends for their support and enormous amount of patience they had with me - it was quite difficult to listen about all my problems with experiments, modeling, lab equipment, weird result numbers, and so on.

На крају, желео бих да се захвалим својим родитељима и сестри, за свесрдну и несебичну подршку и помоћ током свих ових година. Њихово разумевање за све моје проблеме и веровање у мене су ми увек давали мотивацију и охрабрење у остваривању мојих великих циљева и без њих никада не бих постао ово што сам данас.

Enschede,

Željko Kotanjac

November 2009 


\section{Contents}

1 Introduction 1

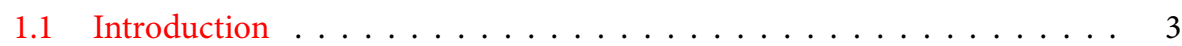

1.2 Current processes for light olefins production $\ldots \ldots \ldots \ldots \ldots \ldots$

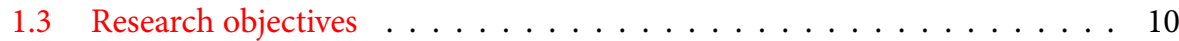

1.4 Thesis outline . . . . . . . . . . . . . . . . . . . . 10

References ....................... 11

2 Literature Survey 13

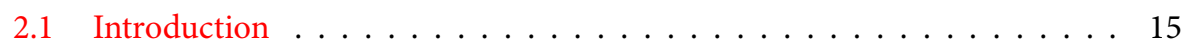

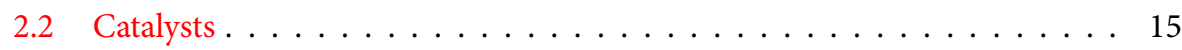

2.3 Process conditions . . . . . . . . . . . . . . . . . . . 19

2.4 Kinetics and kinetic models for $\mathrm{ODH}$ of light alkanes $\ldots \ldots \ldots \ldots 23$

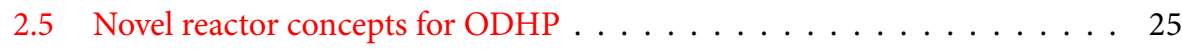

2.6 Conclusions . . . . . . . . . . . . . . . . . . . . . . . 29

References . . . . . . . . . . . . . . . . . . 30

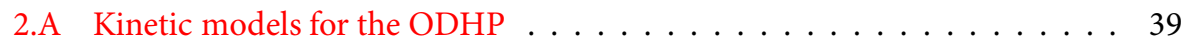

3 Kinetics of the ODHP over $\mathrm{Ga}_{2} \mathrm{O}_{3} / \mathrm{MoO}_{3}$ based catalyst 43

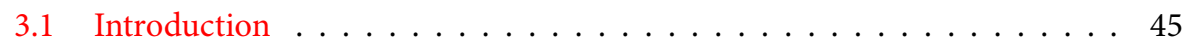

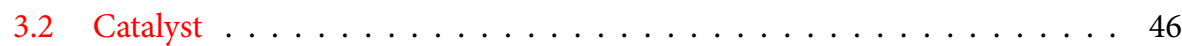

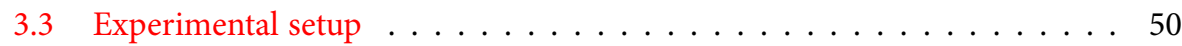

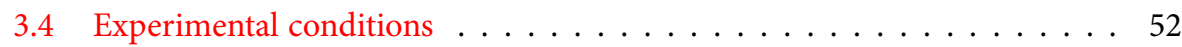

3.5 Kinetic experiments . . . . . . . . . . . . . . . . . 57

3.6 Results and discussion $\ldots \ldots \ldots \ldots \ldots \ldots \ldots \ldots$ 
iv $\quad$ Contents

3.7 Reaction mechanism and kinetic model . . . . . . . . . . . . . . . . . . . 64

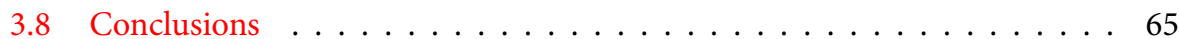

References ............................. 66

4 Modeling of a packed bed membrane reactor for the ODHP 69

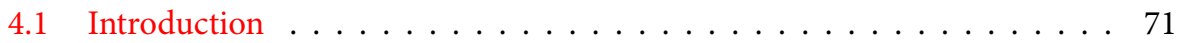

4.2 General model assumptions . . . . . . . . . . . . . . . 71

4.3 Description of the PBMR model . . . . . . . . . . . . . . . . . . . 74

4.4 Results and discussion $\ldots \ldots \ldots \ldots \ldots \ldots$. . . . . . . . . 78

4.5 Conclusions . . . . . . . . . . . . . . . . . . . 90

References .............................. 93

4.A Transport parameters ...................... 96

4.B Physical properties . . . . . . . . . . . . . . . . 98

5 Experimental demonstration of ODHP in a PBM reactor 103

5.1 Introduction . . . . . . . . . . . . . . . . . . . . . . . 105

5.2 Objectives . . . . . . . . . . . . . . . . . . . . 105

5.3 Experimental . . . . . . . . . . . . . . . . . . . . . . 105

5.4 Results and discussion . . . . . . . . . . . . . . . . . . . . . 112

5.5 Conclusions . . . . . . . . . . . . . . . . . . . . . . . 118

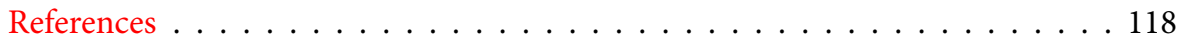

$\begin{array}{ll}\text { Summary } & 121\end{array}$

$\begin{array}{ll}\text { Samenvatting } & 125\end{array}$

$\begin{array}{lr}\text { Сажетак } & 129\end{array}$

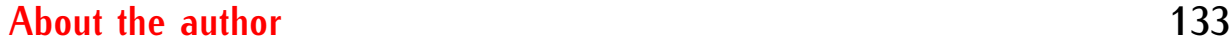




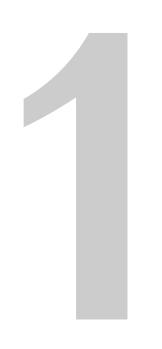

\section{Introduction}

With an increasing demand for lower olefins, especially propylene, it is anticipated that the existing routes for its production will become insufficient, which paves the road for the development of a new process - the oxidative dehydrogenation of propane. Not suffering from thermodynamic limitations, as is the case with direct dehydrogenation processes, not producing carbonaceous deposits which may deteriorate the catalytic activity and with a possibility to produce propylene at much lower temperatures without expensive heat exchange equipment (i.e. improved energy efficiency), this new process is potentially very promising. The oxidative dehydrogenation of propane has been an important research area for a number of years. The research described in this thesis focuses on the reactor technology development for this process. In this chapter a brief introduction to the process of oxidative dehydrogenation of propane will be given, together with the research questions and the thesis outline. 



\subsection{Introduction}

L

IGHT OLEFINS ARE IMPORTANT CHEMICALS in synthesis processes because of their high chemical activity in the reactions. The total amount of ethylene and propylene consumed in 2005 by the global chemical industry have been estimated to be about 107 Mton and 67.1 Mton, respectively [1]. Propylene, one of the most valuable petrochemicals, is nowadays produced either by steam cracking of liquid feedstocks such as naphtha as well as LPGs, where propylene comes out as a by-product [2], or is recovered from off-gases produced in fluid catalytic cracking (FCC) units in refineries (see Table 1.1). The remainder of propylene (currently only $3 \%$, but growing) is produced via on-purpose technologies such as propane dehydrogenation (PDH) and metathesis.

Table 1.1: Commercial sources of world propylene production in 2002, according to Walther [3]

\begin{tabular}{|c|c|c|c|}
\hline \multirow{2}{*}{ Propylene source } & \multicolumn{2}{|c|}{ World production } & \multirow{2}{*}{$\begin{array}{c}\text { Annual growth, } \\
\%, 2001-15\end{array}$} \\
\hline & million tons & $\%$ share & \\
\hline Steam crackers & 35.9 & 68.0 & 4.3 \\
\hline Refinery FCC units & 15.3 & 29.0 & 5.0 \\
\hline Metathesis/cracking/dehydrogenation & 1.6 & 3.0 & 6.5 \\
\hline Methanol-to-olefins & design stage & - & - \\
\hline Total & 52.8 & 100.0 & 4.7 \\
\hline
\end{tabular}

The primary source of propylene as a side product is from cracking naphtha and other liquids such as gas oil and condensates, which mainly produces ethylene. By altering the cracking severity and the feedstock, the propylene:ethylene ratio can be increased from 0.4:1 to $0.75: 1$. Smaller amounts of propylene are obtained from cracking propane and butane. The cracking of liquid feedstocks is carried out predominately in Europe and Asia, while a growing source of propylene, particularly in the US, is from refineries where splitters recover the propylene from the off-gases produced by FCCs [3]. However, refinery propylene needs further purification for chemical and polymer use.

With a propylene demand growing faster than the demand for ethylene, combined with the construction of more ethane crackers, rather than naphtha crackers, on-purpose technologies for the production of propylene are highly desirable. The main on-purpose process currently industrially applied is propane dehydrogenation $(\mathrm{PDH})$ but it is only economically viable in cases where low-cost LPGs are available. These processes suffer from thermodynamic limitations, coke formation and require costly heat exchange at high operating temperatures because of the endothermicity of the reaction.

In the next section a brief description is given of current industrial processes for light olefins production. 


\subsection{Current processes for light olefins production}

Typical processes for the commercial production or having a great potential for light olefins production are those using petroleum distillates as a feedstock. The processes can be classified into four groups:

1. thermal cracking

2. catalytic pyrolysis

3. catalytic cracking and

4. catalytic dehydrogenation.

The main characteristics of these processes are described subsequently.

\subsubsection{Thermal cracking}

Thermal cracking includes processes, such as steam cracking in a tubular furnace, a sand furnace and a coke particles fluidized bed (K-K process) [4]. Without the introduction of catalytic particles into the process, the cracking reactions are the result of thermal cracking. The tubular furnace cracking is the most widely used process for light olefins production today, which provides over $99 \%$ of the entire ethylene production in the world [5]. However, the difficulty in treating heavy feeds has limited its application range greatly. Because the solids can carry the coke deposited out of the reactor, the sand furnace and the fluidized bed consisting of coke particles are capable of treating heavy feeds, however the low yields of light olefins caused by significant backmixing in these reactors have made them give way to the tubular furnace.

\subsubsection{Catalytic pyrolysis}

Next to thermal cracking processes, there are pyrolytic processes which use catalysts accelerating cracking reactions, adopted to increase the yields of olefins and reduce the operating temperature. Those processes are classified as catalytic pyrolysis [5]. However, the temperature is still high enough for thermal cracking reactions, so the distribution of products is determined by both thermal and catalytic reactions. Different catalysts require different operating conditions and result in different product distributions [6,7], but none of these processes is widely used in commercial production. The reason may lie in the undesired economic drawback caused by the large number of low value byproducts (for example, dry gas and coke) in the produced gas. 


\subsubsection{Catalytic cracking}

Although the fact that dry gas from the FCC processes contains light olefins was known long ago and was also regarded as an important source for light olefins, it was only in recent years that catalytic cracking was developed into independent processes for light olefins production. Besides the MAXOFIN process [8] and the PetroFCC process [9], a series of similar processes (MIP [10], MGG [11], ARGG [12], etc.) with different desired products were developed. Because the thermal effect is very weak at the relatively lowtemperature operating conditions, the conversion and selectivity strongly depend on the performance of the catalyst (usually a kind of zeolite catalyst similar to the FCC catalyst).

Propylene or butylene, but not ethylene, has the highest yield among the overall gas products. Additionally, some liquid products are also obtained in these processes, however the high content of olefins makes their direct use often difficult. In comparison with thermal and catalytic cracking, catalytic pyrolysis seems to be more suitable to obtain the maximum light olefins (including ethylene, propylene and butylene) at a relatively low temperature by adopting both thermal cracking and catalytic cracking, although the high yield of low-value byproducts needs to be reduced. Novel processes in this area are still encouraged.

\subsubsection{Catalytic dehydrogenation}

Conventional catalytic dehydrogenation of light paraffins is well established and practiced commercially worldwide. Most important are the following processes: CATOFIN (United Catalysts/ABB Lummus Crest) [13], OLEFLEX (UOP) [14], FBD (Snamprogetti, Yarsintez) [15] and STAR (Uhde) [16]. Although these processes and their respective catalysts are highly optimized, they all suffer from the common disadvantage that their olefin yields are thermodynamically limited. These processes differ in the way heat is provided for the endothermic dehydrogenation and in the way carbonaceous deposits on the catalyst particles, formed as a side product during the dehydrogenation, are removed. The following paragraphs describe these processes more in detail, while a short summary is presented in Table 1.2.

\section{CATOFIN process}

The CATOFIN process converts propane to propylene over a fixed-bed chromia-alumina catalyst. The unconverted propane is recycled so that propylene is the main product. Operating conditions for the process are selected to optimize the relationship among selectivity, conversion, and energy consumption. Side reactions occurring simultaneously with the main reaction cause the formation of some light and heavy hydrocarbons as well as the deposition of coke on the catalyst [17]. 
Table 1.2: An overview of the industrial technologies for the dehydrogenation of lower alkanes

\begin{tabular}{|c|c|c|c|c|}
\hline process & CATOFIN & OLEFLEX & STAR & FBD \\
\hline operating mode & cyclic & moving bed & cyclic & $\begin{array}{c}\text { fluidized } \\
\text { bed }\end{array}$ \\
\hline reactor type & adiabatic & adiabatic & isothermal & adiabatic \\
\hline total number of reactors & 5 & 4 & 8 & 1 \\
\hline duration of cycle & $25 \mathrm{~min}$ & continuous & $8 \mathrm{~h}$ & continuous \\
\hline \multicolumn{5}{|l|}{ process conditions } \\
\hline temperature, $\mathrm{K}$ & $798-950$ & $798-978$ & $755-894$ & $793-873$ \\
\hline pressure, bar & $0.1-0.7$ & $1-3$ & $3-8$ & $1.1-1.5$ \\
\hline propane conversion, $\%$ & 65 & 40 & $30-40$ & - \\
\hline selectivity to $\mathrm{C}_{3} \mathrm{H}_{6}$ & 87 & 90 & $80-90$ & - \\
\hline isobutane conversion, $\%$ & $60-65$ & $45-50$ & $45-55$ & $\sim 50$ \\
\hline selectivity to iso- $\mathrm{C}_{4} \mathrm{H}_{8}$ & 95 & $91-92$ & $85-90$ & $>90$ \\
\hline
\end{tabular}

The process is endothermic and takes place in several parallel fixed-bed reactors that operate on a cyclic basis to permit continuous uninterrupted flow of the major process streams. In one complete cycle, hydrocarbon vapors are dehydrogenated and the reactor is then purged with steam and blown with air to reheat the catalyst and burn off the small amount of coke (less than $0.1 \%$ on catalyst) which is deposited during the reaction cycle. These steps are followed by an evacuation and reduction and subsequently another cycle is started.

One of the negative aspects of this process is the need for external heating and cooling. The feed is preheated through a fired heater before being passed over the catalyst in the reactors. The hot reactor effluent is cooled, compressed, and sent to the product fractionation and recovery system. The need for external heating and cooling obviously influences the overall energy efficiency of the system.

\section{OLEFLEX process}

This process for isobutane and propane dehydrogenation was first introduced in Thailand in 1990 [18]. The process was developed on the basis of the following two successfully operating UOP processes: the Pacol process for the dehydrogenation of paraffins from a kerosene fraction to monoolefins and the CCR platforming process used for reforming of naphtha in the production of high-octane gasoline. The OLEFLEX process is performed with a moving bed of a bead platinum catalyst in a multiple-stage reactor unit via a reactor-regenerator circuit with intermediate heat absorption between the units [19]. Three or four reactors are required for $\sim 40 \%$ conversion in the dehydrogenation of isobutylene 
or propane, respectively. This process is characterized by high capital investments because of the sophisticated apparatuses required. Moreover, this technology requires a high mechanical strength of the catalyst. It is likely that, for the above reasons, the first plant in Thailand was put into operation with a ten year delay despite of a large publicity program.

The main disadvantage of this process is low equilibrium conversion and the need to operate at a pressure lower than atmospheric to achieve a reasonable ethane conversion [16]. Again the need for external inter-stage heaters and coolers contribute to lowering the overall energy efficiency of the system.

\section{Steam active reforming (STAR) process}

STAR, the acronym for STeam Active Reforming, is a commercially established technology for the dehydrogenation of light paraffins, such as propane or butane. Initially developed by Phillips Petroleum Company, USA, the technology was acquired by Uhde in December 1999. In the period from 2000 to 2003 the performance of the STAR process was significantly increased by addition of an oxydehydrogenation step, which enhances the process economics in terms of investment and operating costs.

The fresh $\mathrm{C}_{3} / \mathrm{C}_{4}$ paraffin feed, recycled unconverted light paraffins and process steam are preheated and fed to the first part of the reaction section - the STAR process reformer. The reformer is a tubular top-fired reactor furnace, where the tubes are filled with STAR catalyst, based on a zinc and calcium aluminate support, impregnated with various noble metals. This catalyst is extremely stable at high temperatures in the presence of steam and oxygen and demonstrates excellent dehydrogenation properties with very high selectivities at near equilibrium conversion. The endothermic dehydrogenation reaction takes place at $773-873 \mathrm{~K}$ and pressures of 6-9 bar.

In the second step, part of the hydrogen from the intermediate reaction product, leaving the reformer, reacts selectively with oxygen or oxygen-enriched air at a maximum $873 \mathrm{~K}$ and $5-6$ bar in the adiabatic catalytic oxyreactor, thereby producing steam. This is followed by further dehydrogenation over the same STAR catalyst bed.

Internally supplied heat from the exothermic hydrogen combustion significantly reduces the load on external heat required for the endothermic dehydrogenation, which contributes to better energy efficiency in comparison to CATOFIN and OLEFLEX processes.

The reaction section operates on an eight-hour operational cycle, i.e. seven hours of operation followed by one hour regeneration. A typical design features two parallel reaction trains, each with a reformer and a downstream oxyreactor. Within an eight-hour cycle both trains are in operation for six hours and in the other two hours each of the two trains is regenerated for an hour while the other is in operation. Fluctuation of the product flow due to the process cycle is equalized in an intermediate storage vessel upstream of the fractionation section. 


\section{Fluidized bed dehydrogenation (FBD) process}

A dehydrogenation technology employing a fluidized bed reactor [20, 21] was developed in the former Soviet Union during the fifties, to supply $\mathrm{C}_{4}-\mathrm{C}_{5}$ olefins for the production of synthetic rubbers.

In the last decade, Snamprogetti and the Russian company Yarsintez have further developed this technology improving both chemical and engineering aspects to make it economically competitive in Western markets [22]. A new technology for the production of the catalyst was developed, enhancing its chemical activity and improving dramatically its mechanical resistance against particle attrition, a particularly important aspect in fluidized bed systems: the consumption of the catalyst by attrition has been decreased by a factor of thirty in comparison with the original Russian catalyst. The result of this joint effort is the FBD (fluidized bed dehydrogenation) technology that is now commercialized by Snamprogetti for the dehydrogenation of $\mathrm{C}_{3}, \mathrm{C}_{4}$ and $\mathrm{C}_{5}$ paraffins (FBD-3, -4 and -5).

In the FBD technology, the reaction section consists of two units, a reactor-regenerator assembly similar to that used in the FCC process. The dehydrogenation step occurs in a staged fluidized catalytic bed, without diluents, operating at pressures slightly above atmospheric. Fresh feed is vaporized, mixed with a recycle from an olefins user unit (e.g. MTBE), preheated by cross-exchange with the reactor effluent, then fed to the reactor vessel from the bottom of the catalytic bed. Reaction products are separated from the entrained catalyst powder by means of high efficiency cyclones and, after a complete dust elimination in a suitable scrubbing system, are sent to compression and separation sections to separate $\mathrm{C}_{3} / \mathrm{C}_{4}$ stream from hydrogen and by-products. The heart of the process is the reactor-regenerator system.

Catalyst circulates continuously from the reactor vessel to the regenerator and viceversa by means of pneumatic transfer lines, creating a countercurrent gas-solid contact both in the reactor and in the regenerator. In the regenerator vessel the catalyst restores its initial activity by combustion of the low amounts of coke deposited on its surface: additional fuel is catalytically burned directly on the catalyst to satisfy the overall thermal balance. The heat developed in the regenerator is stored by the catalyst itself and used for the dehydrogenation reactions. Before being conveyed to the regenerator, the catalyst is stripped with nitrogen to avoid loss of adsorbed products.

The same operation is performed on the bottom of the regenerator to avoid oxygen transport to the reactor vessel, which may result in a loss of selectivity.

\subsubsection{Oxidative dehydrogenation of propane}

In contrast to dehydrogenation processes, a potentially better alternative to the conventional propylene production processes is in principle the oxidative dehydrogenation of propane, or shortly, ODHP. This process offers operation at lower temperatures, avoids 
coke formation due to the presence of oxygen and has a good internal thermal integration of the overall slightly exothermic process without the requirement for high temperature heat exchange equipment, but, there are still many challenges to be overcome in order to make the ODHP commercially attractive.

Research performed by many different scientists during the last 30 years certainly contributed to a better understanding of the ODH reactions. Many different catalysts were tested, many different operating conditions and parameters were explored and many improvements were made. However, a reactor design for the specific needs of the process of oxidative dehydrogenation of propane appears to be a relatively unexplored area. The aim of this thesis is to show that with a sophisticated reactor design, significant improvements in the yield of the desired reaction product, propylene, can be achieved, while at the same time the yield of undesired carbon oxides can be decreased.

Although the actual reaction network is very complex, the reaction scheme of propylene formation via ODHP can be simplified as indicated in equation 1.1:

$$
\text { target product: } \mathrm{C}_{3} \mathrm{H}_{8}+\frac{1}{2} \mathrm{O}_{2} \longrightarrow \mathrm{C}_{3} \mathrm{H}_{6}+\mathrm{H}_{2} \mathrm{O}
$$

where undesired carbon oxides can be formed either by direct propane combustion (equation 1.2), or by deep oxidation of propylene (equation 1.3).

$$
\text { waste products: } \begin{array}{ll}
\mathrm{C}_{3} \mathrm{H}_{8}+\frac{1}{2}(4+3 \mathrm{x}) \mathrm{O}_{2} \longrightarrow 3 \mathrm{CO}_{\mathrm{x}}+4 \mathrm{H}_{2} \mathrm{O} \\
& \mathrm{C}_{3} \mathrm{H}_{6}+\frac{3}{2}(2+\mathrm{x}) \mathrm{O}_{2} \longrightarrow 3 \mathrm{CO}_{\mathrm{x}}+3 \mathrm{H}_{2} \mathrm{O}
\end{array}
$$

In such partial oxidation systems, the reaction order of oxygen for the formation of the desired product is typically lower than the reaction order for the formation of waste products. In this case, lowering the oxygen inlet concentration is very beneficial for increasing the selectivity to the desired product, which, combined with a high conversion, would result in a significantly higher yield of olefins [23]. For a proper reactor design, it is necessary to have information whether the waste products are obtained in reactions where both, desired and waste products are formed directly from the reactants in the feed (parallel reaction scheme), or in reactions of an intermediate (and simultaneously target!) product with oxygen in the feed (consecutive reaction scheme).

In the parallel reaction scenario, there are two possible reactor configurations: a wellmixed reactor, such as a fluidized bed reactor, where the oxygen concentration can be kept low, due to the back-mixing, or a packed bed membrane reactor with a distributive oxygen feed. The main problem associated with the well-mixed reactor is that due to the backmixing of the products, the reactant concentration is also relatively low, so that a large reactor volume is required. On the other hand, in case of a consecutive reaction scheme gas back-mixing should be avoided and the oxygen concentration should remain low in order to achieve optimal product selectivity. A membrane reactor with a distributive oxygen feed would be, in terms of reactor volume and/or propylene yield, the best solution, due to the much lower axial gas dispersion. 


\subsection{Research objectives}

The primary goal of this research is to develop a packed bed membrane reactor for the oxidative dehydrogenation of propane and to quantify the benefit of a distributive oxygen feed on the propylene selectivity and yield in comparison to the packed bed reactor with premixed reactants flow both computationally and experimentally. Together with the reactor design, also the operating conditions are examined, in order to maximize the yield of propylene.

It is important to mention that in the research performed, the membrane is observed as an oxygen distributor (porous membrane), while the actual transport of oxygen through the membrane was not studied.

The outline of this study is described in the following section.

\subsection{Thesis outline}

The research described in this thesis starts in chapter 2 with a literature survey on the catalysts used in the ODH of propane, as well as temperature, pressure, feed composition and other process conditions studied by other researchers. This served as a basis for the selection of a suitable catalyst system for the experimental work and the development of the experimental setup.

Kinetic studies of the ODHP over the selected $\mathrm{Ga}_{2} \mathrm{O}_{3} / \mathrm{MoO}_{3}$ catalyst are described in chapter 3. Experiments were performed in a differentially operated lab-scale packed bed reactor to obtain detailed kinetic information on the propane and propylene reaction rates. Reaction orders in the hydrocarbons and in oxygen were determined for both target and side reactions. Also the importance of the non-catalyzed system is investigated.

In chapter 4 a detailed mathematical model is developed in order to assess and quantify the possible benefits of a packed bed membrane reactor for the process of propane oxidative dehydrogenation. A pseudohomogeneous, 1-D model is developed based on mass and energy conservation equations, as well as the kinetic equations derived from the experiments described in chapter 3. The results include, among others, how the reactor length, oxygen concentration and feed dilution influence the yields of propylene and side products.

Subsequently, the necessary experimental validation of the results obtained from numerical simulations discussed in chapter 4 were carried out and these results are presented in chapter 5. The influence of feed composition, flow rate and extent of dilution were measured for both, premixed and distributed oxygen feed and compared with numerical simulations. 


\section{References}

[1] M. Eramo. Ethylene, propylene demand will experience increased growth in 200510. Oil \& Gas Journal, 103(45), 52-60 (2005).

[2] A. M. Aitani. Propylene Production. In S. Lee, editor, Encyclopedia of Chemical Processing, volume 5, pages 2461-2466. Taylor \& Francis (2005).

[3] M. Walther. Refinery sources will fill the future "propylene gap". Oil \& Gas Journal, 101(4), 52-54 (2003).

[4] Z. B. Ouyang, Z. C. Guo, N. Duan and Q. Qiao. Experimental study on coke and heavy oil co-conversion process for production of light olefins and synthesis gas. Energy Conversion and Management, 48(9), 2439-2446 (2007).

[5] R. S. Deng, F. Wei, Y. Jin, Q. H. Zhang and Y. Jin. Downer catalytic pyrolysis (DCP): A novel process for light olefins production. Chemical Engineering \& Technology, 25(7), 711-716 (2002).

[6] X. F. Li, B. J. Shen, Q. X. Guo and J. S. Gao. Effects of large pore zeolite additions in the catalytic pyrolysis catalyst on the light olefins production. Catalysis Today, 125(3-4), 270-277 (2007).

[7] X. H. Meng, C. M. Xu and J. S. Gao. Production of light olefins by catalytic pyrolysis of heavy oil. Petroleum Science and Technology, 24(3-4), 413-422 (2006).

[8] M. J. Tallman, C. Santner and R. B. Miller. Integrated catalytic cracking and steam pyrolysis process for olefins. United States Patent, (7128827) (2004).

[9] I. Young. UOP Technology Selected for Philippines Propylene Project. Chemical Week, 168(7), 18 (2006).

[10] X. H. Wang, S. Q. Gao, Y. H. Xu and J. S. Zhang. Gas-solids flow patterns in a novel dual-loop FCC riser. Powder Technology, 152(1-3), 90-99 (2005).

[11] Z. H. Qiu, Y. B. Lu and C. Y. Li. FCC catalyst with high LPG yield and lower gasoline olefin content. Fluid Catalytic Cracking Vi: Preparation and Characterization of Catalysts, 149, 297-304 (2004).

[12] Z. B. Chen, Y. Q. Huo, L. S. Zhong, Z. Y. Wang and X. Q. Wang. Residue Catalytic Cracking to Produce Light Olefins and Gasoline. Preprints - American Chemical Society. Division of Petroleum Chemistry, 40(4), 773-775 (1995).

[13] R. A. Buyanov and N. A. Pakhomov. Catalysts and processes for paraffin and olefin dehydrogenation. Kinetics and Catalysis, 42(1), 64-75 (2001).

[14] P. R. Pujado and B. V. Vora. Make $\mathrm{C}_{3}-\mathrm{C}_{4}$ olefins selectively. Hydrocarbon Processing, 69(3), 65-70 (1990).

[15] D. Sanfilippo, F. Buonomo, G. Fusco, M. Lupieri and I. Miracca. Fluidized bed reactors for paraffins dehydrogenation. Chemical Engineering Science, 47(9-11), 23132318 (1992). 


\section{Chapter 1}

[16] M. M. Bhasin, J. H. McCain, B. V. Vora, T. Imai and P. R. Pujadó. Dehydrogenation and oxydehydrogenation of paraffins to olefins. Applied Catalysis A: General, 221(12), 397-419 (2001).

[17] E. L. Tucci. Technical and commercial development of the Houdry catadiene/catofin dehydrogenation process. Abstracts of Papers of the American Chemical Society, 211, 86-IEC (1996).

[18] B. V. Vora and T. Imai. $\mathrm{C}_{2} / \mathrm{C}_{5}$ Dehydrogenation Updated. Hydrocarbon Processing, 61(4), 171-174 (1982).

[19] P. Chaiyavech. Commericialization of the world's first oleflex unit. Abstracts of Papers of the American Chemical Society, 223, U648-U648 (2002).

[20] D. Sanfilippo, F. Buonomo, G. Fusco, I. Miracca and G. R. Kotelnikov. Paraffins activation through Fluidized Bed Dehydrogenation: the answer to light olefins demand increase. Studies in surface science and catalysis, 119, 919-924 (1998).

[21] G. Fusco and M. Hyland. Fluidized-Bed Dehydrogenation for MTBE Plants (Snamprogetti Yersintez Process). Abstracts of Papers of the American Chemical Society, 200, 21-Cmec (1990).

[22] D. Sanfilippo. Dehydrogenation in a Fluidized-Bed - an East-West Collaboration. Chemtech, 23(8), 35-39 (1993).

[23] U. Kürten, M. van Sint Annaland and J. A. M. Kuipers. Oxygen distribution in packed bed membrane reactors for partial oxidation systems and the effect on the product selectivity. International Journal of Chemical Reaction Engineering, 2(A24), $1-24(2004)$. 


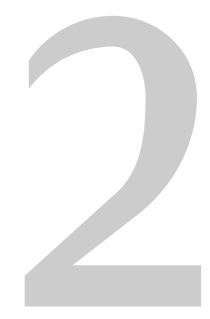

\section{Literature Survey}

As an alternative route for the production of propylene, the oxidative dehydrogenation of propane (ODHP) has been in focus of scientific research for more than thirty years. During this long period, various aspects of the process have been examined, especially the search for the best catalyst system and best operating conditions that achieve the largest yield of the desired product, propylene. This was also accompanied with research on possible reactor concepts: packed bed reactors with premixed or distributed oxygen feed, as well as reactors using fluidized bed technology were investigated. In this chapter an overview of these and other aspects of ODHP will be given. 



\subsection{Introduction}

W ITH THE INCREASING DEMAND for (light) olefins, [1-3] the existing routes for their production might become insufficient, forcing research to develop an alternative way for the production of these industrially important olefins. One of the potentially most attractive routes is the oxidative dehydrogenation.

Processes based on the catalytic dehydrogenation of alkanes show some major disadvantages related to thermodynamic limitations on the maximum single-pass conversion, high capital investment in high temperature heat exchange equipment to provide the required reaction energy and a high tendency to coking and corresponding short catalyst life times [4]. A route to overcome thermodynamic limitations is to combine the dehydrogenation reaction with hydrogen oxidation. Presence of oxygen in the reaction system also prevents coke formation and significantly extends catalyst lifetime, although the main problem, low olefin yield, still remains. Despite the research efforts invested and many different catalysts tested, the maximum propylene yield has not exceeded $30 \%$, which makes oxidative dehydrogenation process still far away from industrial commercialization. Variations in temperature, flow rate and feed composition also revealed the importance of operating conditions on overall process performance. Therefore, the properties of catalytic systems, process conditions and alternative reactor concepts are of crucial importance for further process improvement. A literature survey on catalyst, process conditions and reactor concepts for the ODHP is presented next.

\subsection{Catalysts}

Various materials have been examined for their potential catalytic enhancement of ODHP and a brief overview of the most important catalyst materials explored is presented here.

Today's often studied systems are vanadium- and molybdenum-containing catalysts. Conventional transition metal oxides with redox properties, such as vanadia catalysts did not show the expected performance [5-10], as (re)adsorption of olefins limits the yield and leads to total oxidation [11]. At the same time the same vanadia supported on alumina or sepiolite gives a more selective catalyst [12]. These catalysts are characterized by a relatively low selectivity $(<40 \%)$ and yield $(8-9 \%)$ to propylene, but they are active at relatively low temperatures $(623-673 \mathrm{~K})$. The catalysts based on the $\mathrm{VMgO}$ system have been investigated in recent years by Owen and Kung [12] and other authors [7, 8, 13-15]. These catalysts are characterized by relatively high selectivities and yields ( $60 \%$ and $20 \%$, respectively), but they also produce oxygenates. However, there is no agreement in the literature as to the nature of the inorganic phase that gives the best catalytic performance $[7,8,12,13]$, and it is likely that factors other than the crystalline structure of the vanadates, such as the presence of small amounts of $\mathrm{V}_{2} \mathrm{O}_{5}$ or alkali metals, enrichment in either magnesium or vanadium, particle size, and so on, may have a significant influence on the catalytic 
activity. Smits et al. $[16,17,18]$ investigated the VNbO system, which exhibits good productivity to propylene and apparently does not yield any oxygenated products. Selectivity to propylene was as high as $90 \%$ for low conversions of propane and the catalyst operated at relatively low temperatures $(653-723 \mathrm{~K})$.

Many authors [19-28] studied ODHP on catalysts based on vanadia and molybdena containing alkali $(\mathrm{K}, \mathrm{Li}, \mathrm{Rb})$ and transition metals $(\mathrm{Ni}, \mathrm{Cr}, \mathrm{V}, \mathrm{Mo}$, and $\mathrm{P})$ as promoters [24-31]. For the $\mathrm{VMgO}$ catalyst, the addition of alkali significantly decreased the activity and increased the selectivity, while redox elements led to an increase in both activity and selectivity. The effect of doping the support with altervalent ions $\left(\mathrm{Ca}^{2+}, \mathrm{Al}^{3+}, \mathrm{Fe}^{3+}, \mathrm{W}^{6+}\right)$ and of the sequence of potassium introduction into the $\mathrm{VO}_{\mathrm{x}} / \mathrm{TiO}_{2}$ catalysts on the physicochemical and catalytic properties in ODHP was also studied [21, 25]. The supports used for the deposition of the vanadium or molybdenum phase range from conventional carriers such as $\mathrm{TiO}_{2}, \mathrm{SiO}_{2}, \mathrm{Al}_{2} \mathrm{O}_{3}, \mathrm{MgO}$ and molecular sieves [23] to highly porous structures of pillared interlayered clays [22]. Isolation of vanadium ions [32,33] inside the zeolite matrix leads to a catalyst with relatively high yields of propylene. The tetrahedron structure of an isolated $\mathrm{VO}_{4}$ was proposed as the active site in the VAPO-5 catalyst.

However, various other catalysts have also been examined for potential use in the ODHP: Fox and Lee [34] have used supported molten salt catalysts, based mainly on alkali chlorides; Dahl et al. [35] have used lithium hydroxide/lithium iodide melts; Ushkov et al. [36] investigated a variety of metal sulphates as catalysts, Takita et al. [37] studied metal phosphates; Mazzocchia et al. [5] have used nickel molybdate catalysts, and Smits et al. [17] have used niobium pentoxide.

On the other hand, magnesia based catalysts mixed with rare-earth oxides and promoted with alkali halide, showed higher activity and higher selectivity for the formation of olefins, compared to the previously mentioned catalytic systems. According to Conway et al. [38], Conway and Lunsford [39] this type of catalyst showed good results in obtaining ethylene from ethane. The composition of the catalyst studied, corresponded closely to catalysts used for methane oxidative coupling [38] and contained mainly $\mathrm{MgO}$ mixed with $\mathrm{Dy}_{2} \mathrm{O}_{3}$ and promoted by alkali metal oxides and halogen (mainly $\mathrm{Cl}$ ). Halogens were claimed to be of great importance in achieving high yields, because of their acidity, which has a positive influence on the dehydrogenation.

Landau et al. [40] investigated the production of mixed olefins from LPG using rare earth catalysts promoted by alkali metal oxides and halogen. The propylene yield was comparable with the maximum obtainable yield of propylene made in a process using $\mathrm{Mg}$ $\mathrm{V}-\mathrm{O}$ catalysts, and also some ethene was formed over rare earth-alkali-halogen catalysts. Overall olefin yields were up to $50 \%$. Buyevskaya et al. [41] reported that the same olefin yield can be obtained from pure propane, and that the propylene yield could be even $17 \%$.

Davies and Taylor [42] studied gallium-molybdenum catalysts which showed increased yield of partial oxidation products by combining the alkane activation properties of $\mathrm{Ga}_{2} \mathrm{O}_{3}$ and the partial oxidation behavior of $\mathrm{MoO}_{3}$ in a synergistic manner. Comparison 
of the propane oxidation over $\mathrm{Ga}_{2} \mathrm{O}_{3}$ and $\mathrm{MoO}_{3}$ showed that the conversion over $\mathrm{Ga}_{2} \mathrm{O}_{3}$ was considerably higher than that for $\mathrm{MoO}_{3}$. This is consistent with the ability of $\mathrm{Ga}_{2} \mathrm{O}_{3}$ to activate alkanes. On the contrary, $\mathrm{MoO}_{3}$ alone was very selective for propane oxidative dehydrogenation to propylene.

The combination of the oxides into the $\mathrm{Ga}_{2} \mathrm{O}_{3} / \mathrm{MoO}_{3}$ catalyst combines the beneficial properties of increased oxidation rate over $\mathrm{Ga}_{2} \mathrm{O}_{3}$ with the selective oxidation function of $\mathrm{MoO}_{3}$ in a beneficial manner. Furthermore, the combination of two oxides demonstrated a synergistic effect to produce a marked increase in propylene yield.

As it could be concluded, many different catalytic systems have been studied in an attempt to understand and improve the process of the oxidative dehydrogenation of propane. To illustrate this, an overview of the selectivity to propylene reached at a certain propane conversion for the most commonly used catalytic systems for the oxidative dehydrogenation of propane has been presented in Figure 2.1. Note that different temperatures, extent of dilution (i.e. propane inlet concentration) and propane/oxygen ratios were used in the different references. The effect of the operating conditions is detailed in the next section.

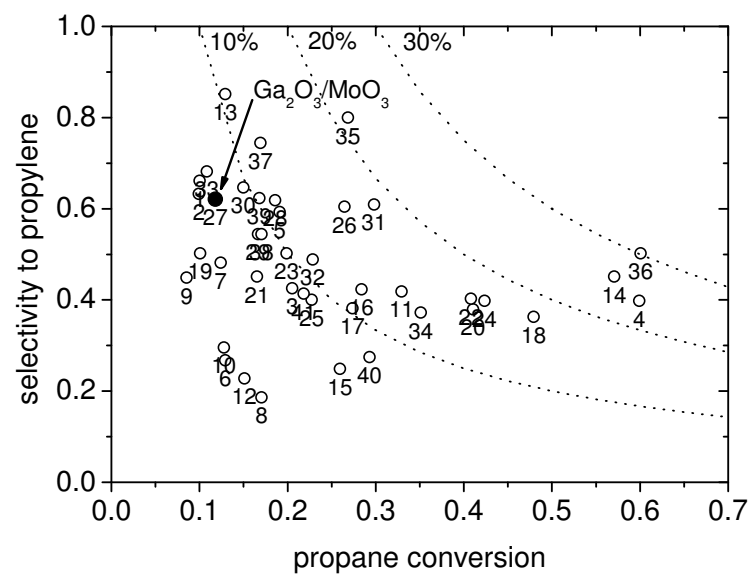

Figure 2.1: Selectivity to propylene as a function of propane conversion for different catalyst systems. Numbers in the figure correspond to the numbers given in the first column of Table 2.1. The $\mathrm{Ga}_{2} \mathrm{O}_{3} / \mathrm{MoO}_{3}$ catalyst used in this research is clearly indicated in the figure.

As can be discerned from the figure, most of the catalysts have a performance around $10 \%$ propylene yield. Only few of the catalytic systems are more active and give $20 \%$ or higher yield, which is, however, from an industrial perspective still far below the limits for commercialization. 


\section{Chapter 2}

Compared to the other catalytic systems shown in Figure 2.1, the $\mathrm{Ga}_{2} \mathrm{O}_{3} / \mathrm{MoO}_{3}$ catalyst used in this research is in terms of performance in the range of numerous other catalysts with a propylene yield of about $10 \%$, however, this catalyst is very easy to prepare (see chapter 3).

Table 2.1: Selectivity to propylene as a function of propane conversion for different catalytic systems at moderate temperature levels, taken from Cavani et al. [43]

\begin{tabular}{|c|c|c|c|c|c|c|}
\hline № & $\mathrm{T},\left[{ }^{\circ} \mathrm{C}\right]$ & catalyst & $\mathrm{C}_{3} \mathrm{H}_{8}: \mathrm{O}_{2}: \mathrm{D}$ & $\mathrm{D}$ & $\mathrm{F}_{\text {tot }}$ & ref. \\
\hline 1 & 550 & V-MCM-41 & $4: 8: 88$ & $\mathrm{He}$ & 75 & {$[44]$} \\
\hline 2 & 500 & $\mathrm{~V}_{2} \mathrm{O}_{5} / \mathrm{K}-\mathrm{SiO}_{2}$ & $7: 19.5: 73.5$ & $\mathrm{~N}_{2}$ & - & {$[29]$} \\
\hline 3 & 550 & $\mathrm{Mo} / \mathrm{Li} / \mathrm{O}-\mathrm{Al}_{2} \mathrm{O}_{3}$ & $4: 4: 92$ & $\mathrm{He}$ & 100 & {$[45]$} \\
\hline 4 & 650 & $\mathrm{Mg} / \mathrm{Dy} / \mathrm{Li} / \mathrm{Cl} / \mathrm{O}$ & $10: 10: 80$ & $\mathrm{He}$ & 10 & {$[46]$} \\
\hline 5 & 300 & $\mathrm{Ce} / \mathrm{Ni} / \mathrm{O}$ & $4: 8: 88$ & $\mathrm{~N}_{2}$ & 100 & {$[20]$} \\
\hline 6 & 500 & Ga-USY & $12: 6: 82$ & $\mathrm{He}$ & 100 & {$[47]$} \\
\hline 7 & 580 & Ga-MFI & $12: 6: 82$ & $\mathrm{He}$ & 100 & {$[48]$} \\
\hline 8 & 450 & $\mathrm{Ni} / \mathrm{Mo} / \mathrm{O}-\mathrm{V}-\mathrm{MCM}-41$ & $10: 10: 80$ & $\mathrm{He}$ & - & {$[49]$} \\
\hline 9 & 450 & $\mathrm{Ni} / \mathrm{Mo} / \mathrm{O}-\mathrm{V}-\mathrm{MCM}-41+\mathrm{N}_{2} \mathrm{O}$ & $10: 10: 80$ & $\mathrm{He}$ & - & {$[49]$} \\
\hline 10 & 450 & $\mathrm{Ni} / \mathrm{Mo} / \mathrm{O}+\mathrm{Sb} / \mathrm{O}+\mathrm{N}_{2} \mathrm{O}$ & $10: 10: 80$ & $\mathrm{He}$ & 30 & {$[50]$} \\
\hline 11 & 550 & Cr-MCF silica & $1: 1: 4$ & $\mathrm{~N}_{2}$ & 12.5 & {$[51]$} \\
\hline 12 & 550 & Cr-MCM-41 & $1: 1: 4$ & $\mathrm{~N}_{2}$ & 12.5 & {$[51]$} \\
\hline 13 & 650 & $\mathrm{Li} / \mathrm{MgO}$ & $10: 10: 2^{a}: 78$ & $\mathrm{He}$ & 30 & {$[52]$} \\
\hline 14 & 550 & $\mathrm{MoO}_{3}(\mathrm{Cl})-\mathrm{SiO}_{2} / \mathrm{TiO}_{2}$ & $26: 13: 61$ & $\mathrm{~N}_{2}$ & 25 & {$[53$} \\
\hline 15 & 500 & $\mathrm{Co} / \mathrm{Mo} / \mathrm{O}-\mathrm{MCM}-41$ & $4: 1: 10$ & $\mathrm{He}$ & 75 & {$[54]$} \\
\hline 16 & 300 & $\mathrm{Ni} / \mathrm{Ti} / \mathrm{O}$ & $1.1: 1: 4$ & $\mathrm{~N}_{2}$ & 15 & {$[55]$} \\
\hline 17 & 275 & $\mathrm{Ni} / \mathrm{Zr} / \mathrm{O}$ & $1.1: 1: 4$ & $\mathrm{~N}_{2}$ & 15 & {$[56]$} \\
\hline 18 & 500 & $\mathrm{Cr}_{2} \mathrm{O}_{3}$-kieshelgur & $20: 5: 50$ & $\mathrm{He}$ & 75 & {$[57]$} \\
\hline 19 & 470 & $\mathrm{MoO}_{3}-\mathrm{Al}_{2} \mathrm{O}_{3}$ & $5: 57: 38$ & $\mathrm{He}$ & 90 & {$[58]$} \\
\hline 20 & 550 & $\mathrm{Mn} / \mathrm{P} / \mathrm{O}$ & $4: 1: 10$ & $\mathrm{He}$ & 75 & {$[59]$} \\
\hline 21 & 500 & $\mathrm{MoO}_{3} / \mathrm{K}-\mathrm{ZrO}_{2}$ & $8: 8: 59$ & $\mathrm{Ne}$ & 75 & {$[60]$} \\
\hline 22 & 550 & $\mathrm{Na} / \mathrm{W} / \mathrm{O}-\mathrm{SiO}_{2}$ & $4: 1: 10$ & $\mathrm{He}$ & 75 & {$[61]$} \\
\hline 23 & 600 & $\mathrm{Mn} / \mathrm{Mo} / \mathrm{O}$ & $29: 15: 56$ & $\mathrm{~N}_{2}$ & 100 & {$[62]$} \\
\hline 24 & 500 & $\mathrm{P} / \mathrm{O}-\mathrm{C}$ nanofibers & $4: 8: 88$ & Ar & 100 & {$[63]$} \\
\hline
\end{tabular}




\begin{tabular}{|c|c|c|c|c|c|c|}
\hline № & $\mathrm{T},\left[{ }^{\circ} \mathrm{C}\right]$ & catalyst & $\mathrm{C}_{3} \mathrm{H}_{8}: \mathrm{O}_{2}: \mathrm{D}$ & $\mathrm{D}$ & $\mathrm{F}_{\text {tot }}$ & ref. \\
\hline 25 & 560 & $\mathrm{Co} / \mathrm{W} / \mathrm{O}$ & $9: 9: 42$ & $\mathrm{~N}_{2}$ & 60 & {$[64]$} \\
\hline 26 & 560 & $\mathrm{Ni} / \mathrm{Mo} / \mathrm{O}$ & 9:9:42 & $\mathrm{N}_{2}$ & 60 & {$[65,66]$} \\
\hline 27 & 460 & $\mathrm{Ga} / \mathrm{Mo} / \mathrm{O}$ & $2: 1: 8.5$ & $\mathrm{He}$ & 40 & {$[42,67]$} \\
\hline 28 & 535 & $\mathrm{Mg} / \mathrm{Mo}(\mathrm{V}) / \mathrm{O}$ & 39.9:13.3:79.8 & $\mathrm{N}_{2}$ & 133 & {$[68]$} \\
\hline 29 & 450 & $\mathrm{Cr}_{2} \mathrm{O}_{3}-\mathrm{Al}_{2} \mathrm{O}_{3}$ & $4: 1: 10$ & $\mathrm{He}$ & 75 & {$[69]$} \\
\hline 30 & 420 & $\mathrm{Cr} / \mathrm{Mo} / \mathrm{Cs} / \mathrm{O}-\mathrm{Al}_{2} \mathrm{O}_{3}$ & $20: 5: 50$ & $\mathrm{He}$ & 75 & {$[70]$} \\
\hline 31 & 500 & $\mathrm{Cr}_{2} \mathrm{O}_{3}-\mathrm{Al}_{2} \mathrm{O}_{3}$ & $4: 1: 10$ & $\mathrm{He}$ & 75 & {$[71]$} \\
\hline 32 & 450 & $\mathrm{Co} / \mathrm{Sr} / \mathrm{O}$-hydr. apatite & $14.5: 4.1: 82.7$ & $\mathrm{He}$ & 30 & {$[72,73]$} \\
\hline 33 & 500 & $\mathrm{Ag} / \mathrm{Mo} / \mathrm{P} / \mathrm{O}$ & $3: 1: 4$ & $\mathrm{~N}_{2}$ & 40 & {$[74]$} \\
\hline 34 & 550 & $\mathrm{MoO}_{3}-\mathrm{SmVO}_{4}$ & $4: 4: 92$ & $\mathrm{He}$ & 50 & {$[75]$} \\
\hline 35 & 600 & $\mathrm{Mo} / \mathrm{Mg} / \mathrm{Al} / \mathrm{O}$ (from $\mathrm{HT}$ ) & 18:9:73 & $\mathrm{He}$ & $25-100$ & [76] \\
\hline 36 & 550 & $\mathrm{MoO}_{3} / \mathrm{K}-\mathrm{SiO}_{2}-\mathrm{TiO}_{2}$ & $2: 1: X^{b}$ & $\mathrm{~N}_{2}$ & 25 & {$[77]$} \\
\hline 37 & 550 & TS-1 & $4: 30: 30: 36^{c}$ & $\mathrm{~N}_{2}$ & 300 & [78] \\
\hline 38 & 450 & $\mathrm{Cr}_{2} \mathrm{O}_{3}-\mathrm{Al}_{2} \mathrm{O}_{3}$ & $4: 1: 10$ & $\mathrm{He}$ & 75 & {$[79]$} \\
\hline 39 & 450 & $\mathrm{Cr} / \mathrm{Mo} / \mathrm{O}-\mathrm{Al}_{2} \mathrm{O}_{3}$ & $4: 1: 10$ & $\mathrm{He}$ & 75 & {$[80]$} \\
\hline 40 & 500 & $\mathrm{MoO}_{3}-\mathrm{Al}_{2} \mathrm{O}_{3}$ & $4: 4: 92$ & $\mathrm{He}$ & 100 & {$[81]$} \\
\hline 41 & 420 & $\mathrm{Ni} / \mathrm{Co} / \mathrm{Mo} / \mathrm{O}$ & $14: 15: 71$ & $\mathrm{He}$ & - & {$[82]$} \\
\hline
\end{tabular}

${ }^{a} \mathrm{CO}_{2}$

${ }^{b}$ dilutant content varied, while propane:oxygen ratio kept constant

${ }^{c}$ water

$\mathrm{F}_{\text {tot }}$ - total flowrate, $\mathrm{ml} / \mathrm{min}$

\subsection{Process conditions}

The conversion of propane and the selectivity to propylene varies considerably between these different systems and is strongly influenced by the experimental operating conditions: temperature, pressure, gas composition, reactant partial pressure, extent of dilution, etc. Some of these aspects are briefly discussed here.

\subsubsection{Influence of gas composition}

The research peformed by Burch and Crabb [84] on the influence of the air/propane ratio on the product distribution show that if the propane/air ratio is increased from 1:3 to 3:1, the conversion of propane tends to rise first and then fall, which can be explained by total consumption of oxygen at the higher propane/air ratios. At each value of conversion 
the selectivity to propylene varies in inverse relation to the conversion, i.e., as the conversion increases, the selectivity decreases. Changing the value of the propane/oxygen ratio (see Table 2.2) changes also selectivities to carbon oxide products, favoring their formation when excess of oxygen is present in the system. The main reason for that is the fact that with an excess of oxygen, catalyst remains in a highly oxidizing state, enabling fast oxidation of propane to carbon oxides, instead to propylene. Important is also to mention is that the selectivity to carbon monoxide raises, when the propane/oxygen ratio falls.

Table 2.2: Conversion and selectivity in the catalyzed ODHP over $V_{52} / \mathrm{MgO}$ for different propane/air ratios at $773 \mathrm{~K}$ taken from Burch and Crabb [84]

\begin{tabular}{cccccc}
\hline \multirow{2}{*}{$\begin{array}{c}\text { propane/air } \\
\text { ratio }\end{array}$} & propane & \multicolumn{4}{c}{ selectivity [\%] } \\
\cline { 3 - 6 } & conversion [\%] & $\mathrm{CO}$ & $\mathrm{CO}_{2}$ & $\mathrm{C}_{2} \mathrm{H}_{4}$ & $\mathrm{C}_{3} \mathrm{H}_{6}$ \\
\hline $3: 1$ & 4.0 & 10.9 & 28.2 & 0.9 & 60.1 \\
$2: 1$ & 5.2 & 13.3 & 27.7 & 1.0 & 58.0 \\
$1: 1$ & 9.9 & 15.2 & 28.4 & 1.1 & 55.3 \\
$1: 2$ & 9.2 & 16.7 & 30.9 & - & 52.4 \\
$1: 3$ & 8.1 & 17.0 & 31.3 & - & 51.6 \\
\hline
\end{tabular}

\subsubsection{Influence of temperature}

In non-catalytic systems, pyrolysis of propane was investigated [84] in order to show that under these conditions a high yield of propylene cannot be obtained. Only a small conversion was observed even with temperatures above $650{ }^{\circ} \mathrm{C}$ and the yield was only about $2.2 \%$. The combined selectivity to methane and ethane is about $80 \%$. Adding air to feed increased the yield significantly, while the temperature could be kept $100-150^{\circ} \mathrm{C}$ lower.

In contrast to the non-catalytic system for the pyrolysis of propane, the oxidative dehydrogenation of propane over a redox type catalyst occurs even below $500^{\circ} \mathrm{C}$. Compared to the autothermal reaction concept, higher selectivities can be obtained [85]. Comparison of catalytic performances in $\mathrm{ODH}$ of propane, for different temperatures, taken from Leveles [86] is given in Table 2.3 showing that the increase in temperature improves the selectivity and yield of olefins, but, at the same time, increases the content of $\mathrm{CO}_{\mathrm{x}}$ in the system.

\subsubsection{Influence of pressure}

According to the work of Leveles et al. [83], the rate of production of propylene (and other products during the ODHP) over lithium promoted magnesia catalyst varies linearly with the propane partial pressure in the range of 0 to 0.3 bar. This indicates a first order 
Table 2.3: Influence of temperature on the selectivity to propylene in the catalyzed ODHP over MgObased catalysts taken from Leveles [86]

\begin{tabular}{|c|c|c|c|c|c|c|}
\hline \multirow{2}{*}{$\mathrm{T}\left[{ }^{\circ} \mathrm{C}\right]$} & \multirow{2}{*}{$\begin{array}{l}\text { catalyst } \\
\text { composition }\end{array}$} & \multirow{2}{*}{$\begin{array}{c}\text { propane con- } \\
\text { version, [mol \%] }\end{array}$} & \multicolumn{3}{|c|}{ selectivity [mol \%] } & \multirow{2}{*}{$\begin{array}{l}\text { olefin yield } \\
\text { [mol \%] }\end{array}$} \\
\hline & & & $\mathrm{C}_{3}^{=}$ & $\mathrm{C}_{2}^{=}$ & $\mathrm{CO}_{\mathrm{x}}$ & \\
\hline \multirow{3}{*}{600} & Mg-Dy-Li-Cl & 20.1 & 51.6 & 28.2 & 17.3 & 16.0 \\
\hline & Mg-Dy-Li & 27.9 & 42.7 & 28.8 & 22.7 & 19.9 \\
\hline & $\mathrm{MgO}$ & 19.5 & 18.8 & 24.4 & 54.7 & 8.4 \\
\hline \multirow{3}{*}{650} & Mg-Dy-Li-Cl & 59.8 & 39.8 & 38.2 & 14.7 & 46.6 \\
\hline & Mg-Dy-Li & 59.8 & 29.1 & 34.1 & 26.2 & 37.8 \\
\hline & $\mathrm{MgO}$ & 39.1 & 21.1 & 33.0 & 39.9 & 21.1 \\
\hline \multirow{3}{*}{700} & Mg-Dy-Li-Cl & 94.8 & 16.6 & 43.3 & 30.3 & 56.8 \\
\hline & Mg-Dy-Li & 81.0 & 18.1 & 35.7 & 32.3 & 43.6 \\
\hline & $\mathrm{MgO}$ & 64.5 & 20.0 & 33.9 & 31.2 & 34.8 \\
\hline
\end{tabular}

reaction, where propane participates in the rate determining step. Above 0.3 bar the rate of formation of propylene, ethylene and methane shows an exponential increase, while the rates of formation of $\mathrm{CO}$ and hydrogen still vary linearly.

Variations in the oxygen partial pressure has a very complex influence on the rates of formation of the products. The rates of formation of propylene, ethylene and methane increase steeply at very low oxygen partial pressure ( 0 to $5 \mathrm{mbar}$ ). Further increase of the oxygen content in the feed influences the rates of formation of different products in a different manner. Propylene continues to increase linearly with oxygen partial pressure, while ethylene remains constant. Rate of methane formation decreases with oxygen partial pressure, while at the same time the formation rate of the $\mathrm{CO}$ increases, according to Leveles et al. [83].

In the work of Barsan and Thyrion [82] the kinetics of oxidative dehydrogenation of propane over a Ni-Co molybdate catalyst was investigated in an integral reactor by nonlinear regression techniques. By performing central composite design experiments, the influence of propane and oxygen partial pressures, propane space-time and temperature were studied. In order to study the influence of the oxygen partial pressure on the reaction products, the propane partial pressure and the propane space-time were kept constant at 0.14 bar and $0.066 \mathrm{~g} \cdot \mathrm{s} \cdot \mu \mathrm{mol}^{-1}$, respectively while the oxygen partial pressure was varied between 0.015 and 0.152 bar.

Several experiments were performed to understand the influence of the propane partial pressure in the feed over the performance of the catalyst, varying the partial pressure of propane between 0.023 and 0.256 bar, while the partial pressure of oxygen was fixed at $0.084 \mathrm{bar}$ and propane space-time was maintained at $0.066 \mathrm{~g} \cdot \mathrm{s} \cdot \mu \mathrm{mol}^{-1}$. 


\section{Chapter 2}

As a conclusion, a consecutive reaction network was proposed for ODHP, in which the propylene is produced by the oxidation of propane, while carbon monoxide is produced by the successive oxidation of propylene and carbon dioxide by the further oxidation of carbon oxide. For the main reaction, ODHP, several kinetic models were studied and the results showed that two surface oxido-reduction models (modifications of Mars van Krevelen model) were the most suitable for ODHP.

\subsubsection{Influence of gas dopes}

There are dynamic effects that occur by introduction of small amounts of $\mathrm{CO}_{2}$ and $\mathrm{N}_{2} \mathrm{O}$ in the reaction feed during the oxidative dehydrogenation of propane to propylene on $\mathrm{NiMoO}_{4}$ catalysts [87]. Recently, $\mathrm{CO}_{2}$ has been claimed to be an effective dope in the oxidation of butane to maleic anhydride [88]. $\mathrm{N}_{2} \mathrm{O}$ has been used as pure oxidant in the oxidative coupling of methane to ethane [89], in the transformation of benzene to phenol [90], or in the oxidation of ethene to epoxide [91, 92]. The effects caused by the introduction of $\mathrm{CO}_{2}$ have been explained by:

1. faster, more extended formation of an oxycarbonate phase and its regeneration,

2. the formation of inactive carbonate species,

3. the formation of an peroxocarbonate intermediate, which is a promoter for gas phase oxidation reactions,

4. a poisoning caused by competitive adsorption on the sites where oxygen (and possibly hydrocarbon) adsorbs and by the inhibition of molecular oxygen adsorption,

5. the decrease of the formation of coke and

6. the lower tendency for hydrocarbons to undergo deep oxidation.

On the other hand, based on indirect observations, it can be suggested that co-adsorbates and gas dopes could modify the surface properties of the catalysts by:

1. changing the coordination and the electronic properties of the superficial metal atoms,

2. a direct participation in the reaction mechanism,

3. changing the acido-basicity of the oxides,

4. blocking chemisorption sites, or

5. inhibiting the diffusion of surface species towards reacting molecules [87]. 
$\mathrm{CO}_{2}$ promotes oxidation reactions probably via the formation of adsorbed oxygen species, $\mathrm{O}(\mathrm{a})$, formed by the dissociation of $\mathrm{CO}_{2}$ on $\mathrm{NiMoO}_{4}$. Catalysts in the presence of $\mathrm{CO}_{2}$ work in a high oxidation state, increasing the propane conversion, but due to their strong oxidizing character, the selectivity to propylene decreases. It has been found that the conversion increases about $18 \%$, but the decrease in selectivity to propane is $23 \%$, which means that the addition of $\mathrm{CO}_{2}$ has an overall negative effect.

In the presence of $\mathrm{N}_{2} \mathrm{O}$, catalytic sites work in a more reduced state. $\mathrm{N}_{2} \mathrm{O}$ inhibits the adsorption of $\mathrm{O}_{2}$, so limiting the formation of non-selective oxygen species and/or the oxidation rate of the catalysts. This explains the increase in the yield of and selectivity to propylene and the lower $\mathrm{O}_{2}$ consumption when $\mathrm{N}_{2} \mathrm{O}$ is added. It is not excluded that $\mathrm{N}_{2} \mathrm{O}$ (via the dissociated oxygen species) could also participate directly as oxidant. If this is the case, the results, in particular at high $\mathrm{N}_{2} \mathrm{O}$ concentration, must thus be regarded as due to superposition of both above described phenomena.

\subsection{Kinetics and kinetic models for ODH of light alkanes}

A kinetic study of the oxidative dehydrogenation of alkanes is one of the ways to elucidate the reaction mechanism and to facilitate selection of the appropriate catalyst for this type of reactions [93]. Previous studies have not explained entirely the mechanism of the $\mathrm{ODH}$ of propane and some controversies in the determination of macroscopic steps of the reaction still exist. Though it is well known that the kinetic studies are not able to unravel the molecular mechanism of the reaction, but they allow to exclude some of the possible paths and to determine the reaction network. Nevertheless, kinetic studies were often used in the past (and are still used) to provide useful information about the studied reaction system and catalyst operation. On the basis of these studies one can define intermediate products, the nature and quantitative participation of particular reaction routes (parallel and consecutive reaction paths, branching of the reactions, etc.) which decide about the selectivity of the process and one can also identify the rate determining step in the sequence of consecutive reactions. The macrokinetic model obtained in this way is usually a good starting point for the description of a molecular mechanism.

As the basis for the development of rate equations, it is postulated that a gas phase chemical reaction, when catalyzed by a solid, actually occurs on the surface of the catalyst and involves the reaction of molecules or atoms that are adsorbed by the active centers of the surface. In the heterogeneous gas-solid system, a catalytic reaction proceeds according to Kiperman [94] through the following stages:

1. Diffusion of the reactants towards the surface of the catalyst

2. Adsorption of the reactants on the surface

3. Reaction on the surface 
4. Desorption of the products from the surface

5. Diffusion of the reaction products from the catalyst surface

It is evident that the rates of these five steps are dependent on different factors, depending on the concentration or concentration gradients involved [95]. Stages 1 and 5 are determined by, among other things, the flow characteristics of the system, such as mass velocity of the fluid stream, diffusional characteristics of the fluid and degree of porosity of the catalyst, dimensions of the pores, and the extent to which they are interconnected. Stages 2 and 4 are determined by the character and extent of the catalytic surface and by specific activation energies required for the adsorption and desorption of the components of the gas phase. Stage 3 is determined by the nature and extent of the catalytic surface and by the activation energies required for the reaction on the surface. If the second, third, and fourth stages are slower than the diffusion processes, a realistic kinetic description can be obtained, otherwise, the conversion rate equations will be dominated by diffusion processes. This means that kinetic constants will not be representative of the chemical reactivity of the system. The main models used for the kinetic description of oxidative dehydrogenation of light alkanes are:

1. Eley-Rideal model

2. Langmuir-Hinshelwood model

3. Gradual oxidation model

4. Mars Van Krevelen model

A short description of the models is given in the Appendix.

The kinetics of the ODH of propane under stationary conditions was analyzed for different systems containing vanadium, like $\mathrm{V}-\mathrm{Mg}-\mathrm{O}$ [96], vanadium oxide supported on $\mathrm{AlPO}_{4}$ [97], VTiO [98] and $\mathrm{Mg}-\mathrm{V}-\mathrm{Sb}-\mathrm{O}$ [99]. In [96], kinetics of ODH of propane was investigated by a non-linear regression analysis using both, simple power law and mechanistic models. In the papers [65, 97-99] the kinetic studies were less extensive and only the relative reaction rates or only qualitative information about the rate of this reaction was provided. Andersson [97] undertook an attempt to compare different models of the $\mathrm{ODH}$ reaction on $\mathrm{V}-\mathrm{Mg}-\mathrm{O}$ catalyst, i.e. the redox model (Mars van Krevelen), the adsorptive model (Langmuir-Hinselwood), and a simple pseudo-homogeneous power law model. Probably due to a limited experimental basis confined to low propane conversions, it was impossible to discriminate between the models. In [100], the parallel-consecutive scheme of the $\mathrm{ODH}$ of propane over $\mathrm{V}_{2} \mathrm{O}_{5} / \mathrm{TiO}_{2}$ and $\mathrm{V}_{2} \mathrm{O}_{5}+\mathrm{Rb} / \mathrm{TiO}_{2}$ was applied. It was assumed that the rate of the reaction is proportional to the concentration of propane and independent of the oxygen concentration.

Kinetic studies of the ODH of propane on the V-containing catalysts by the transient method under non-stationary conditions [101, 102], have led to the conclusion that 
propane reacts directly from the gaseous phase with the catalyst oxygen and the desorption of the products from the surface of the catalyst is rapid, i.e. this step of the reaction occurs according to the Eley-Rideal mechanism. On the other hand, the redox studies have shown that reoxidation of the $\mathrm{VO}_{\mathrm{x}} / \mathrm{TiO}_{2}$ catalyst at the surface layer is much more rapid than the reduction of the catalyst by propane [103]. At stationary conditions, a small degree of catalyst reduction is observed. This shows that the reduction and reoxidation of the catalyst occurs only at the surface layer, which in its turn suggests the application of the steady-state adsorption model, as an adequate way of describing the reaction under study.

\subsection{Novel reactor concepts for ODHP}

In addition to standard fixed bed reactors with premixed feed, other reactor concepts have been proposed for the $\mathrm{ODH}$ of lower alkanes with claimed much better performances. These are described in the next paragraphs.

\subsubsection{Fluidized bed reactors}

There are no data for the production of propylene in fluidized bed reactors, but there are some data available about a very similar process for the production of maleic anhydride from n-butane [104]. It is claimed that the fluidized bed reactors offer many advantages over fixed bed systems. The main advantages are:

1. high heat transfer coefficient to particles and immersed surfaces

2. ease of temperature control and elimination of hot spots and

3. high $\mathrm{C}_{4}$ concentrations in the feed

These advantages result in a lower investment process, particularly for a large scale plant. Several companies have developed fluidized bed processes (Mitsubishi, ALMA, Badger, Sohio/UCB). All claimed to be able to produce maleic anhydride at a lower cost. Catalyst losses due to attrition have been reduced, but generally at some penalty of lower selectivity. Yield losses associated with backmixing are minimized, but not eliminated. The negative impact of lower yields would depend on n-butane price and the value of byproduct steam at a given site. Some scale-up uncertainties remain, except when costly and time consuming experience with very large demonstration plants is gained. Du Pont's attrition resistant catalyst and the circulating solids riser reactor technologies show a potential for a major improvement in overall economics relative to the incremental improvements of the fluidized bed processes. 


\subsubsection{Circulating solids reactors}

Recently Du Pont disclosed [105] a new reactor concept for selective oxidation of n-butane to maleic anhydride which reduces or eliminates most of the negative aspects of fluidized bed reactors, while maintaining their advantages. Additional performance advantages are derived by separating the two steps in the redox process.

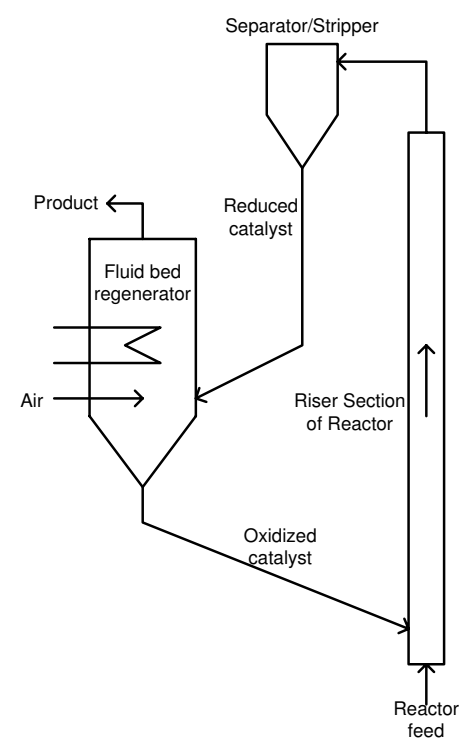

Figure 2.2: Solid riser reactor

Figure 2.2 shows a schematic of the circulating solids riser reactor used for $\mathrm{n}$-butane oxidation. VPO catalyst is continuously circulated around the loop. n-Butane is oxidized by the catalyst in the lean phase, riser section which has plug flow characteristics. The catalyst is reoxidized in the dense phase fluidized bed regenerator. A very high $\mathrm{n}$-butane concentration in the feed gas is possible, and high selectivities are achieved. It is believed that an important selectivity loss pathway involves highly active surface species, such as $\mathrm{O}_{2}^{-}$and $\mathrm{O}^{-}$. Presumably some of these non-selective pathways are eliminated in this reactor by carrying out the oxidation reaction in the absence of gas phase oxygen. Together with the attrition resistant catalyst, the reactor is claimed to give higher than $70 \%$ maleic anhydride yields, lower investment and superior economics relative to alternatives.

\section{Advantages of circulating solids riser reactor}

- Separate catalyst oxidation and reduction zones

- Independent control of two zones with catalyst in transient cyclic state 
- High selectivity. Low oxygen concentration in reactor and control of nonselective oxygen species

- Concentrated product streams

* High hydrocarbon concentration in feed

* Product gas separate from regenerator off gas

- High throughput

- Low catalyst inventory

- No explosion problems

- Riser reactor zone

- High selectivity. Plug flow. No hot spots.

- No free board burning

- High turndown ratio

- Ease of scale-up

- Fluidized bed regenerator zone

- High heat transfer coefficient

- Good temperature control

Referring to Bharadwaj and Schmidt [106] it is possible to obtain propylene from propane with a selectivity of about $60-70 \%$ and a propane conversion of about $90 \%$. Ethylene production dominates at high temperatures and long contact times, while propylene production is maximized at lower temperatures and short contact times.

This is explained by the fact that for propane and $\mathrm{n}$-butane, $\beta$-alkyl elimination is favored over $\beta$-hydrogen elimination. When the primary carbon atom adsorbs, $\beta$-methyl elimination of n-propyl and $\beta$-ethyl elimination of $\mathrm{n}$-butyl lead to $\mathrm{C}_{2} \mathrm{H}_{4}$. Adsorption of the secondary carbon atom results in $\mathrm{C}_{3} \mathrm{H}_{6}$ from both alkanes (via $\beta$-hydrogen elimination of adsorbed isopropyl and $\beta$-methyl elimination of adsorbed 2-butyl). At higher temperatures, more $\mathrm{C}_{2} \mathrm{H}_{4}$ is formed, which is explained by the higher activation energy for $\mathrm{C}_{2} \mathrm{H}_{4}$ formation. Increasing the flow rates decreases the contact time and allows formation of more $\mathrm{C}_{3} \mathrm{H}_{6}$. Just as with ethane, $\alpha$-hydrogen elimination eventually leads to $\mathrm{CH}_{4}, \mathrm{CO}$, $\mathrm{CO}_{2}$ and $\mathrm{H}_{2} \mathrm{O}$.

In these tests, Pt based catalysts were used, together with those based on $\mathrm{Rh}$ and $\mathrm{Ni}$. Contact times were about $50-200 \mathrm{~ms}$ at temperatures between 800 and $850{ }^{\circ} \mathrm{C}$. Since the fluidized bed reactor was operated close to the turbulent mode, these results should simulate the behavior of a large scale reactor operating in the turbulent regime fairly closely, allowing straightforward scale-up. The relatively short contact times would result in reactor sizes at least an order of magnitude smaller than current commercial thermal pyrolysis 
furnaces. The high selectivities, autothermal operation and absence of carbon formation in fluidized beds provide an energy efficient alternate route to synthesize olefins from alkanes.

\subsubsection{Membrane reactors}

For the partial oxidation systems, different reactor concepts with membranes integrated inside the reactor have been proposed, with potentially even much higher propane conversions and propylene yields. Generally, membrane reactors can be classified into two major groups: reactors with porous and dense membranes. The permeability of porous membranes is rather high, compared to dense membranes, while the permselectivity is only moderate, if any. Due to the low values of permeability for dense membranes, the flux of permeating gas (oxygen, in case of partial oxidation reactions) is normally increased by electrochemical pumping.

A porous membrane in the membrane reactor can be a catalytic active membrane (catalytic membrane reactor, CMR), or an inert membrane (inert membrane reactor, IMR).

Two important domains where membrane reactors could be applied in order to improve the performance compared to conventional reactor concepts are the following:

- dosing of a certain reactant into the reactor to enhance the selective formation of a desired product and

- the selective extraction of a limiting reaction product in a reversible reaction outside the reactor

The case of optimized dosing, of a particular interest in this research, has been investigated theoretically and experimentally for different partial oxidation systems. One example is the oxidative dehydrogenation of ethane [107], where theoretical results, based on a simplified triangular reaction network revealed the potential for an increase of selectivity. However, the experimental part of the research emphasized the need for more realistic models, concerning both the selected reaction network and the individual rate equations. The reaction order appeared to play a decisive influence on the effect of the dosing of a particular reactant.

In the formation of oxygenates by partial oxidations, the use of a catalytically active membrane has been proposed in order to increase the selective formation of the oxygenated intermediate. [108] The gas mixture containing propane and oxygen was fed to the axis of a porous cylinder supporting the catalyst layer, while the products were collected on the outside of the device. Compared to the conventional fixed bed reactor, the yield of acrolein increased six times, when the catalytically active membrane was sufficiently small. This result was a consequence of a residence time reduction in the reaction zone, which interrupts the reaction network at an earlier stage, preventing further oxidation. 
Catalytic membranes have also been studied in the partial oxidation of toluene as an alternative to the main production route, the liquid phase oxidation, in order to reduce the formation of by-products. [109] The reported values of the reactor selectivity to benzaldehyde are still very low. However, the selectivity versus conversion shows a significant increase for the membrane reactor in comparison with a conventional fixed bed reactor.

In contrast to the investigations described before, the application of membrane reactors in the partial oxidation of butane aims at the improvement of a process already realized industrially that gives unsatisfactory yields. The use of inert membranes is proposed to realize a locally distributed feed of one reactant, especially the oxidant. If the oxygen is distributed through an inert membrane to a fixed bed of a typical VPO catalyst [110], the butane/oxygen ratio can be up to seven times higher than in industrial practice where 1 to $2 \%$ butane in air is co-fed. This is possible because the device is inherently safer due to the hydrocarbon and oxygen mixing in the presence of solids, which are efficient flame inhibitors. However, the yields remain poor, even though that the inert membrane reactor may be considered as a "promising contactor".

\subsection{Conclusions}

In this chapter a literature survey on important aspects concerning the catalysts, process conditions and novel reactor concepts for the ODHP was presented.

Various catalytic systems were discussed and it was found that the combination of the oxides into the $\mathrm{Ga}_{2} \mathrm{O}_{3} / \mathrm{MoO}_{3}$ catalyst combines the beneficial properties of increased oxidation rate over $\mathrm{Ga}_{2} \mathrm{O}_{3}$ with the selective oxidation function of $\mathrm{MoO}_{3}$ in a beneficial manner. Also, this catalyst is very easy to prepare, while its performance is quite comparable to the performance of other, much more sophisticated (hence expensive) catalytic systems. However, kinetic data for this specific catalytic system have not been reported in literature, therefore, for the assessment of the reactor concept, a kinetic study was performed in this work, which will be discussed in the following chapter.

Research on process conditions showed that the oxidative dehydrogenation of propane can be performed at moderate temperature levels, which is certainly a large benefit in terms of energy utilization, in comparison to more conventional dehydrogenation processes. Operation at atmospheric, or close-to-atmospheric pressure was also reported to give optimal results. This was then further used in the selection of conditions for experimental work described in this thesis.

Commercialized reactor concepts used in today's production of propylene have already been described in chapter 1 . Alternatives to conventional packed bed reactors are fluidized bed reactors and membrane reactors. 


\section{References}

[1] D. Dharia, W. Letzsch, H. Kim, D. McCue and L. Chapin. Increase light olefins production. Hydrocarbon Processing, 83(4), 61 (2004).

[2] F. Nierlich. Oligomerize for better gasoline. Hydrocarbon Processing, (2), 45-46 (1992).

[3] J. Cosyns, J. Chordorge, D. Commereuc and B. Torck. Maximize propylene production. Hydrocarbon Processing, 61, 22 (1998).

[4] F. Cavani and F. Trifirò. The oxidative dehydrogenation of ethane and propane as an alternative way for the production of light olefins. Catalysis Today, 24(3), 307-313 (1995).

[5] C. Mazzocchia, C. Aboumrad, C. Diagne, E. Tempesti, J. Herrmann and G. Thomas. On the $\mathrm{NiMoO}_{4}$ oxidative dehydrogenation of propane to propene - some physical correlations with the catalytic activity. Catalysis Letters, 10(3-4), 181-191 (1991).

[6] A. A. Lemonidou, G. J. Tjatjopoulos and I. A. Vasalos. Investigations on the oxidative dehydrogenation of n-butane over VMgO-type catalysts. Catalysis Today, 45(1-4), 65-71 (1998).

[7] P. M. Michalakos, M. C. Kung, I. Jahan and H. H. Kung. Selectivity patterns in alkane oxidation over $\mathrm{Mg}_{3}\left(\mathrm{VO}_{4}\right)_{2}-\mathrm{MgO}, \mathrm{Mg}_{2} \mathrm{~V}_{2} \mathrm{O}_{7}$, and $(\mathrm{VO})_{2} \mathrm{P}_{2} \mathrm{O}_{7}$. Journal of Catalysis, 140(1), 226-242 (1993).

[8] M. A. Chaar, D. Patel, M. C. Kung and H. H. Kung. Selective oxidative dehydrogenation of butane over $\mathrm{V}-\mathrm{Mg}-\mathrm{O}$ catalysts. Journal of Catalysis, 105(2), 483-498 (1987).

[9] H. H. Kung and M. A. Chaar. Oxidative dehydrogenation of alkanes to unsaturated hydrocarbons. US Patent \& Trademark Office, (4777319. A. 881011) (1988).

[10] M. A. Chaar, D. Patel and H. H. Kung. Selective oxidative dehydrogenation of propane over V-Mg-O catalysts. Journal of Catalysis, 109(2), 463-467 (1988).

[11] H. H. Kung. Oxidative dehydrogenation of light (C-2 to C-4) alkanes. Advances in Catalysis, 40, 1-38 (1994).

[12] O. S. Owen and H. H. Kung. Effect of cation reducibility on oxidative dehydrogenation of butane on orthovanadates. Journal of Molecular Catalysis, 1-3, 265-284 (1993).

[13] M. C. Kung and H. H. Kung. The effect of potassium in the preparation of magnesium orthovanadate and pyrovanadate on the oxidative dehydrogenation of propane and butane. Journal of Catalysis, 134(2), 668-677 (1992).

[14] D. S. H. Sam, V. Soenen and J. C. Volta. Oxidative dehydrogenation of propane over $\mathrm{V}-\mathrm{MgO}$ catalysts. Journal of Catalysis, 123(2), 417-435 (1990). 
[15] X. T. Gao, P. Ruiz, Q. Xin, X. X. Guo and B. Delmon. Preparation and characterization of 3 pure magnesium vanadate phases as catalysts for selective oxidation of propane to propene. Catalysis Letters, 23(3-4), 321-337 (1994).

[16] R. H. H. Smits, K. Seshan, H. Leemreize and J. R. H. Ross. Influence of preparation method on the performance of vanadia-niobia catalysts for the oxidative dehydrogenation of propane. Catalysis Today, 16(3-4), 513-523 (1993).

[17] R. H. H. Smits, K. Seshan and J. R. H. Ross. The Selective oxidative dehydrogenation of propane over niobium pentoxide. Journal of the Chemical Society - Chemical Communications, 20(8), 558-559 (1991).

[18] R. H. H. Smits, K. Seshan and J. R. H. Ross. Selective oxidative dehydrogenation of propane on promoted niobium pentoxide. ACS Symposium Series, 523, 380-388 (1993).

[19] M. Gasior, I. Gressel, V. A. Zazhigalov and B. Grzybowska. Effect of additives to VPO system on its catalytic properties in oxidative dehydrogenation of propane and ethane. Polish Journal of Chemistry, 77(7), 909-915 (2003).

[20] P. Boizumault-Moriceau, A. Pennequin, B. Grzybowska and Y. Barbaux. Oxidative dehydrogenation of propane on $\mathrm{Ni}-\mathrm{Ce}-\mathrm{O}$ oxide: effect of the preparation method, effect of potassium addition and physical characterization. Applied Catalysis A: General, 245(1), 55-67 (2003).

[21] B. Grzybowska, J. Słoczyński, R. Grabowski, K. Samson, I. Gressel, K. Wcisło, L. Gengembre and Y. Barbaux. Effect of doping of $\mathrm{TiO}_{2}$ support with altervalent ions on physicochemical and catalytic properties in oxidative dehydrogenation of propane of vanadia-titania catalysts. Applied Catalysis A: General, 230(1-2), 1-10 (2002).

[22] K. Bahranowski, R. Grabowski, B. Grzybowska, A. Kielski, E. M. Serwicka, K. Wcisło, E. Wisła-Walsh and K. Wodnicka. Synthesis and physicochemical properties of vanadium-doped zirconia-pillared montmorillonites in relation to oxidative dehydrogenation of propane. Topics in Catalysis, 11(1-4), 255-261 (2000).

[23] M. Ziółek, A. Lewandowska, B. Grzybowska and A. Klisińska. NbMCM-41 mesoporous molecular sieves in oxidative dehydrogenation of ethane and propane. Reaction Kinetics and Catalysis Letters, 80(2), 199-206 (2003).

[24] A. Klisińska, K. Samson and B. Grzybowska. Oxidative dehydrogenation of propane on supported molybdena catalysts: Effect of the support nature and of additives. Polish Journal of Chemistry, 77(12), 1867-1874 (2003).

[25] D. Courcot, A. Ponchel, B. Grzybowska, Y. Barbaux, M. Rigole, M. Guelton and J. P. Bonnelle. Effect of the sequence of potassium introduction to $\mathrm{V}_{2} \mathrm{O}_{5} / \mathrm{TiO}_{2}$ catalysts on their physicochemical properties and catalytic performance in oxidative dehydrogenation of propane. Catalysis Today, 33(1-3), 109-118 (1997). 
[26] R. Grabowski, B. Grzybowska and K. Wcisło. Properties of $\mathrm{V}_{2} \mathrm{O}_{5} / \mathrm{TiO}_{2}$ CatalyticSystem Promoted with Alkali-Metal Cations in Oxidative Dehydrogenation of Propane and in Isopropanol Decomposition. Polish Journal of Chemistry, 68(9), 1803-1811 (1994).

[27] R. Grabowski, B. Grzybowska, K. Samson, J. Słoczyński, J. Stoch and K. Wcisło. Effect of Alkaline Promoters on Catalytic Activity of $\mathrm{V}_{2} \mathrm{O}_{5} / \mathrm{TiO}_{2}$ and $\mathrm{MoO}_{3} / \mathrm{TiO}_{2}$ Catalysts in Oxidative Dehydrogenation of Propane and in Isopropanol Decomposition. Applied Catalysis A: General, 125(1), 129-144 (1995).

[28] D. Courcot, B. Grzybowska, Y. Barbaux, M. Rigole, A. Ponchel and M. Guelton. Effect of potassium addition to the $\mathrm{TiO}_{2}$ support on the structure of $\mathrm{V}_{2} \mathrm{O}_{5} / \mathrm{TiO}_{2}$ and its catalytic properties in the oxidative dehydrogenation of propane. Journal of the Chemical Society — Faraday Transactions, 92(9), 1609-1617 (1996).

[29] A. Klisińska, A. Haras, K. Samson, M. Witko and B. Grzybowska. Effect of additives on properties of vanadia-based catalysts for oxidative dehydrogenation of propane - Experimental and quantum chemical studies. Journal of Molecular Catalysis A: Chemical, 210(1-2), 87-92 (2004).

[30] B. Grzybowska, P. Mekss, R. Grabowski, K. Wcisło, Y. Barbaux and L. Gengembre. Effect of Potassium Addition to $\mathrm{V}_{2} \mathrm{O}_{5} / \mathrm{TiO}_{2}$ and $\mathrm{MoO}_{3} / \mathrm{TiO}_{2}$ Catalysts on Their Physicochemical and Catalytic Properties in Oxidative Dehydrogenation of Propane. New Developments in Selective Oxidation II, 82, 151-158 (1994).

[31] R. Grabowski, B. Grzybowska, A. Kozłowska, J. Słoczyński, K. Wcisło and Y. Barbaux. Effect of alkali metals additives to $\mathrm{V}_{2} \mathrm{O}_{5} / \mathrm{TiO}_{2}$ catalyst on physicochemical properties and catalytic performance in oxidative dehydrogenation of propane. Topics in Catalysis, 3(3-4), 277-288 (1996).

[32] P. Concepcion, J. M. L. Nieto and J. Perezpariente. The Selective Oxidative Dehydrogenation of Propane on Vanadium Aluminophosphate Catalysts. Catalysis Letters, 19(4), 333-337 (1993).

[33] G. Centi, S. Perathoner, F. Trifirò, A. Aboukais, C. F. Aissi and M. Guelton. Physicochemical Characterization of V-Silicalite. Journal of Physical Chemistry, 96(6), 2617-2629 (1992).

[34] D. B. Fox and E. H. Lee. Supported molten salt catalysts for dehydrogenation. Chemtech, 3(3), 186-189 (1973).

[35] I. M. Dahl, H. Grande, K. J. Jens, E. Rytter and A. Slagtern. Oxidative dehydrogenation of propane in lithium hydroxide/lithium iodide melts. Applied Catalysis A: General, 77, 163-174 (1991).

[36] S. B. Ushkov, Z. G. Osipova, V. D. Sokolovskii and S. V. Ketchik. Catalytic activity of some sulphates in the reaction of oxidative dehydrogenation of propane. Kinetics and Catalysis, 29(1), 195-198 (1988). 
[37] Y. Takita, H. Yamashita and K. Moritaka. Selective partial oxidation of propane over metal phosphate catalysts. Chemistry Letters, 18(10), 1733-1736 (1989).

[38] S. J. Conway, D. J. Wang and J. H. Lunsford. Selective oxidation of methane and ethane over $\mathrm{Li}^{+}-\mathrm{MgO}-\mathrm{Cl}^{-}$catalysts promoted with metal oxides. Applied Catalysis A: General, 79(1), L1-L5 (1991).

[39] S. J. Conway and J. H. Lunsford. The oxidative dehydrogenation of ethane over chlorine-promoted lithium-magnesium oxide catalysts. Journal of Catalysis, 131(2), 513-522 (1991).

[40] M. V. Landau, P. F. van den Oosterkamp, M. L. Kaliya, P. S. G. Bocqué and M. Herskowitz. Produce light olefins from paraffins by catalytic oxidation. Chemtech, 26, 24-29 (1996).

[41] O. V. Buyevskaya, D. Wolf and M. Baerns. Ethylene and propene by oxidative dehydrogenation of ethane and propane - Performance of rare-earth oxide-based catalysts and development of redox-type catalytic materials by combinatorial methods. Catalysis Today, 62(1), 91-99 (2000).

[42] T. Davies and S. H. Taylor. The oxidative dehydrogenation of propane using gallium-molybdenum oxide-based catalysts. Journal of Molecular Catalysis A: Chemical, 220(1), 77-84 (2004).

[43] F. Cavani, N. Ballarini and A. Cericola. Oxidative dehydrogenation of ethane and propane: How far from commercial implementation? Catalysis Today, 127(1-4), 113-131 (2007).

[44] M. L. Peña, A. Dejoz, V. Fornes, E. Rey, M. I. Vazquez and J. M. L. Nieto. Vcontaining MCM-41 and MCM-48 catalysts for the selective oxidation of propane in gas phase. Applied Catalysis A - General, 209(1-2), 155-164 (2001).

[45] M. C. Abello, M. F. Gomez, M. Casella, O. A. Ferretti, M. A. Banares and J. L. G. Fierro. Characterization and performance for propane oxidative dehydrogenation of Li-modified $\mathrm{MoO}_{3} / \mathrm{Al}_{2} \mathrm{O}_{3}$ catalysts. Applied Catalysis A - General, 251(2), 435447 (2003).

[46] L. Leveles, S. Fuchs, K. Seshan, J. A. Lercher and L. Lefferts. Oxidative conversion of light alkanes to olefins over alkali promoted oxide catalysts. Applied Catalysis A - General, 227(1-2), 287-297 (2002).

[47] A. Kubacka, E. Wloch, B. Sulikowski, R. X. Valenzuela and V. C. Corberan. Oxidative dehydrogenation of propane on zeolite catalysts. Catalysis Today, 61(1-4), 343-352 (2000).

[48] V. C. Corberan, R. X. Valenzuela, B. Sulikowski, M. Derewinski, Z. Olejniczak and J. Krysciak. Gallium oxide promoted zeolite catalysts for oxidehydrogenation of propane. Catalysis Today, 32(1-4), 193-204 (1996).

[49] O. Demoulin, I. Seunier, F. Dury, M. Navez, R. Rachwalik, B. Sulikowski, S. R. Gonzalez-Carrazan, E. M. Gaigneaux and P. Ruiz. Modulation of selective sites 
by introduction of $\mathrm{N}_{2} \mathrm{O}, \mathrm{CO}_{2}$ and $\mathrm{H}_{2}$ as gaseous promoters into the feed during oxidation reactions. Catalysis Today, 99(1-2), 217-226 (2005).

[50] O. Demoulin, F. Dury, A. Navez, E. M. Gaigneaux and P. Ruiz. Modification of active catalytic sites with $\mathrm{N}_{2} \mathrm{O}$ and $\mathrm{CO}_{2}$ as gas promoters during oxidation reactions. Catalysis Today, 91-92, 27-31 (2004).

[51] Y. M. Liu, W. L. Feng, L. C. Wang, Y. Cao, W. L. Dai, H. Y. He and K. N. Fan. Chromium supported on mesocellular silica foam (MCF) for oxidative dehydrogenation of propane. Catalysis Letters, 106(3-4), 145-152 (2006).

[52] C. Trionfetti, I. V. Babich, K. Seshan and L. Lefferts. Formation of high surface area $\mathrm{Li} / \mathrm{MgO}$ - Efficient catalyst for the oxidative dehydrogenation/cracking of propane. Applied Catalysis A - General, 310, 105-113 (2006).

[53] C. Liu, R. B. Watson and U. S. Ozkan. Spectroscopic characterization of Cl-modified $\mathrm{Mo} / \mathrm{Si}$ : Ti catalysts for oxidative dehydrogenation of propane. Topics in Catalysis, 41(1-4), 63-72 (2006).

[54] B. Y. Jibril and S. Ahmed. Oxidative dehydrogenation of propane over $\mathrm{Co}, \mathrm{Ni}$ and Mo mixed oxides/MCM-41 catalysts: Effects of intra- and extra-framework locations of metals on product distributions. Catalysis Communications, 7(12), 990-996 (2006).

[55] Y. Wu, Y. M. He, T. Chen, W. Z. Weng and H. L. Wan. Low temperature catalytic performance of nanosized $\mathrm{Ti}-\mathrm{Ni}-\mathrm{O}$ for oxidative dehydrogenation of propane to propene. Applied Surface Science, 252(14), 5220-5226 (2006).

[56] Y. M. He, Y. Wu, T. Chen, W. Z. Weng and H. L. Wan. Low-temperature catalytic performance for oxidative dehydrogenation of propane on nanosized $\mathrm{Ti}(\mathrm{Zr})-\mathrm{Ni}-\mathrm{O}$ prepared by modified sol-gel method. Catalysis Communications, 7(5), 268-271 (2006).

[57] B. Y. Jibril, M. C. Al-Kinany, S. H. Al-Khowaiter, S. A. Al-Drees, H. A. Al-Megren, M. A. Al-Dosari, R. H. Al-Rasheed, S. M. Al-Zahrani and A. E. Abasaeed. Performances of new Kieselguhr-supported transition metal oxide catalysts in propane oxydehydrogenation. Catalysis Communications, 7(2), 79-85 (2006).

[58] M. A. Banares and S. J. Khatib. Structure-activity relationships in aluminasupported molybdena-vanadia catalysts for propane oxidative dehydrogenation. Catalysis Today, 96(4), 251-257 (2004).

[59] B. Y. Jibril. Effects of feed compositions on oxidative dehydrogenation of propane over Mn-P-O catalyst. Industrial \& Engineering Chemistry Research, 44(4), 702-706 (2005).

[60] S. N. Koc, G. Gurdag, S. Geissler, M. Guraya, M. Orbay and M. Muhler. The oxidative dehydrogenation of propane over potassium-promoted molybdenum oxide/sol-gel zirconia catalysts. Journal of Molecular Catalysis A: Chemical, 225, 197-202 (2005). 
[61] B. Y. Jibril. Catalytic performances and correlations with metal oxide band gaps of metal-tungsten mixed oxide catalysts in propane oxydehydrogenation. Reaction Kinetics and Catalysis Letters, 86(1), 171-177 (2005).

[62] L. A. Palacio, A. Echavarria, L. Sierra and E. A. Lombardo. Cu, Mn and Co molybdates derived from novel precursors catalyze the oxidative dehydrogenation of propane. Catalysis Today, 107-108, 338-345 (2005).

[63] Z. J. Sui, J. H. Zhou, Y. C. Dai and W. K. Yuan. Oxidative dehydrogenation of propane over catalysts based on carbon nanofibers. Catalysis Today, 106(1-4), 9094 (2005).

[64] D. L. Stern and R. K. Grasselli. Propane oxydehydrogenation over metal tungstates. Journal of Catalysis, 167(2), 570-572 (1997).

[65] D. L. Stern and R. K. Grasselli. Reaction network and kinetics of propane oxydehydrogenation over nickel cobalt molybdate. Journal of Catalysis, 167(2), 560-569 (1997).

[66] D. L. Stern and R. K. Grasselli. Propane oxydehydrogenation over molybdate-based catalysts. Journal of Catalysis, 167(2), 550-559 (1997).

[67] T. Davies and S. H. Taylor. The oxidative dehydrogenation of propane using gallium-molybdenum based catalyst. Catalysis Letters, 93(3-4), 151-154 (2004).

[68] J. D. Pless, B. B. Bardin, H. S. Kim, D. G. Ko, M. T. Smith, R. R. Hammond, P. C. Stair and K. R. Poeppelmeier. Catalytic oxidative dehydrogenation of propane over Mg-V/Mo oxides. Journal of Catalysis, 223(2), 419-431 (2004).

[69] B. Y. Jibril. Propane oxidative dehydrogenation over chromium oxide-based catalysts. Applied Catalysis A - General, 264(2), 193-202 (2004).

[70] B. Y. Jibril, S. M. Al-Zahrani, A. E. Abasaeed and R. Hughes. Oxidative dehydrogenation of propane over supported chromium-molybdenum oxides catalysts. Catalysis Communications, 4(11), 579-584 (2003).

[71] S. M. Al-Zahrani, B. Y. Jibril and A. E. Abasaeed. Selection of optimum chromium oxide-based catalysts for propane oxidehydrogenation. Catalysis Today, 81(3), 507516 (2003).

[72] S. Sugiyama and H. Hayashi. Role of hydroxide groups in hydroxyapatite catalysts for the oxidative dehydrogenation of alkanes. International Journal of Modern Physics B, 17(8-9), 1476-1481 (2003).

[73] S. Sugiyama, T. Shono, D. Makino, T. Moriga and H. Hayashi. Enhancement of the catalytic activities in propane oxidation and H-D exchangeability of hydroxyl groups by the incorporation with cobalt into strontium hydroxyapatite. Journal of Catalysis, 214(1), 8-14 (2003).

[74] X. Zhang, H. L. Wan, W. Z. Weng and X. D. Yi. Effect of Ag promoter on redox properties and catalytic performance of Ag-Mo-P-O catalysts for oxidative dehydrogenation of propane. Applied Surface Science, 220(1-4), 117-124 (2003). 
[75] B. P. Barbero and L. E. Cadus. Molybdenum role: Mo-Sm-V-O catalytic system for propane oxidative dehydrogenation. Applied Catalysis A - General, 252(1), 133147 (2003).

[76] P. C. H. Mitchell and S. A. Wass. Propane dehydrogenation over molybdenum hydrotalcite catalysts. Applied Catalysis A - General, 225(1-2), 153-165 (2002).

[77] R. B. Watson and U. S. Ozkan. K/Mo catalysts supported over sol-gel silica-titania mixed oxides in the oxidative dehydrogenation of propane. Journal of Catalysis, 191(1), 12-29 (2000).

[78] W. Schuster, J. P. M. Niederer and W. F. Hoelderich. The gas phase oxidative dehydrogenation of propane over TS-1. Applied Catalysis A: General, 209(1-2), 131-143 (2001).

[79] S. M. Al-Zahrani, B. Y. Jibril and A. F. Abasaeed. Activities of gamma- $\mathrm{Al}_{2} \mathrm{O}_{3}$ supported metal oxide catalysts in propane oxidative dehydrogenation. Catalysis Letters, 85(1-2), 57-67 (2003).

[80] B. Y. Jibril, S. M. Al-Zahrani, A. E. Abasaeed and R. Hughes. Effects of reducibility on propane oxidative dehydrogenation over gamma- $\mathrm{Al}_{2} \mathrm{O}_{3}$-supported chromium oxide-based catalysts. Catalysis Letters, 87(3-4), 121-132 (2003).

[81] M. C. Abello, M. F. Gomez and O. Ferretti. Oxidative conversion of propane over $\mathrm{Al}_{2} \mathrm{O}_{3}$-supported molybdenum and chromium oxides. Catalysis Letters, 87(1-2), 43-49 (2003).

[82] M. M. Barsan and F. C. Thyrion. Kinetic study of oxidative dehydrogenation of propane over Ni-Co molybdate catalyst. Catalysis Today, 81(2), 159-170 (2003).

[83] L. Leveles, K. Seshan, J. A. Lercher and L. Lefferts. Oxidative conversion of propane over lithium promoted magnesia catalyst: I. Kinetics and mechanism. Journal of Catalysis, 218, 296-306 (2003).

[84] R. Burch and E. M. Crabb. Homogeneous and heterogeneous contributions to the oxidative dehydrogenation of propane on oxide catalysts. Applied Catalysis A: General, 100(1), 111-130 (1993).

[85] D. Wolf, N. Dropka, Q. Smejkal and O. Buyevskaya. Oxidative dehydrogenation of propane for propylene production - comparison of catalytic processes. Chemical Engineering Science, 56(2), 713-719 (2001).

[86] L. Leveles. Oxidative conversion of lower alkanes to olefins. Ph.D. thesis, University of Twente, The Netherlands (2002).

[87] F. Dury, M. A. Centeno, E. M. Gaigneaux and P. Ruiz. An attempt to explain the role of $\mathrm{CO}_{2}$ and $\mathrm{N}_{2} \mathrm{O}$ as gas dopes in the feed in the oxidative dehydrogenation of propane. Catalysis Today, 81(1), 95-105 (2003).

[88] E. Xue, J. R. H. Ross, R. Mallada, M. Menendez, J. Santamaria, J. Perregard and P. E. H. Nielsen. Catalytic oxidation of butane to maleic anhydride enhanced yields 
in the presence of $\mathrm{CO}_{2}$ in the reactor feed. Applied Catalysis A: General, 210(1-2), 271-274 (2001).

[89] G. I. Panov, A. S. Kharitonov and V. I. Sobolev. Oxidative hydroxylation using dinitrogen monoxide: a possible route for organic synthesis over zeolites. Applied Catalysis A: General, 98(1), 1-20 (1993).

[90] A. S. Kharitonov, T. N. Aleksandrova, G. I. Panov, V. I. Sobolev, G. A. Sheveleva and E. A. Paukshtis. Evidence for the participation of the alpha-form of oxygen in the oxidation of benzene into phenol on Fe-ZSM-5 zeolite. Kinetics and Catalysis, 35(2), 270-271 (1994).

[91] E. N. Voskresenskaya, L. I. Kurteeva, G. G. Pervyshina and A. G. Anshits. Comparison of $\mathrm{O}_{2}$ and $\mathrm{N}_{2} \mathrm{O}$ as oxidants for the oxidative coupling of methane over Bicontaining oxide catalysts. Catalysis Today, 24(3), 277-279 (1995).

[92] D. H. V. Duma and W. Krysmann. Method of producing epoxy resins by gas phase epoxidation. US Patent \& Trademark Office, (6392065) (2000).

[93] R. Grabowski, J. Słoczyński and N. M. Grzesik. Kinetics of oxidative dehydrogenation of propane over $\mathrm{V}_{2} \mathrm{O}_{5} / \mathrm{TiO}_{2}$ catalyst. Applied Catalysis A: General, 242(2), 297-309 (2003).

[94] S. L. Kiperman. An Introduction to the Kinetics of Heterogeneous Catalytic Reactions. Nauka, Moscow (1964).

[95] O. A. Hougen and K. M. Watson. Solid catalysts and reaction rates - General principles. Industrial \& Engineering Chemistry, 35(5), 529-541 (1943).

[96] D. B. Creaser and B. Andersson. Oxidative dehydrogenation of propane over $\mathrm{V}-\mathrm{Mg}-\mathrm{O}$ : Kinetic investigation by nonlinear regression analysis. Applied Catalysis A: General, 141(1-2), 131-152 (1996).

[97] S. L. T. Andersson. Kinetic study of the oxidative dehydrogenation of propane over vanadia supported on amorphous $\mathrm{AlPO}_{4}$. Applied Catalysis A: General, 112(2), 209-218 (1994).

[98] N. Boisdron, A. Monnier, L. Jalowiecki-Duhamel and Y. Barbaux. Oxydehydrogenation of propane on $\mathrm{V}_{2} \mathrm{O}_{5} / \mathrm{TiO}_{2}$ catalyst - kinetic and mechanistic aspects. Journal of the Chemical Society - Faraday Transactions, 91(17), 2899-2905 (1995).

[99] J. N. Michaels, D. L. Stern and R. Grasselli. Oxydehydrogenation of propane over $\mathrm{Mg}-\mathrm{V}-\mathrm{Sb}$-oxide catalysts 2: Reaction kinetics and mechanism. Catalysis Letters, 42(3-4), 139-148 (1996).

[100] J. Słoczyński, R.Grabowski, K. W. o and B. Grzybowska-Świerkosz. Kinetic network for oxidative dehydrogenation of propane on vanadia-titania catalysts. Polish Journal of Chemistry, 71(11), 1585-1593 (1997).

[101] R. Grabowski, S. Pietrzyk, J. Słoczyński, F. Genser, K. Wcisło and B. GrzybowskaSwierkosz. Kinetics of the propane oxidative dehydrogenation on vanadia/titania 
catalysts from steady-state and transient experiments. Applied Catalysis A: General, 232(1-2), 277-288 (2002).

[102] A. Holzwarth, P. Denton, H. Zanthoff and C. Mirodatos. Combinatorial approaches to heterogeneous catalysis: strategies and perspectives for academic research. Catalysis Today, 67(4), 309-318 (2001).

[103] J. Słoczyński. Kinetics and mechanism of reduction and reoxidation of the alkali metal promoted vanadia-titania catalysts. Applied Catalysis A: General, 146(2), 401-423 (1996).

[104] R. M. Contractor and A. W. Sleight. Maleic anhydride from C-4 feedstocks using fluidized bed reactors. Catalysis Today, 1(5), 587-607 (1987).

[105] R. M. Contractor, H. E. Bergna, H. S. Horowitz, C. M. Blackstone, B. Malone, C. C. Torardi, B. Griffiths, U. Chowdry and A. W. Sleight. Butane oxidation to maleic anhydride over vanadium phosphate catalysts. Catalysis Today, 1(1-2), 49-58 (1987).

[106] S. S. Bharadwaj and L. D. Schmidt. Olefins by catalytic oxidation of alkanes in fluidized-bed reactors. Journal of Catalysis, 155(2), 403-413 (1995).

[107] A. Tóta, C. Hamel, S. Thomas, M. Joshi, F. Klose and A. Seidel-Morgenstern. Theoretical and experimental investigation of concentration and contact time effects in membrane reactors. Chemical Engineering Research \& Design, 82(A2), 236-244 (2004).

[108] B. C. Zhu, H. B. Li and W. S. Yang. Ag Bi V Mo oxide catalytic membrane for selective oxidation of propane to acrolein. Catalysis Today, 82(1-4), 91-98 (2003).

[109] A. Bottino, G. Capannelli, F. Cerutti, A. Comite and R. Di Felice. Inorganic membrane reactors for the gas phase partial oxidation of toluene. Chemical Engineering Research \& Design, 82(A2), 229-235 (2004).

[110] R. Mallada, M. Menéndez and J. Santamaria. Use of membrane reactors for the oxidation of butane to maleic anhydride under high butane concentrations. Catalysis Today, 56(1-3), 191-197 (2000).

[111] D. D. Eley and E. K. Rideal. The catalysis of the parahydrogen conversion by tungsten. Proceedings of the Royal Society of London Series A: Mathematical and Physical Sciences, 178, 429-451 (1941).

[112] I. Langmuir. Part II. - Heterogeneous reactions. Chemical reactions on surfaces. Transactions of the Faraday Society, 17, 607-621 (1922).

[113] C. Hinshelwood. Kinetics of Chemical Change. Oxford University Press, Oxford (1940).

[114] P. Boutry and R. Montarna. Choix d un schema reactionnel pour l oxidation catalitique $\mathrm{d}$ une olefine en acide ou anhydride carboxylique. Comptes Rendus Hebdomadaries des Seances de l Academie des Sciences Serie C, 263(19), 1102 (1966). 
[115] G. Thomas, R. Montarna and P. Boutry. Formal kinetics of consecutive heterogeneous catalytic reactions. Comptes Rendus Hebdomadaries des Seances de $l$ Academie des Sciences Serie C, 269(4), 283 (1969).

[116] M. Ai, P. Boutry, R. Montarna and G. Thomas. Kinetics of oxidation of butenes to maleic anhydride on $\mathrm{V}_{2} \mathrm{O}_{5}-\mathrm{P}_{2} \mathrm{O}_{5}$.2. Interpretation and applications of experimental results. Bulletin de la Societe Chimique de France, 8-9, 2783-2789 (1970).

[117] P. Mars and D. W. V. Krevelen. Oxidations carried out by means of vanadium oxide catalysts. Chemical Engineering Science, 3, 41-59 (1954).

[118] K. A. Shelstad, J. Downie and W. F. Graydon. Kinetics of the Vapor-Phase Oxidation of Naphthalene over a Vanadium Catalyst. Canadian Journal of Chemical Engineering, 38, 102-107 (1960).

[119] J. A. Jussola, R. F. Mann and J. Downie. The Kinetics of the Vapor-Phase Oxidation of o-Xylene over a Vanadium Oxide Catalyst. Journal of Catalysis, 17(1), 106-113 (1970).

[120] I. F. Boag, D. W. Bacon and J. Downie. Analysis of the Reaction Network for the Vanadia-Catalyzed Oxidation of ortho-Xylene. Journal of Catalysis, 38(1-3), 375384 (1975).

[121] G. C. A. Schuit and L. L. van Reijen. The Structure and Activity of Metal-on-Silica Catalysts. Advances in Catalysis, 10, 242-317 (1958).

\section{A Kinetic models for the ODHP}

\section{A.1 Eley-Rideal model}

According to the Eley-Rideal (ER) model [111], equilibrated adsorption of species A on the catalyst's surface is assumed and next its subsequent reaction with molecules B provided by the gas phase.

$$
\begin{aligned}
& \mathrm{A}_{\mathrm{g}} \stackrel{K}{\leftrightarrow} \mathrm{A}_{\mathrm{ads}} \\
& \mathrm{A}_{\mathrm{ads}}+\mathrm{B}_{\mathrm{g}} \stackrel{k}{\rightarrow} \mathrm{C}_{\mathrm{ads}} \longrightarrow \mathrm{C}_{\mathrm{g}}
\end{aligned}
$$

Applying the Langmuir assumptions for the adsorption of $\mathrm{A}$, taking partial order for $\mathrm{B}$ as one, and assuming a rapid desorption or low-coverage byproducts, the reaction rate can be then expressed by

$$
r=\frac{k K p_{A} p_{B}}{1+K p_{A}}
$$

or in the linearized form

$$
\frac{1}{r}=\frac{1}{k p_{B}}\left(1+\frac{1}{K p_{A}}\right)
$$




\section{$40 \quad$ Chapter 2}

\section{A.2 Langmuir-Hinshelwood model}

This model (LH) is based on the findings of Langmuir [112]. During the 1920s and 1930s, the kinetics used in the heterogeneous catalysis was based largely on the Langmuir lattice model of a surface consisting of non-interacting adsorption sites. These so-called Langmuir kinetics were developed by Hinshelwood [113]. He reasoned that chemisorbed molecules remained on the surface for a longer time than molecules in close contact during collision in a homogeneous phase; thus, the probability of attaining the required activation energy is higher on the surface of catalysts than for molecules that react in the homogeneous phase. This type of reaction can be schematically depicted by the following sequence of reactions

$$
\begin{aligned}
& \mathrm{A}_{\mathrm{g}}+\mathrm{B}_{\mathrm{g}} \longleftrightarrow \mathrm{A}_{\mathrm{ads}}+\mathrm{B}_{\mathrm{ads}} \\
& \mathrm{A}_{\mathrm{ads}}+\mathrm{B}_{\mathrm{ads}} \longrightarrow \mathrm{C}_{\mathrm{ads}} \\
& \mathrm{C}_{\mathrm{ads}} \longleftrightarrow \mathrm{C}_{\mathrm{g}}
\end{aligned}
$$

The Langmuir-Hinshelwood mathematical treatment is more difficult and starts from the assumption that all stages but one, the rate-determining step (e.g., the surface reaction), are very close to a thermodynamic equilibrium (pseudo steady-state assumption). The concentrations of the components prevailing in these equilibrium stages are interrelated by the conditions for the chemical equilibrium. Different rate-determining steps are possible. For example:

1. The rate is determined by the rate of the adsorption of $A$ :

$$
r=k_{a d s A} \cdot p_{A} \cdot\left(1-\theta_{A}-\theta_{B}-\theta_{C}\right)
$$

while the equilibrium conditions apply to the other stages and components

$$
\begin{aligned}
& K_{A} \cdot p_{A}=\frac{\theta_{B}}{\left(1-\theta_{A}-\theta_{B}-\theta_{C}\right)} \\
& K_{C} \cdot p_{C}=\frac{\theta_{C}}{\left(1-\theta_{A}-\theta_{B}-\theta_{C}\right)} \\
& K_{\text {surf.react }}=\frac{\theta_{C}}{\theta_{A} \cdot \theta_{B}}
\end{aligned}
$$

2. The rate is determined by the rate of the surface reaction:

$$
\begin{gathered}
r=k \cdot \theta_{A} \cdot \theta_{B} \\
\theta_{A}=\frac{K_{A} p_{A}}{\left(1+K_{A} p_{A}+K_{B} p_{B}+K_{C} p_{C}\right)}
\end{gathered}
$$

and similar for $\theta_{B}$ and $\theta_{C}$. 
3. The rate is determined by the rate of the desorption of product C:

$$
r=k_{\text {des } C} \cdot \theta_{C}
$$

where $\theta_{i}$ are calculated from the Langmuir expressions and are interrelated by the equilibrium condition for the surface reactions. If all values of $\theta_{i}$ in the above equations are expressed in terms of pressures of the components, one can finally obtain the kinetic equation in the form:

$$
r=f\left(p_{A}, p_{B}, p_{C}, T, \tau\right)
$$

which can be done only for rather simple cases.

\section{A.3 Gradual oxidation model}

The process of oxidative dehydrogenation $(\mathrm{ODH})$ may be regarded as a set of reactions by which a molecule is gradually oxidized to the products of total oxidation. As a consequence, dehydrogenation products represent intermediate products in the series of consecutive reactions. The selectivity towards a certain product of $\mathrm{ODH}$ does depend on the ratio of the rate constant of the formation and the subsequent reaction of this product. Boutry and Montarna [114] and Thomas et al. [115] advanced an idea that the consecutive reactions occur on the surface of the catalyst. This model was applied to the oxidation of butene to maleic anhydride [116].

Let $A, B$, and $C$ be the reactants in the gaseous phase; $\theta_{A}, \theta_{B}$, and $\theta_{C}$ be the degrees of the surface coverage of the corresponding reactants in adsorbed phase; $k_{1}, k_{2}$, and $k_{3}$ be the rate constants of the adsorption; $k_{1}^{\prime}, k_{2}^{\prime}$, and $k_{3}^{\prime}$ be the rate constants for the desorption; and $k_{1 S}$ and $k_{2 S}$ be the rate constants for the surface reactions. Taking into account that the reaction orders with respect to the pressures of $\mathrm{A}, \mathrm{B}$, and $\mathrm{C}$ and to the concentrations of the adsorbed phases $\theta_{i}$ are 1 and assuming the presence of only one type of adsorption site, one can write down equations for all surface coverages.

$$
\begin{aligned}
& k_{A} p_{A} \theta_{V}=\left(k_{1}^{\prime}+k_{1 S}\right) \theta_{A} \\
& k_{1} \theta_{A}+k_{2} p_{B} \theta_{V}=\left(k_{2}^{\prime}+k_{2 S}\right) \theta_{B} \\
& k_{2 S} \theta_{B}+k_{3} p_{C} \theta_{V}=k_{3}^{\prime} \theta_{C}
\end{aligned}
$$

where $\theta_{V}$ is fraction of the free adsorption sites and

$$
\theta_{A}+\theta_{B}+\theta_{C}+\theta_{V}=1
$$

The system of equations $2.16-2.18$ can be solved for $\theta_{i}$ and their values can be introduced 


\section{Chapter 2}

in the differential equations for $\mathrm{A}, \mathrm{B}$, and $\mathrm{C}$.

$$
\begin{aligned}
& \frac{d p_{A}}{d t}=-k_{1} \cdot p_{A} \cdot \theta_{V}+k_{1}^{\prime} \cdot \theta_{A} \\
& \frac{d p_{B}}{d t}=-k_{2} \cdot p_{B} \cdot \theta_{V}+k_{2}^{\prime} \cdot \theta_{B} \\
& \frac{d p_{C}}{d t}=-k_{3} \cdot p_{C} \cdot \theta_{V}+k_{3}^{\prime} \cdot \theta_{C}
\end{aligned}
$$

The system of differential equations $2.20-2.22$ is usually solved numerically and the solutions are fitted to the experimental data, which allows one to determine rate constants $k_{A}$, $k_{B}$, and $k_{C}$.

\section{A.4 Mars Van Krevelen model}

The redox model was developed by Mars and Van Krevelen (MK) [117] for naphthalene oxidation. According to this model, oxygen for the reaction comes from the lattice of the catalyst and the reduced catalyst is then reoxidized by gaseous oxygen. These two steps can be represented schematically as follows:

1. reduction of the oxidized catalyst

$$
\text { hydrocarbon }+ \text { oxidized catalyst } \longrightarrow \text { products }+ \text { reduced catalyst }
$$

2. oxidation of the reduced catalyst

$$
\text { oxygen }+ \text { reduced catalyst } \longrightarrow \text { oxidized catalyst }
$$

In the stationary state, the oxidation rate of the catalyst is equal to its reduction rate. The stationary state is determined by the ratio of the rate constants of both reactions. A steadystate adsorption model (SSAM), which can be regarded as a surface variant of the MK model, was developed by Shelstad et al. [118] and applied also to describe kinetics of the vapor-phase oxidation of o-xylene over the vanadium oxide catalyst. [119, 120] In this model, a steady state is assumed between the rate of adsorption of oxygen on the surface and the rate of removal of oxygen by the reaction with hydrocarbons from the gas phase. Some additional assumptions can be made in this model, such as

1. oxygen dissociates or

2. oxygen desorption is not negligible.

The ER, LH, and gradual oxidation model describe the catalytic reaction, while the redox model concerns variations in the state of the catalyst. The ER and LH models are the concurrent models, while they are not concurrent with respect to the redox models (e.g., ER and SSAM), i.e., it is possible that reaction proceeds according to the ER-SSAM model. 


\section{Kinetics of the ODHP over $\mathrm{Ga}_{2} \mathrm{O}_{3} / \mathrm{MoO}_{3}$ based catalyst}

A kinetic study of the ODHP over a $\mathrm{Ga}_{2} \mathrm{O}_{3} / \mathrm{MoO}_{3}$ catalyst has been performed, aiming especially at reaction orders in hydrocarbons and oxygen. Reaction rates were experimentally determined under differential reaction conditions for the catalyzed $\left(\mathrm{Ga}_{2} \mathrm{O}_{3} / \mathrm{MoO}_{3}\right.$ catalyst) and non-catalyzed system. The results obtained in this research showed that the reaction orders in oxygen are higher for the side reactions, than for the main reaction, indicating that distributive oxygen feed via a packed bed membrane reactor can be used to maximize the propylene yield. 



\subsection{Introduction}

$\mathrm{P}$ ARTIAL OXIDATION REACTION SYSTEMS are very complex systems, where numerous reactions may take place. In such systems, oxygen plays an important role as the reaction rates for both, target and waste product are strongly influenced by its concentration. In the processes of ethylene epoxidation or selective oxidation of butane to maleic anhydride, the reaction order in oxygen for the target product is higher than for the waste product(s) $[1,2]$ and therefore these processes are operated with an excess of oxygen to optimize the product selectivity. On the other hand, in the oxidative dehydrogenation of ethylbenzene to styrene, or in the ODH of methanol to formaldehyde, the reaction order in oxygen for the waste product is higher than for the target product $[3,4]$, requiring thus low oxygen concentrations to maximize the selectivity toward the desired product. However, this leads to low yields of target products and further improvements such as distributive reactant dozing are necessary in order to have these processes commercially attractive.

The oxidative dehydrogenation of propane is no exception - the oxygen concentration has a large influence on product yields and distribution. For a better understanding of the ODHP process, the complex reaction scheme may be simplified, without loosing essential information. According to Chen et al. [5, 6] and Argyle et al. [7], the overall reaction scheme can be simplified as shown in Figure 3.1.

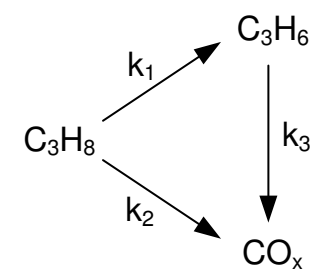

Figure 3.1: Simplified reaction network for ODHP

Reactions in this system can be divided into three categories:

- reactions of propane, with propylene as a product

- reactions of propane, with epoxides and $\mathrm{CO}_{\mathrm{x}}$ as products

- secondary reactions, or reactions of propylene, with $\mathrm{CO}_{\mathrm{x}}$ as products 
Expressed in terms of chemical formulae, these reactions can be written as

$$
\begin{array}{ll}
\mathrm{C}_{3} \mathrm{H}_{8}+\frac{1}{2} \mathrm{O}_{2} \longrightarrow \mathrm{C}_{3} \mathrm{H}_{6}+\mathrm{H}_{2} \mathrm{O} & r_{1}=k_{1} p_{\mathrm{C}_{3}}^{m_{1}} p_{\mathrm{O}_{2}}^{n_{1}} \\
\mathrm{C}_{3} \mathrm{H}_{8}+\frac{1}{2}(3 \mathrm{x}+4) \mathrm{O}_{2} \longrightarrow 3 \mathrm{CO}_{\mathrm{x}}+4 \mathrm{H}_{2} \mathrm{O} & r_{2}=k_{2} p_{\mathrm{C}_{3}}^{m_{2}} p_{\mathrm{O}_{2}}^{n_{2}} \\
\mathrm{C}_{3} \mathrm{H}_{6}+\frac{1}{2}(3 \mathrm{x}+3) \mathrm{O}_{2} \longrightarrow 3 \mathrm{CO}_{\mathrm{x}}+3 \mathrm{H}_{2} \mathrm{O} & r_{3}=k_{3} p_{\mathrm{C}_{3}}^{m_{3}} p_{\mathrm{O}_{2}}^{n_{3}}
\end{array}
$$

where $m$ and $n$ represent the reaction orders in hydrocarbons and oxygen for the different reactions, respectively.

Many researchers have focused on the development of highly selective catalysts for the ODHP, however, the reaction kinetics has been investigated only in a limited number of publications. [8-11] For the catalytic system containing $\mathrm{Ga}_{2} \mathrm{O}_{3} / \mathrm{MoO}_{3}$ based catalysts, reaction kinetics has not yet been reported.

The main objective of this part of the research is to carry out an experimental study to gain information on the reaction orders in the hydrocarbons and oxygen for the main reaction and side reactions. The obtained reaction kinetics data constitutes essential information for the numerical simulations and subsequent determination of optimal reactor type for the ODHP.

Details on catalyst preparation and characterization are given in the first part of this chapter. The subsequent description of the experimental setup and its operation are further followed by the presentation and discussion on the experimental results.

\subsection{Catalyst}

\subsubsection{Preparation}

For catalytic experiments, an equimolar mixture of $\mathrm{Ga}_{2} \mathrm{O}_{3}$ (Aldrich, 99.99\% ) and $\mathrm{MoO}_{3}$ (Aldrich, 99.99\%) was used. Components were thoroughly ground in a pestle and mortar, after which tablets were pressed. These tablets were then crushed and sieved to obtain a particle size of $0.85-1.00 \mathrm{~mm}$. Subsequently, the catalyst was calcined at $873 \mathrm{~K}$ for 3 hours in an oxidizing helium/oxygen (1:1 volume ratio) atmosphere. This material appeared to be very weak and attrition was a common problem in the experimental work.

\subsubsection{Characterization}

\section{Powder X-ray diffraction}

Provided that a material is sufficiently crystalline to diffract X-rays (crystallites larger than $3-5 \mathrm{~nm}$ ) and is present in an amount greater than $\sim 1 \%$, X-ray diffraction can be used for qualitative and quantitative chemical phase analyses. [12] The principle of this technique 
is that crystal structures consist of planes formed by repetitive arrangements of atoms, which are capable of diffracting X-rays. The angles of diffraction differ for the various planes within the crystal, so actually every (crystalline) compound has its own diffraction pattern. The differences in these patterns allow us to determine various structures of the catalyst.

In this research, the catalyst was characterized by XRD, on a Panalitical X'Pert-APD diffractometer equipped with a curved graphical monochromator using $\mathrm{Cu} \mathrm{K} \alpha$ radiation. The conditions were: a voltage $50 \mathrm{kV}$, a tube current $35 \mathrm{~mA}$, a scanning interval $0.005^{\circ}$, a scanning angle $2 \theta=20-70^{\circ}$ and a scanning step time $0.25 \mathrm{~s}$. The diffraction patterns for fresh catalyst is shown in Figure 3.2. As it can be observed, the catalyst shows mainly $\mathrm{MoO}_{3}$ peaks, while $\mathrm{Ga}_{2} \mathrm{O}_{3}$ peaks are low in intensity and almost invisible. The pattern obtained from XRD experiments matched the pattern shown in the work of Davies and Taylor [13], while the characteristic peaks are in good agreement with reference peaks for each compound, which are obtained from the database of the International Center for Diffraction Data.

Powder X-ray diffraction of a used catalyst (see Figure 3.3), after the experiments, shows strong presence of $\mathrm{MoO}_{2}$ as a result of the reduction of $\mathrm{Mo}$ (VI) to $\mathrm{Mo}$ (IV) during the oxidative dehydrogenation reactions. Again, $\mathrm{MoO}_{2}$ peaks are of much higher intensity compared to $\mathrm{Ga}_{2} \mathrm{O}_{3}$ peaks. This qualitative description is further quantified in TGA experiments, described in the following paragraph.

\section{TGA measurements}

A very convenient method to determine the oxidation state of a certain component of the catalyst is to reduce or oxidize a sample in a controlled environment and measure the weight change by a microbalance. This technique is known as thermogravimetric analysis (TGA). [14] A reactive gas is introduced to the inert gas stream and the corresponding weight changes are monitored. Since the total quantity of the active catalyst component is known, the fraction of accessible active sites can be easily calculated. In this research, the catalyst behavior under oxidizing conditions was determined on a Mettler-Toledo TGASDTA instrument. Samples of $40-60 \mathrm{mg}$ were placed in a $70 \mu \mathrm{g}$ alumina holder. Total flow of oxygen used for analysis was $60 \mathrm{ml} / \mathrm{min}$, while the temperature was increased to $1273 \mathrm{~K}$ with a ramp of $10 \mathrm{~K} / \mathrm{min}$. Analysis was performed at atmospheric pressure.

From the Figure 3.4 it can be clearly seen that a significant mass loss occurs at a temperature of about $1173 \mathrm{~K}$ for both, fresh and used catalyst. This irreversible mass loss is a consequence of $\mathrm{MoO}_{3}$ sublimation $(\sim 1023 \mathrm{~K})$ and later evaporation from the liquid phase $(1068 \mathrm{~K})$. From this graph we may also conclude that in the temperature range used in this research $(\leq 873 \mathrm{~K})$ the catalyst is very stable and even hot spots which may occur during the catalyst regeneration cannot seriously damage the composition/structure of macro catalyst bed. The increase of mass for the used catalyst came as a consequence of re-oxidation 


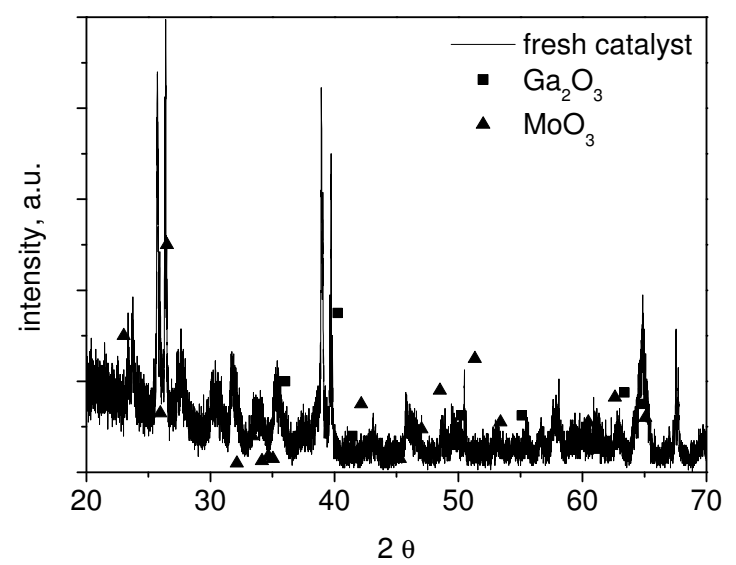

Figure 3.2: XRD pattern for the fresh $\mathrm{Ga}_{2} \mathrm{O}_{3} / \mathrm{MoO}_{3}$ catalyst

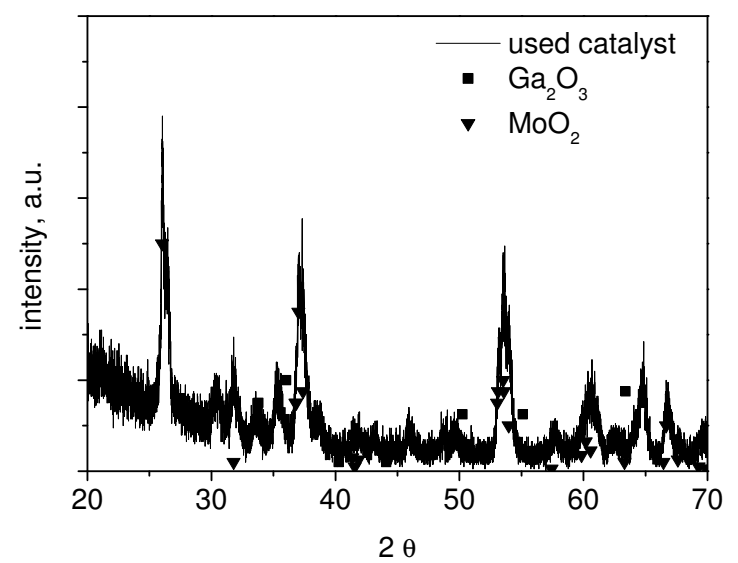

Figure 3.3: XRD pattern for the used $\mathrm{Ga}_{2} \mathrm{O}_{3} / \mathrm{MoO}_{3}$ catalyst 


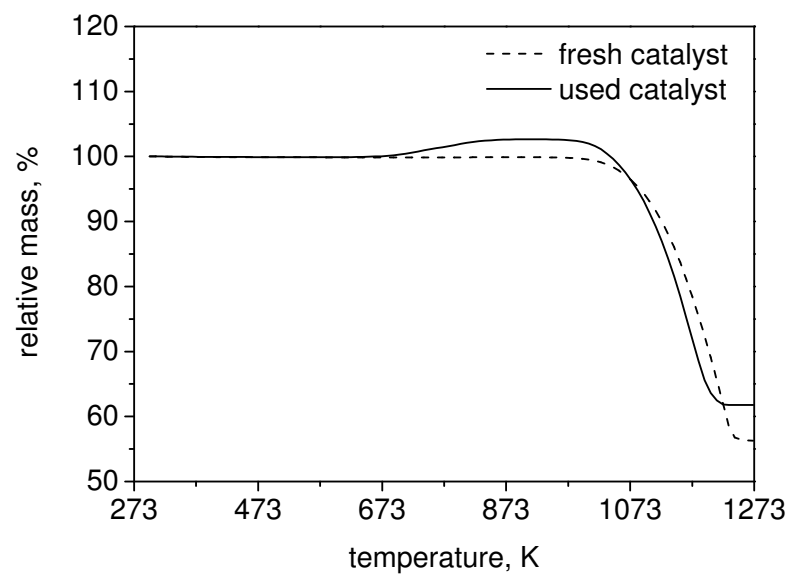

Figure 3.4: Thermogravimetric curves for fresh and used catalyst

of $\mathrm{MoO}_{2}$ to $\mathrm{MoO}_{3}$ : calculation shows that for an equimolar mixture of $\mathrm{Ga}_{2} \mathrm{O}_{3}$ and $\mathrm{MoO}_{2}$ the expected mass increase due to the re-oxidation of $\mathrm{MoO}_{2}$ to $\mathrm{MoO}_{3}$ is $\sim 5 \mathrm{wt} \%$, which corresponds also qualitatively to the data shown in the next section.

\section{Specific surface area}

Surface area, pore size and pore volume are among the most important properties of a catalyst because they determine the measure of its internal surface available to accommodate active sites, accessibility of the active sites to reactants and the extent to which transport of products from the catalyst surface to the bulk fluid is facilitated.

The most common procedure to measure the surface area and pore size is certainly gas adsorption - for determining the internal surface area of a mesoporous material, with surface area in the range of $2-1200 \mathrm{~m}^{2} / \mathrm{g}$. The method is based on the adsorption and condensation of $\mathrm{N}_{2}$ at the temperature of liquid $\mathrm{N}_{2}$ using static vacuum procedures. The sample, enclosed in a glass cell is first evacuated, or purged with inert gas while heated to $373-673 \mathrm{~K}$ and then cooled to about $77 \mathrm{~K}$ with a container of liquid nitrogen. The partial pressure of $\mathrm{N}_{2}$ above the sample is gradually increased and the amount of $\mathrm{N}_{2}$ adsorbed (and equilibrated!) at each pressure increment is recorded. The process is then reversed, i.e. the pressure is gradually decreased and curves similar to those shown in Figure 3.5 are obtained. 


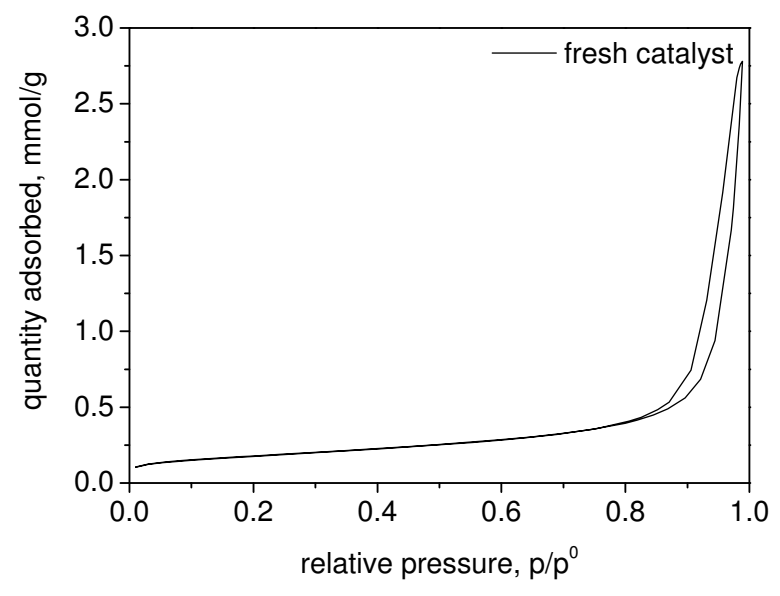

Figure 3.5: $\mathrm{BET}$ adsorption curve for the $\mathrm{Ga}_{2} \mathrm{O}_{3} / \mathrm{MoO}_{3}$ catalyst

Specific surface areas were measured on a TriStar 3000 V6.03 A instrument by $\mathrm{N}_{2}$ adsorption at $77 \mathrm{~K}$ according to the BET theory. Catalyst surface areas determined by the BET method showed that the fresh catalyst (Figure 3.5) has a surface area of $14.4 \mathrm{~m}^{2} / \mathrm{g}$, which is an expected value for $1: 1$ physical mixture of $\mathrm{Ga}_{2} \mathrm{O}_{3}$ and $\mathrm{MoO}_{3}$. The surface area of catalyst after 10 cycles of a 5 hours lasting experiment has somewhat decreased, to the value of $11.2 \mathrm{~m}^{2} / \mathrm{g}$, which can be explained by sintering of the catalyst particles during the reaction (733 and $773 \mathrm{~K}$ ) and regeneration $(893 \mathrm{~K})$ cycle.

\subsection{Experimental setup}

For research on optimal process conditions and subsequent kinetic measurements, an experimental setup was constructed. This setup, shown in Figure 3.6, has two main sections: top, preheating section (R1) and bottom, reaction section (R2). Feed, consisting of propane and oxygen, diluted with helium, entered the reactor via the top of the preheating section. Both sections were equipped with a quartz liner of $9 \mathrm{~mm}$ in diameter to avoid possible side reactions with the steel reactor walls.

Four Brooks 5850 mass flow controllers were used to regulate the gas composition, before entering the preheating section of the setup. Adjusting a three-way valve after the mass flow controllers, it was possible to bypass the reactor, which was used to determine the exact concentrations of the gases in the feed. Pressure was regulated using valve PR. The experimental setup was designed to withstand a maximum pressure of $10 \mathrm{bar}$, but was normally operated at the atmospheric pressure. Two independent ovens of $1.2 \mathrm{~kW}$ 


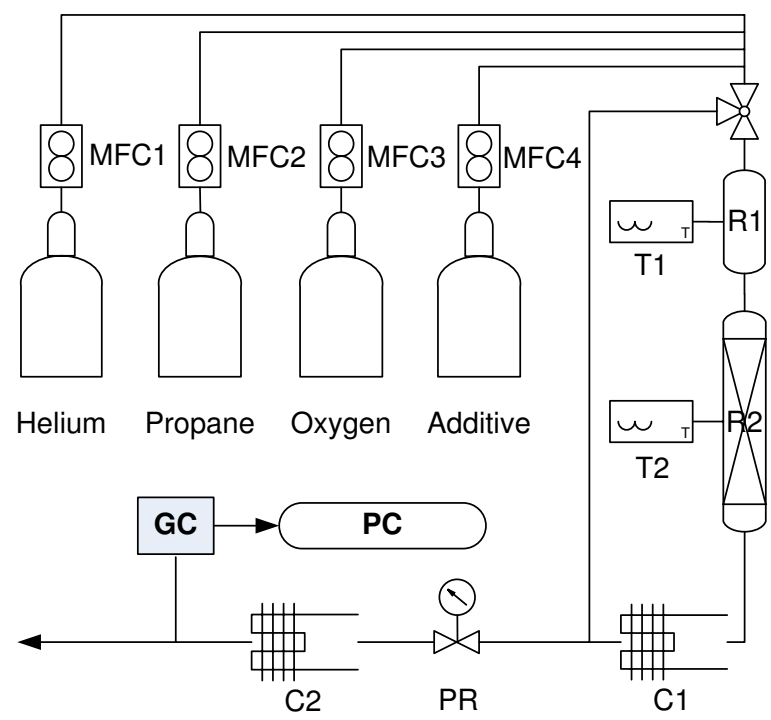

Figure 3.6: Schematic overview of the experimental setup used in this research: R1-2 - Reactor sections, MFC1-4 - Mass flow controllers, T1-2 - Temperature controllers/indicators, C1-2 - Condensers, $P R-$ Pressure regulator, GC - Gas chromatograph

were used for heating the reaction and preheating sections of the reactor to a maximum temperature of $1073 \mathrm{~K}$. Ovens were controlled by Eurotherm 91e controllers connected to K-type Chromel/Alumel thermocouples. The operating temperature in all experiments did not exceed $813 \mathrm{~K}$, except for the catalyst activation/regeneration, when it was set to $893 \mathrm{~K}$.

After cooling to room temperature and removing condensed water from the stream, the reaction products were analyzed using a Varian MicroGC 4900. A molsieve $5 \AA$ column was used for the detection of oxygen, nitrogen, methane and carbon monoxide, while a $\mathrm{Al}_{2} \mathrm{O}_{3} / \mathrm{KCl}$ column measured the ethane, ethylene, propane and propylene concentrations. Thermal conductivity detectors were attached to both columns and absolute concentrations were obtained from the chromatogram peaks. It is also important to mention that for an accurate analysis, water removal was crucial, since the GC columns are very sensitive to the presence of water vapor. The relative accuracy of the gas concentrations measured with the chromatograph was within $2 \%$ and it was regularly checked by analyzing a gas mixture of known composition.

Due to the possible inhomogeneity in reactor temperature caused by the tubular oven, the temperature profile was experimentally determined. An indicator thermocouple was sequentially moved along the reactor in steps of 2 centimeters and the temperature was recorded for each point, while the thermocouple used to control the reactor temperature was placed in the middle of the reactor. The temperature profile measured under non- 


\section{Chapter 3}

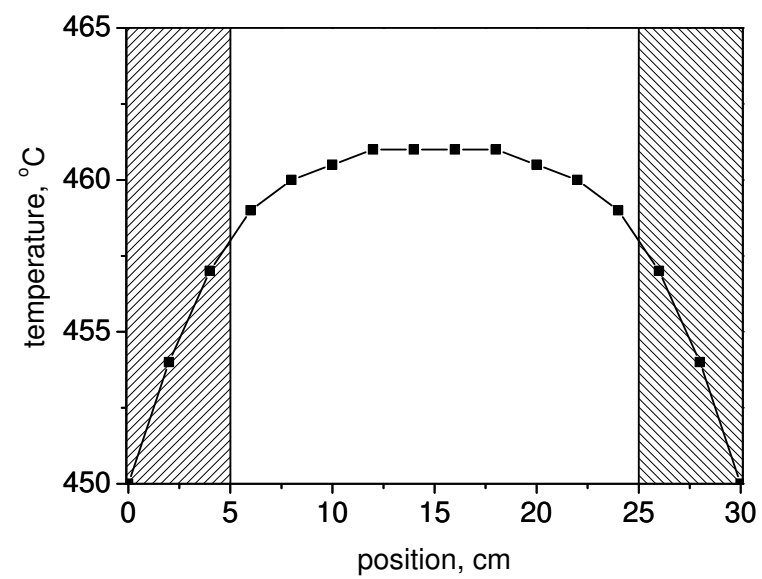

Figure 3.7: Experimentally determined temperature profile in the reactor

reactive conditions (helium flow of $100 \mathrm{ml} / \mathrm{min}$ ) is shown in the Figure 3.7. Since the top and bottom sections showed larger deviation from the temperature set-point, these sections (shaded area in the figure) were not used in catalytic experiments.

For the section outside the shaded areas shown in the previous figure, the heating oven provides an approximately constant temperature profile.

\subsection{Experimental conditions}

It is important to mention that mixtures of hydrocarbons and oxygen are flammable and may explode within certain composition limits [15]. Mixtures of propane and air are flammable between propane/oxygen ratios of 0.10 and 0.49 (see Figure 3.8) and as the amount of nitrogen diluent decreases, the flammability limits widen. Mixtures of propane and (pure) oxygen are flammable between propane/oxygen ratios of 0.02 and 0.72 . Some experimental data on auto-ignition of propane/air mixtures at atmospheric pressure can be found in the work of Mullins [16], while high pressure data can be found in the research of Kong et al. [17], Norman et al. [18] and Cadman et al. [19].

Since the operation of the reactor within the flammability limits may lead to a severe hazard, special care has been taken. The experiments may either be performed in the propane-rich regime, where propane/oxygen ratios are greater than the upper flammability limit, or in the oxygen-rich regime, where propane/oxygen ratios are lower than the lower flammability limit. Having in mind that excess of oxygen in this particular system 


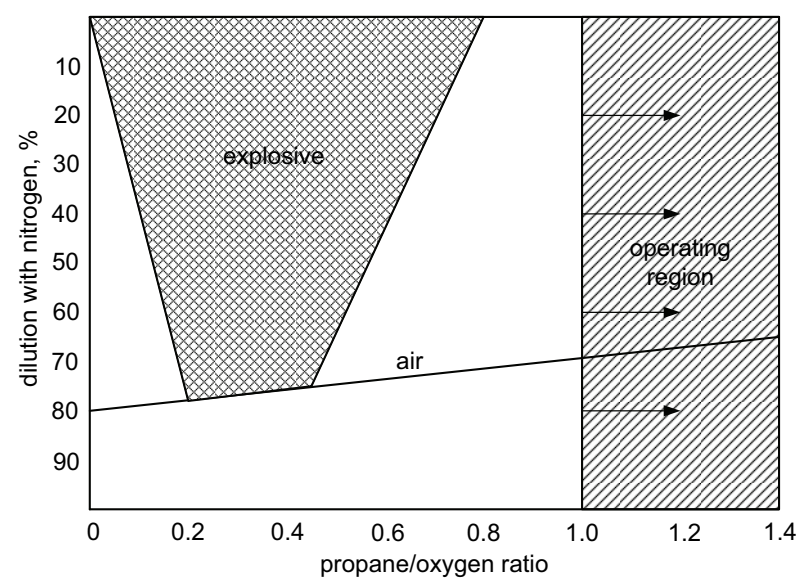

Figure 3.8: Flammability range of a propane-air mixture as a function of propane/oxygen ratios and dilution with nitrogen - the operating region of experiments performed in this research is far from the flammability region

would lead to the total combustion of propane to carbon dioxide and water, it is obvious that the operating range of experiments is the propane-rich regime. Thus, experiments were performed with a propane/oxygen ratio exceeding 1.0, assuring operation outside the flammability limits.

In order to obtain reliable results, which can further be used in explaining ODH reaction kinetics, a thorough planning of experiments had to be done. Since it is known (see subsection 2.3.2) that conversion and selectivities are strongly temperature dependent, a series of screening experiments was carried out.

The process was examined in the temperature range of $693-813 \mathrm{~K}$, at a propane partial pressure of $60 \mathrm{kPa}$, while keeping the propane to oxygen ratio equal to 2:1. The main products detected were propylene and carbon monoxide, accompanied by small amounts of ethylene and carbon dioxide. As can be seen from Figure 3.9, the conversion has an exponential increase in the temperature range studied, which is in agreement with results from Davies and Taylor [13] obtained with the same catalyst. The performance of this catalytic system in comparison to other catalytic systems was already discussed earlier (see section 2.2 at page 17$)$.

The importance of axial mass dispersion was checked using the criterion suggested by Mears [20],

$$
\frac{L}{d_{p}}>\frac{20 n D_{a x}}{d_{p} u_{s}} \ln \frac{C_{\text {inlet }}}{C_{\text {outlet }}}
$$

and it has been found that due to the small conversion (differential operation) the axial mass dispersion in the laboratory reactor used in this research does not affect the results. The existence of internal mass transfer limitations was tested using the effectiveness factor 
54 Chapter 3

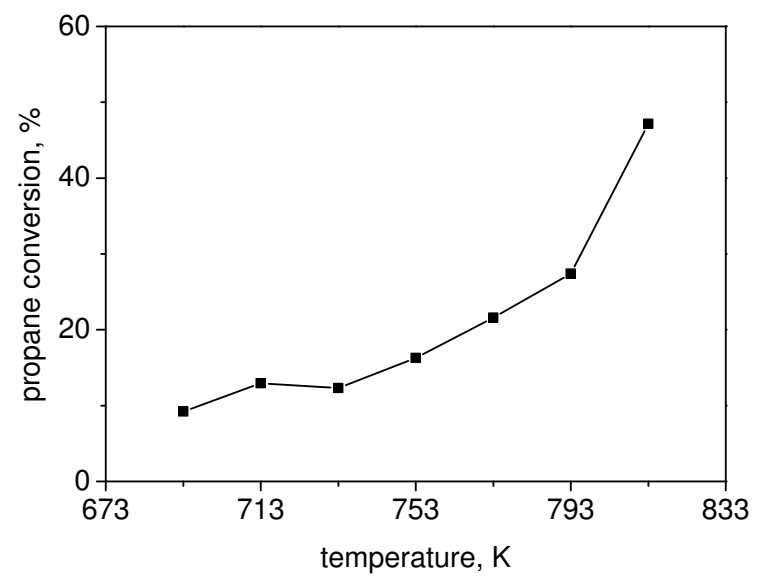

Figure 3.9: Conversion as a function of temperature in ODHP over $\mathrm{Ga}_{2} \mathrm{O}_{3} / \mathrm{MoO}_{3}$ based catalyst $\left(p=1\right.$ bar, $\left.\mathrm{C}_{3} \mathrm{H}_{8}: \mathrm{O}_{2}=2: 1\right)$

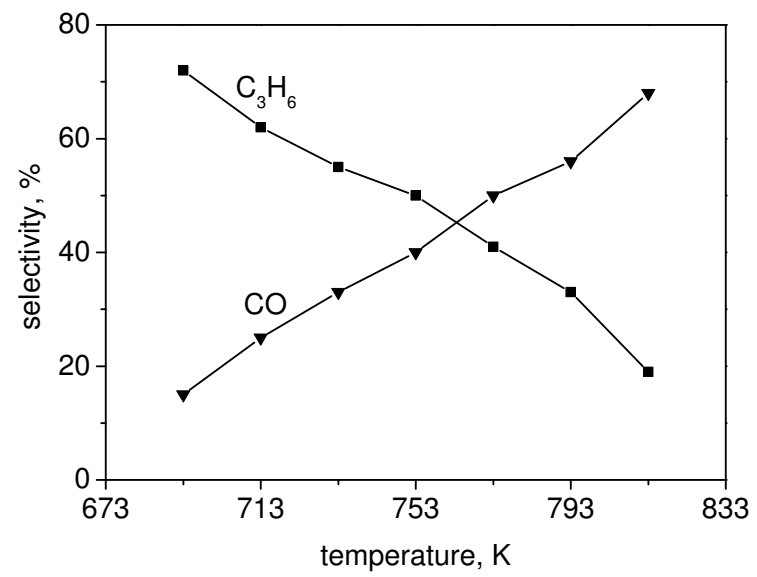

Figure 3.10: Selectivities to the main reaction products as a function of temperature in ODHP over $\mathrm{Ga}_{2} \mathrm{O}_{3} / \mathrm{MoO}_{3}$ based catalyst ( $\mathrm{p}=1 \mathrm{bar}, \mathrm{C}_{3} \mathrm{H}_{8}: \mathrm{O}_{2}=2: 1$ ) 
$\eta$, which was calculated on the basis of the derived kinetics.

$$
\eta=\frac{3 \phi-\tanh (3 \phi)}{3 \phi^{2} \tanh (3 \phi)}
$$

It was found that $\eta$ is close to one $(\eta>0.95)$.

According to Gunn [22], a gas-to-particle heat transfer coefficient can be estimated by

$$
N u=\left(7-10 \epsilon_{g}+5 \epsilon_{g}^{2}\right)\left(1+0.7 \operatorname{Re}^{0.2} \operatorname{Pr}^{0.33}\right)+\left(1.33-2.44 \epsilon_{g}+1.2 \epsilon_{g}^{2}\right) \operatorname{Re}^{0.7} \operatorname{Pr}^{0.33}
$$

while the existence of temperature gradients inside catalyst particles was tested applying the criterion developed initially by Anderson [21]

$$
\frac{\left|\Delta H_{r}\right| \mathcal{R} d_{p}^{2}}{4 \lambda_{s} T_{s}}<0.75 \frac{T_{s} R}{E_{a}}
$$

which showed that the catalyst particles are practically isothermal. Thus, kinetics were determined at intrinsic kinetic conditions, since internal and external mass and heat transfer limitations were absent.

Discussing the selectivity to desired reaction product, it is clear that the selectivity to propylene tends to fall with increasing temperatures. At the same time, the selectivity to undesired carbon monoxide increased with a temperature increase, which is shown in Figure 3.10 .

The experiments in an empty reactor were also performed, under the same conditions as for the catalyzed system. Below $713 \mathrm{~K}$, no activity was observed. At temperature levels of $733 \mathrm{~K}$ and $773 \mathrm{~K}$ the conversion of propane was $\sim 1 \%$ and $\sim 3.5 \%$, respectively. Similar results were found earlier in work of Burch and Crabb [23], where the ODHP in an empty reactor was examined in the range $723-923 \mathrm{~K}$. Propane conversion detected at $773 \mathrm{~K}$ was found to be $0.3 \%$, while at $873 \mathrm{~K}$ it was even $18 \%$. No reaction was recorded in an reactor filled with inert (quartz) particles. For easier understanding of the results discussed, an overview of the experiments performed is shown in Table 3.1.

Table 3.1: Schematic overview of experiments performed

\begin{tabular}{ccccc}
\hline propane, kPa & propylene, kPa & oxygen, kPa & dilution & catalyst \\
\hline 60 & - & $10-40$ & $\checkmark$ & $2.6 \mathrm{~g}$ \\
70 & - & $5-25$ & $\checkmark$ & - \\
$30-70$ & - & 20 & $\checkmark$ & $2.6 \mathrm{~g}$ \\
$20-65$ & - & 20 & $\checkmark$ & - \\
- & 60 & $10-35$ & $\checkmark$ & $2.6 \mathrm{~g}$ \\
- & $15-60$ & 20 & $\checkmark$ & $2.6 \mathrm{~g}$ \\
\hline
\end{tabular}




\section{Chapter 3}

The catalyst was also tested for stability in experiments performed for a longer period of time. After an initially high propane conversion, which is the consequence of relatively large amount of highly active oxygen species from $\mathrm{MoO}_{3}$, the conversion becomes constant and shows almost no variations during the experimental cycle, as shown in Figure 3.11. In the research that followed, a fixed temperature of $733 \mathrm{~K}$ was chosen for

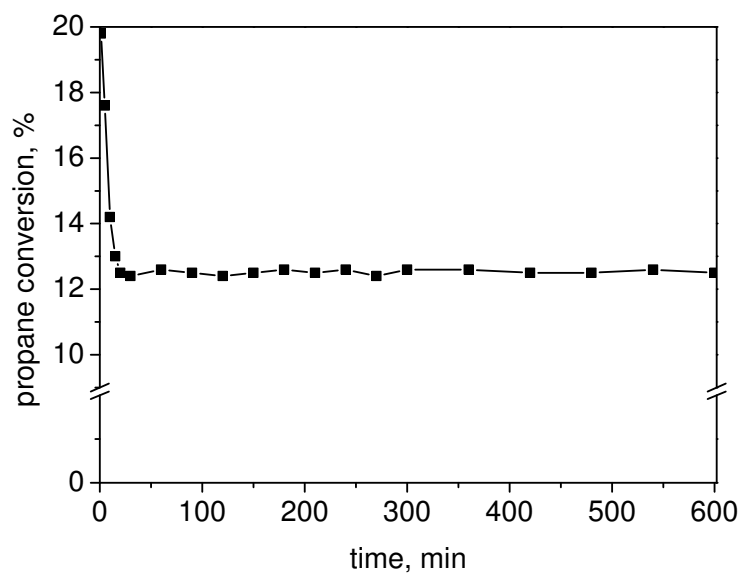

Figure 3.11: Stability of the catalyst - propane conversion as a function of time at $733 \mathrm{~K}$ ( $p=1$ bar, $\mathrm{C}_{3} \mathrm{H}_{8}: \mathrm{O}_{2}=2: 1, m_{\text {cat }}=2.5 \mathrm{~g}, \mathrm{~F}_{\text {tot }}=60 \mathrm{ml} / \mathrm{min}$ )

studying characteristics of the ODHP process over $\mathrm{Ga}_{2} \mathrm{O}_{3} / \mathrm{MoO}_{3}$ catalysts, as well as in the empty reactor. This temperature was chosen because the conversion of propane is significant, while at the same time the selectivity to propylene is reasonably high (see Figure 3.10).

It should also be mentioned that a mixture of gallium oxide and molybdenum oxide was very difficult to pelletize and make particles of a desired size. The material appeared to be sensitive to attrition, so the particles very easily disintegrated and became a powder.

Although smaller particles would reduce possible mass transfer limitations, problems may arise from the increase in the pressure drop over the bed:

- In the case of premixed feed in a quartz or (dense) alumina reactor (without a membrane), powdered catalyst easily form larger aggregates, forming a considerable resistance to gas flow (see Figure 3.12). This further increases the pressure drop over the packed bed and may also lead to breakage of the reactor tube.

- In the membrane reactor, if the pressure drop over the packed bed is higher than the transmembrane pressure difference, the gas from the tube side can easily bypass 
the catalyst, as schematically depicted in Figure 3.12. In this way a considerable amount of reactants may be lost and in this particular case may even form explosive mixtures.

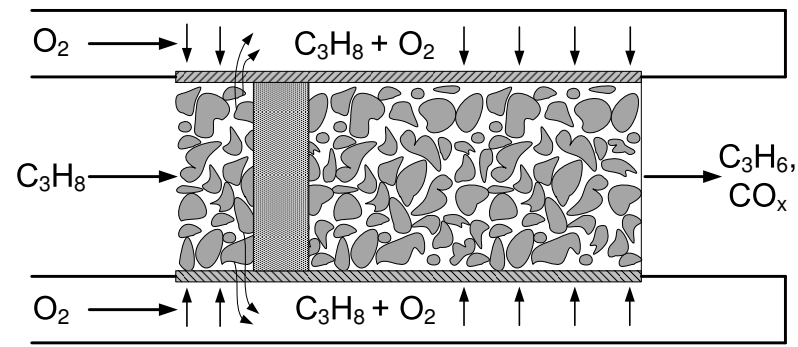

Figure 3.12: Schematic representation of bypassing in the membrane reactor. Catalyst aggregates may form a barrier which causes a large pressure drop and forces propane to the shell side, where it is mixed with oxygen. Gases permeate back to the tube side, in case of a dead end shell configuration.

In the experimental work, these problems were circumvented by frequent replacement of the catalyst.

\subsection{Kinetic experiments}

Having estimates of temperature and (partial) pressure ranges which are suitable for the kinetic study, an experimental program was carried out taking into account the following:

- The conversion of all reactants was kept low in all experiments, so that the operating conditions may be considered as differential (facilitating the interpretation of the experimental results).

- The reaction temperature was kept constant at $733 \mathrm{~K}$ during the reaction cycle.

- Every experiment lasted for $5 \mathrm{~h}$ - data collection started after one hour, since this is the period necessary for the catalytic activity to achieve a steady state. Thus, the reaction kinetics determined from the experimental data describes the steady state reaction rates, and not the initial reaction rate.

- Regeneration of the catalyst was performed after every experiment by increasing the temperature to $893 \mathrm{~K}$ and changing the feed to helium/oxygen 1:1 mixture for a period of two hours.

- No change in catalytic activity was found during the long lasting $(24 \mathrm{~h})$ and repeated experiments. 


\subsection{Results and discussion}

\subsubsection{Reactions of propane}

The key reactions of propane and the appropriate kinetic rate expressions in the form of a power law can be written as

$$
\begin{array}{ll}
\mathrm{C}_{3} \mathrm{H}_{8}+\frac{1}{2} \mathrm{O}_{2} \longrightarrow \mathrm{C}_{3} \mathrm{H}_{6}+\mathrm{H}_{2} \mathrm{O} & r_{\mathrm{C}_{3}=}=k_{1} \cdot p_{\mathrm{O}_{2}}^{n_{1}} \cdot p_{\mathrm{C}_{3}}^{m_{1}} \\
\mathrm{C}_{3} \mathrm{H}_{8}+3 \frac{1}{2} \mathrm{O}_{2} \longrightarrow 3 \mathrm{CO}+4 \mathrm{H}_{2} \mathrm{O} & r_{\mathrm{CO}}=k_{2} \cdot p_{\mathrm{O}_{2}}^{n_{2}} \cdot p_{\mathrm{C}_{3}}^{m_{2}}
\end{array}
$$

The partial pressure of oxygen, $p_{\mathrm{O}_{2}}$ remained almost unchanged during the experiments (conversion well below $12 \%$ ), so pseudo reaction rate constant can be defined as

$$
\begin{aligned}
& k_{\mathrm{C}_{3}}=k_{1} \cdot p_{\mathrm{O}_{2}}^{n_{1}} \\
& k_{\mathrm{CO}}=k_{2} \cdot p_{\mathrm{O}_{2}}^{n_{2}}
\end{aligned}
$$

so the reaction rates can be reduced to

$$
\begin{aligned}
& r_{\mathrm{C}_{3}=}=k_{\mathrm{C}_{3}} \cdot p_{\mathrm{C}_{3}}^{m_{1}} \\
& r_{\mathrm{CO}}=k_{\mathrm{CO}} \cdot p_{\mathrm{C}_{3}}^{m_{2}}
\end{aligned}
$$

\section{Propane partial pressure variation}

The reaction rate of propylene formation during the oxidative dehydrogenation reaction showed a less than proportional increase with an increase of propane partial pressure. In the range of (propane partial) pressure studied, i.e. $30-70 \mathrm{kPa}$, it has been found that in the catalyzed ODHP the reaction order in propane is 0.74 for the reaction of propylene formation, while for the reaction of $\mathrm{CO}$ formation the reaction order was negative and approximatelly equal to -0.22 . In the non-catalyzed (empty) system, the reaction order in propane for the propylene formation (equation 3.8) was found to be almost twice as high, 1.36. Reaction orders and pre-exponential coefficients determined from the experimental data by standard non-linear regression are summarized in Table 3.2.

Keeping the oxygen concentration constant, it is obvious that an increase in the propane concentration leads to an increase in the propylene reaction rate. As shown in Figure 3.13, it appears that at higher propane partial pressure levels the relative increase in the rate of propylene production is lower compared to the one at lower propane partial pressures, i.e.

$$
\left.\frac{\Delta r_{\mathrm{C}_{3}}=}{\Delta p_{\mathrm{C}_{3}}}\right|_{\text {high } p_{\mathrm{C}_{3}}}<\left.\frac{\Delta r_{\mathrm{C}_{3}}=}{\Delta p_{\mathrm{C}_{3}}}\right|_{\text {low } p_{\mathrm{C}_{3}}}
$$

which is probably due to the saturation of catalyst active sites with propane. At the same time, the rate of $\mathrm{CO}$ formation decreases. This may result from the fact that the propylene 

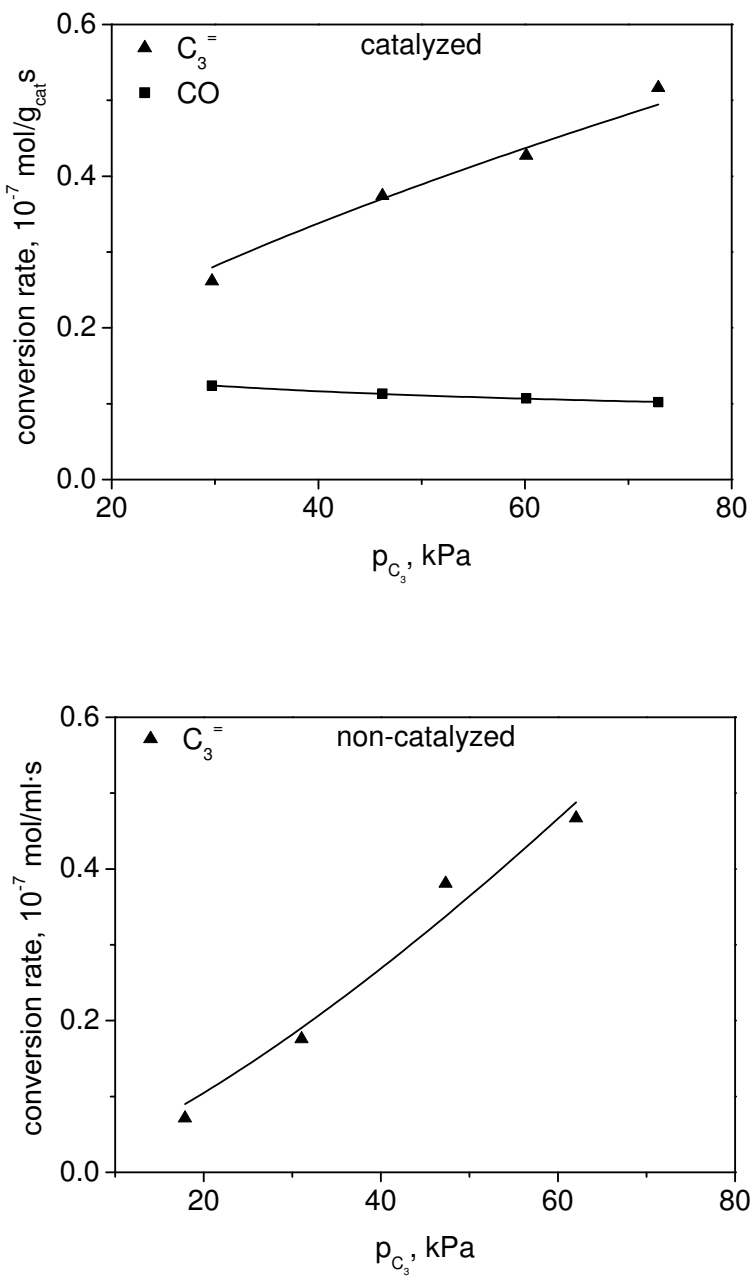

Figure 3.13: Conversion rate of propane to propylene and carbon monoxide in the catalyzed and non-catalyzed ODHP at $733 \mathrm{~K}$ as a function of propane partial pressure $\left(\mathrm{O}_{\mathrm{O}_{2}}=20 \mathrm{kPa}\right)$ 
Table 3.2: Reaction rate parameters for the catalyzed and non-catalyzed ODHP at $733 \mathrm{~K}$ (component partial pressure in $\mathrm{kPa}$, reaction rate in $\mathrm{mol} / \mathrm{g}_{\mathrm{cat}} \cdot \mathrm{s}$ )

\begin{tabular}{cccc}
\hline \multicolumn{1}{c}{ reaction } & $\mathrm{k}$ & $\mathrm{m}$ & $\mathrm{n}$ \\
\hline \multicolumn{5}{c}{ catalytic } \\
\hline $\mathrm{C}_{3} \mathrm{H}_{8}+\frac{1}{2} \mathrm{O}_{2} \longrightarrow \mathrm{C}_{3} \mathrm{H}_{6}+\mathrm{H}_{2} \mathrm{O}$ & $4.89 \cdot 10^{-10}$ & 0.74 & 0.35 \\
$\mathrm{C}_{3} \mathrm{H}_{8}+3 \frac{1}{2} \mathrm{O}_{2} \longrightarrow 3 \mathrm{CO}+4 \mathrm{H}_{2} \mathrm{O}$ & $5.88 \cdot 10^{-10}$ & -0.22 & 1.22 \\
$\mathrm{C}_{3} \mathrm{H}_{6}+3 \mathrm{O}_{2} \longrightarrow 3 \mathrm{CO}+3 \mathrm{H}_{2} \mathrm{O}$ & $9.69 \cdot 10^{-11}$ & 0 & 1.21 \\
\hline \multicolumn{5}{c}{ non-catalytic } \\
\hline $\mathrm{C}_{3} \mathrm{H}_{8}+\frac{1}{2} \mathrm{O}_{2} \longrightarrow \mathrm{C}_{3} \mathrm{H}_{6}+\mathrm{H}_{2} \mathrm{O}$ & $5.87 \cdot 10^{-12}$ & 1.36 & 1.13 \\
$\mathrm{C}_{3} \mathrm{H}_{8}+3 \frac{1}{2} \mathrm{O}_{2} \longrightarrow 3 \mathrm{CO}+4 \mathrm{H}_{2} \mathrm{O}$ & $2.83 \cdot 10^{-13}$ & 0 & 2.99 \\
$\mathrm{C}_{3} \mathrm{H}_{6}+3 \mathrm{O}_{2} \longrightarrow 3 \mathrm{CO}+3 \mathrm{H}_{2} \mathrm{O}$ & - & - & - \\
\hline
\end{tabular}

formed is stronger adsorbed at the catalyst surface (see Barsan and Thyrion [24]) and in this way reduces the direct oxidation of propane to carbon oxides.

\section{Oxygen partial pressure variation}

Since the partial pressure of propane, $p_{\mathrm{C}_{3} \mathrm{H}_{8}}$ remained almost unchanged during the experiments with different oxygen inlet concentrations(propane conversion less than $10 \%$ ), the reaction rates are

$$
\begin{aligned}
& r_{\mathrm{C}_{3}=}=k_{\mathrm{C}_{3}}^{\prime} \cdot p_{\mathrm{O}_{2}}^{n_{1}} \\
& r_{\mathrm{CO}}=k_{\mathrm{CO}}^{\prime} \cdot p_{\mathrm{O}_{2}}^{n_{2}}
\end{aligned}
$$

from which the reaction orders in oxygen, $n_{1}$ and $n_{2}$ were determined via standard nonlinear regression.

From the Figure 3.14 can be seen that the reaction order in oxygen is higher for the formation of carbon monoxide than for the formation of propylene. The dashed line represents the total carbon monoxide formation rate, from both propane and propylene, while the solid line represents only carbon monoxide obtained directly from propane. The total carbon monoxide formation rate was determined from experiments with propane and oxygen in the feed, while the amounts which come only from propane are calculated based on additional (experimental) information on carbon monoxide production rates in the reaction of propylene and oxygen under the same conditions.

Here it can be concluded that the the amount of the carbon monoxide produced in the primary reaction of propane and oxygen increases with an increase of the oxygen partial pressure, however, also a significant amount of CO is formed via secondary reactions (see Figure 3.16) of propylene oxidation. 
Summarized pre-exponential factors and reaction orders in oxygen were already given in Table 3.2.

\subsubsection{Propylene reactions}

In order to further examine the process of oxidative dehydrogenation of propane, a series of kinetic experiments was performed with propylene and oxygen as reactants (see eq. 3.3).

In the first of two series of experiments, the oxygen concentration was varied while the propylene concentration was kept constant and in the second series the propylene concentration was varied under constant oxygen partial pressure.

In a general case, the reaction rate for the reaction of propylene combustion (eq. 3.3) can be expressed as follows:

$$
r_{\mathrm{CO}\left(\mathrm{C}_{3}=\right)}=k_{\mathrm{CO}\left(\mathrm{C}_{3}=\right)} \cdot p_{\mathrm{O}_{2}}^{n_{3}} \cdot p_{\mathrm{C}_{3}^{=}}^{m_{3}}
$$

Here, a subscript $\mathrm{CO}\left(\mathrm{C}_{3}^{=}\right)$is used to indicate the $\mathrm{CO}$ formation from propylene.

Both catalyzed and non-catalyzed systems were examined, however, for the non-catalyzed system at $733 \mathrm{~K}$ no reaction was observed.

\section{Propylene partial pressure variation}

The variation of the propylene partial pressure, as shown in Figure 3.15, did not have a significant influence on the reaction rate. The reaction order in propylene was close to zero, which may occur if the catalyst surface is saturated with propylene. [24] At the same time, this indirectly confirms the observation about the absence of gas phase reactions if the gas phase reactions would occur, then the reaction rate would also be influenced by the variation of the propylene partial pressure.

\section{Oxygen partial pressure variation}

On the other hand, variation of the oxygen partial pressure had a much larger influence on the reaction rate. An increase of the oxygen partial pressure was followed by an increase in the reaction rate with an order in oxygen close to one (see Figure 3.16). A large excess of propylene turns oxygen into a limiting reactant, so variations in its concentration strongly influence the reaction rates. 
62 Chapter 3
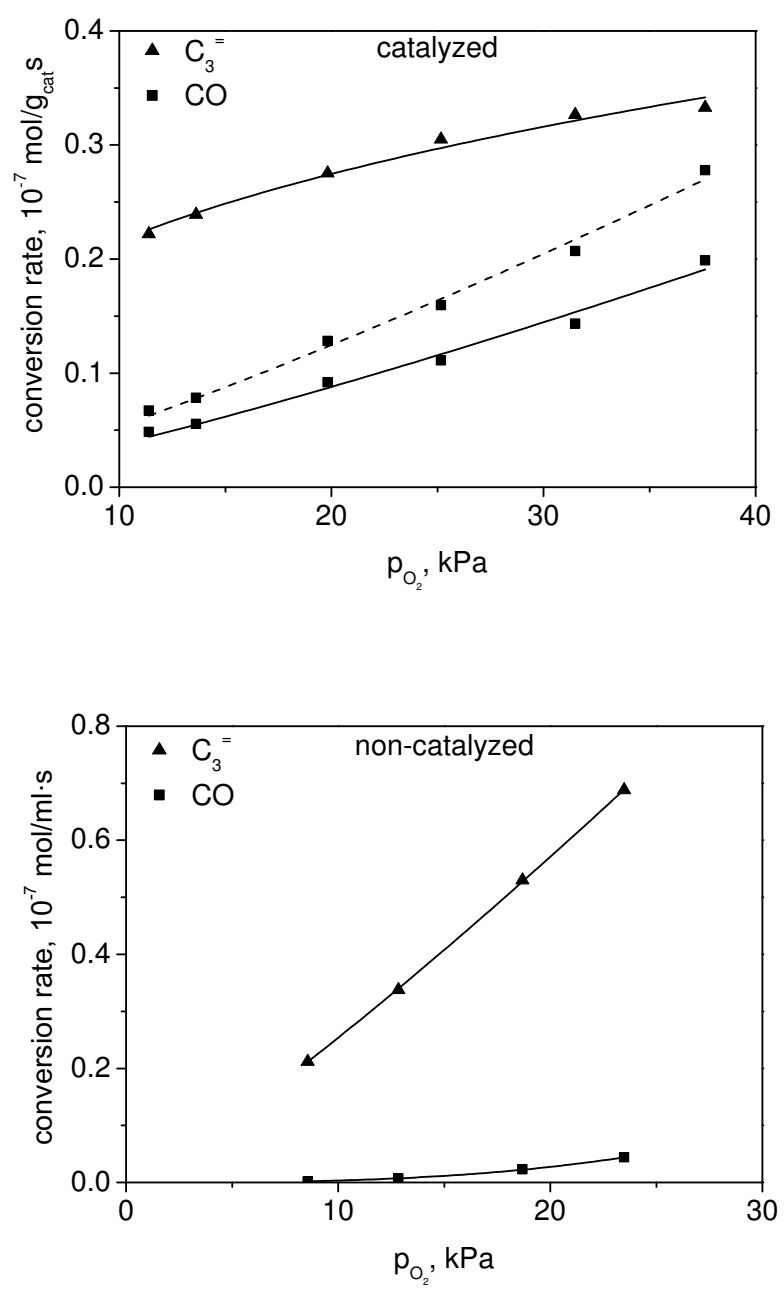

Figure 3.14: Conversion rate of propane to propylene and carbon monoxide in the catalyzed and noncatalyzed ODHP at $733 \mathrm{~K}$ as a function of oxygen partial pressure $\left(p_{\mathrm{C}_{3}}^{\text {cat }}=60 \mathrm{kPa}, p_{\mathrm{C}_{3}}^{\text {noncat }}=70 \mathrm{kPa}\right.$ ). Dashed line indicates total CO formed from both propane and propylene. 


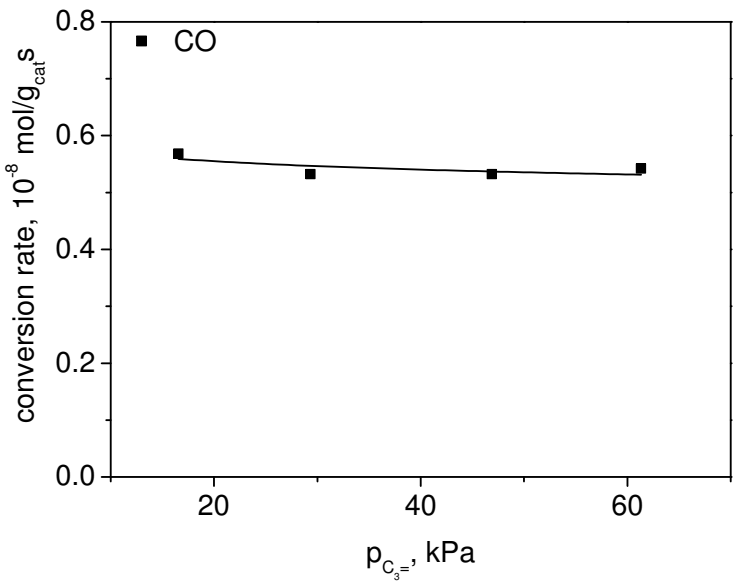

Figure 3.15: Conversion rate of propylene to carbon monoxide in the catalyzed ODHP at $733 \mathrm{~K}$ as a function of propylene partial pressure $p_{\mathrm{O}_{2}}^{\text {cat }}=20 \mathrm{kPa}$

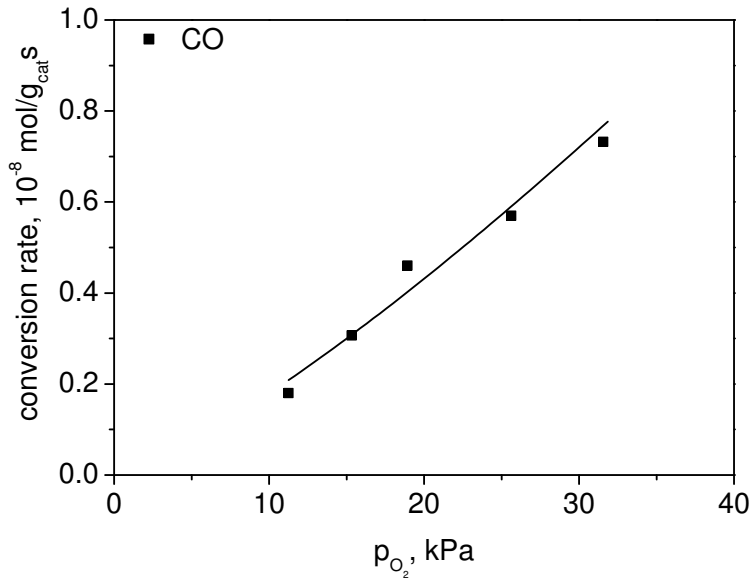

Figure 3.16: Conversion rate of propylene to carbon monoxide in the catalyzed ODHP at $733 \mathrm{~K}$ as a function of oxygen partial pressure $p_{C_{3}^{c a t}}^{\text {cat }}=60 \mathrm{kPa}$ 


\subsection{Reaction mechanism and kinetic model}

\subsubsection{Homogeneous reactions}

Gas phase reactions, i.e. reactions in the absence of catalyst proceed via a radical mechanism $[25,26]$. Although it would be expected that no radical reaction proceeds at the temperature level of only $733 \mathrm{~K}$, which was used in the experiments described before, it is very likely that the oven heating mechanism is responsible for the ignition of radical reactions. Temperature level maintenance by the thermoregulator works in a way such that the oven is repeatedly turned on and off around the desired temperature, keeping very low difference between desired and actual temperature in the reactor. However, the radiation heat transfer caused by the oven's red-hot wires can be sufficient for instantaneous temperature increase which then "ignite" the radical type governed processes and start the gas phase oxidative dehydrogenation reactions. However, in the reactor filled with quartz particles, no reaction was observed.

Having in mind that the oxidative dehydrogenation is a slightly exothermic reaction (the reaction heat is $\Delta H_{r}(693 \mathrm{~K})=-116.72 \mathrm{~kJ} / \mathrm{mol}$, according to Barsan and Thyrion [24]) it is obvious that once started, reaction can easily produce a high adiabatic temperature rise. The adiabatic temperature rise can be calculated with

$$
\Delta T_{a d}=\frac{\left(-\Delta H_{r}\right) c_{0}}{\rho C_{p}} \chi
$$

with the resulting temperature difference of $\sim 170 \mathrm{~K}$. This, at the end, provides a higher temperature level in the reactor and explains why the radical reactions can actually occur.

The radical reactions are initiated by splitting of a propane molecule into ethyl and methyl radical, which can further react with a new propane molecule and form (iso)propyl radical [25]:

$$
\begin{aligned}
\mathrm{C}_{3} \mathrm{H}_{8} & \longleftrightarrow \mathrm{C}_{2} \mathrm{H}_{5}^{\bullet}+\mathrm{CH}_{3}^{\bullet} \\
\mathrm{C}_{2} \mathrm{H}_{5}^{\bullet}\left(\mathrm{CH}_{3}\right)+\mathrm{C}_{3} \mathrm{H}_{8} & \longleftrightarrow \mathrm{C}_{3} \mathrm{H}_{7}^{\bullet}+\mathrm{C}_{2} \mathrm{H}_{6}\left(\mathrm{CH}_{4}\right)
\end{aligned}
$$

After a propyl radical is formed, it can react with oxygen and form propylene, while ethyl radicals in the similar reaction form ethylene:

$$
\begin{aligned}
\mathrm{C}_{3} \mathrm{H}_{7}^{\bullet}+\mathrm{O}_{2} & \longleftrightarrow \mathrm{C}_{3} \mathrm{H}_{6}+\mathrm{HO}_{2}^{\bullet} \\
\mathrm{C}_{2} \mathrm{H}_{5}^{\bullet}+\mathrm{O}_{2} & \longleftrightarrow \mathrm{C}_{2} \mathrm{H}_{4}+\mathrm{HO}_{2}^{\bullet} \\
\mathrm{HO}_{2}^{\bullet}+\mathrm{C}_{3} \mathrm{H}_{8} & \longleftrightarrow \mathrm{H}_{2} \mathrm{O}_{2}+\mathrm{C}_{3} \mathrm{H}_{7}^{\bullet}
\end{aligned}
$$

Two $\mathrm{HO}_{2}^{\bullet}$ formed in reactions 3.21 and 3.22 can undergo a disproportionation reaction, where one molecule of hydrogen peroxide is formed:

$$
\mathrm{HO}_{2}^{\bullet}+\mathrm{HO}_{2}^{\bullet} \longleftrightarrow \mathrm{H}_{2} \mathrm{O}_{2}+\mathrm{O}_{2}
$$


This is a termination step, where two chain carriers are being removed, however, it can also be a possible source of new radical species, according to the following equation:

$$
\mathrm{H}_{2} \mathrm{O}_{2}+\mathrm{M} \longleftrightarrow \mathrm{OH}^{\bullet}+\mathrm{OH}^{\bullet}+\mathrm{M}
$$

$\mathrm{OH}^{\bullet}$ can, in reaction with propane form again (iso)propyl radical:

$$
\mathrm{OH}^{\bullet}+\mathrm{C}_{3} \mathrm{H}_{8} \longleftrightarrow \mathrm{H}_{2} \mathrm{O}+\mathrm{C}_{3} \mathrm{H}_{7}^{\bullet}
$$

The increase in the propylene concentration with the increased oxygen inlet concentration is also in agreement with works of Taylor and Kulich [27], Niclause et al. [28] and Blakemore et al. [29].

\subsubsection{Catalyzed reactions}

Creaser and Andersson [9] investigated the ODHP over a VMgO type catalyst, also considering a consecutive reaction scheme, and found that several Mars-van Krevelen type models fit the experimental data, but were unable to distinguish between them. Pantazidis and Mirodatos [30] and Pantazidis et al. [31] suggested a parallel reaction pathway for ODHP reaction over a $\mathrm{VMgO}$ catalyst. Propane selective and non-selective oxidations take place at the same site, where the nucleophilic lattice oxygen is used for selective oxidation, while the adsorbed electrophilic oxygen is used for deep oxidation. Also considering that the formation of $\mathrm{CO}_{\mathrm{x}}$ species is due to the electrophilic oxygen, Pietrzyk et al. [32] studied the ODHP over $\mathrm{NiMoO}_{4}$ catalyst, under transient and steady state conditions, which were simulated in a "redox" mode circulating bed reactor.

Experiments carried out in this research showed that both, parallel and consecutive reaction scheme applies - kinetic experiments where propylene oxidation was studied indicated that the total amount of carbon oxides is being produced in the direct oxidation of propane as well as in the subsequent deep oxidation of propylene.

The reaction order in propylene for the secondary reactions (see equation 3.3), i.e. propylene oxidation to $\mathrm{CO}_{\mathrm{x}}$ was found to be close to zero. The possible explanation for this [24] is that the catalyst surface is saturated with propylene, so that the propylene gas phase partial pressure does not influence the reaction rate. Dependence in oxygen concentration results from the fact that the experiments were conducted in large excess of propylene, so oxygen became the limiting reactant.

\subsection{Conclusions}

In this chapter the reaction kinetics of the oxidative dehydrogenation of propane has been studied. Experiments had been performed where propane, propylene and oxygen concentrations (i.e. partial pressures) were varied, at a constant temperature of $733 \mathrm{~K}$ over a $\mathrm{Ga}_{2} \mathrm{O}_{3} / \mathrm{MoO}_{3}$ catalyst. 
The results of this research clearly showed that the reaction order in oxygen is higher for the side reactions of both propane and propylene, compared with the reaction order in oxygen for the reaction of propylene formation.

The higher reaction order in oxygen for the side reactions indicates that the selectivity to $\mathrm{CO}$ is strongly influenced by the oxygen concentration. Thus, the key for the successful operation of ODHP process is in keeping low oxygen concentration levels in the reactor. Since the contribution of secondary reactions is showed not to be insignificant, the best possible solution for the operation at a high propane conversion with a high propylene and low $\mathrm{CO}_{\mathrm{x}}$ yield is a distributed oxygen feed, which can be achieved in a packed bed membrane reactor.

\section{References}

[1] D. Lafarga, M. A. Al-Juaied, C. M. Bondy and A. Varma. Ethylene epoxidation on $\mathrm{Ag}-\mathrm{Cs} / \alpha-\mathrm{Al}_{2} \mathrm{O}_{3}$ catalyst: experimental results and strategy for kinetic parameter determination. Industrial and Engineering Chemistry Research, 39, 2148-2156 (2000).

[2] M. Pedernera, R. Mallada, M. Menéndez and J. Santamaría. Simulation of an inert membrane reactor for the synthesis of maleic anhydride. AIChE Journal, 46, 24892498 (2000).

[3] G. V. Shakhnovich, I. P. Belomestnykh, N. V. Nekrasov, M. M. Kostyukovsky and S. L. Kiperman. Kinetics of ethylbenzene oxidative dehydrogenation to styrene over vanadia/magnesia catalyst. Applied Catalysis, 12, 23-34 (1984).

[4] V. Diakov, B. Blackwell and A. Varma. Methanol oxidative dehydrogenation in a catalytic packed-bed membrane reactor: experiments and model. Chemical Engineering Science, 57, 1563-1569 (2002).

[5] K. Chen, A. Khodakov, J. Yang, A. T. Bell and E. Iglesia. Isotopic tracer and kinetic studies of oxidative dehydrogenation pathways on vanadium oxide catalysts. Journal of Catalysis, 186(2), 325-333 (1999).

[6] K. Chen, S. Xie, A. T. Bell and E. Iglesia. Structure and properties of oxidative dehydrogenation catalysts based on $\mathrm{MoO}_{3} / \mathrm{Al}_{2} \mathrm{O}_{3}$. Journal of Catalysis, 198, 232-242 (2001).

[7] M. D. Argyle, K. Chen, E. Iglesia and A. T. Bell. Effect of catalyst structure on oxidative dehydrogenation of ethane and propane on alumina-supported vanadia. Journal of Catalysis, 208(1), 139-149 (2002).

[8] R. Grabowski and J. Słoczyński. Kinetics of oxidative dehydrogenation of propane and ethane on $\mathrm{VO}_{\mathrm{x}} / \mathrm{SiO}_{2}$ pure and with potassium additive. Chemical Engineering and Processing, 44(10), 1082-1093 (2005). 
[9] D. B. Creaser and B. Andersson. Oxidative dehydrogenation of propane over $\mathrm{V}-\mathrm{Mg}-\mathrm{O}$ : Kinetic investigation by nonlinear regression analysis. Applied Catalysis A: General, 141(1-2), 131-152 (1996).

[10] D. Creaser, B. Andersson, R. R. Hudgins and P. L. Silveston. Transient kinetic analysis of the oxidative dehydrogenation of propane. Journal of Catalysis, 182(1), 264-269 (1999).

[11] F. C. Meunier, A. Yasmeen and J. R. H. Ross. Oxidative dehydrogenation of propane over molybdenum-containing catalysts. Catalysis Today, 37(1), 33-42 (1997).

[12] J. I. Langford and D. Louër. Powder diffraction. Reports on Progress in Physics, 59(2), 131-234 (1996).

[13] T. Davies and S. H. Taylor. The oxidative dehydrogenation of propane using galliummolybdenum oxide-based catalysts. Journal of Molecular Catalysis A: Chemical, 220(1), 77-84 (2004).

[14] D. Dollimore. Thermal Analysis. Analytical Chemistry, 68(12), 63-71 (1996).

[15] B. Lewis and G. von Elbe. Combustion, Flames and Explosions of Gases. Academic Press, New York, 3 edition (1987).

[16] B. P. Mullins. Spontaneous Ignition of Liquid Fuels. Butterworths, London (1955).

[17] D. Kong, R. K. Eckhoff and F. Alfert. Auto-ignition of $\mathrm{CH}_{4}$ /air, $\mathrm{C}_{3} \mathrm{H}_{8}$ /air, $\mathrm{CH}_{4} / \mathrm{C}_{3} \mathrm{H}_{8}$ /air and $\mathrm{CH}_{4} / \mathrm{CO}_{2}$ /air using a 11 ignition bomb. Journal of Hazardous Materials, 40(1), 69-84 (1995).

[18] F. Norman, F. Van den Schoor and F. Verplaetsen. Auto-ignition and upper explosion limit of rich propane-air mixtures at elevated pressures. Journal of Hazardous Materials, 137(2), 666-671 (2006).

[19] P. Cadman, G. O. Thomas and P. Butler. The auto-ignition of propane at intermediate temperatures and high pressures. Physical Chemistry Chemical Physics, 2(23), 54115419 (2000).

[20] D. E. Mears. Role of Axial Dispersion in Trickle-Flow Laboratory Reactors. Chemical Engineering Science, 26(9), 1361-1365 (1971).

[21] J. B. Anderson. A Criterion for Isothermal Behaviour of a Catalyst Pellet. Chemical Engineering Science, 18(2), 147-148 (1963).

[22] D. J. Gunn. Transfer of heat or mass to particles in fixed and fluidised beds. International Journal of Heat and Mass Transfer, 21(4), 467-476 (1978).

[23] R. Burch and E. M. Crabb. Homogeneous and heterogeneous contributions to the oxidative dehydrogenation of propane on oxide catalysts. Applied Catalysis A: General, 100(1), 111-130 (1993).

[24] M. M. Barsan and F. C. Thyrion. Kinetic study of oxidative dehydrogenation of propane over Ni-Co molybdate catalyst. Catalysis Today, 81(2), 159-170 (2003). 
[25] S. K. Layokun. Oxidative Pyrolysis of Propane. Industrial \& Engineering Chemistry Process Design and Development, 18(2), 241-245 (1979). Gn460 Times Cited:11 Cited References Count:25.

[26] N. Yamauchi, A. Miyoshi, K. Kosaka, M. Koshi and N. Matsui. Thermal decomposition and isomerization processes of alkyl radicals. Journal of Physical Chemistry A, 103(15), 2723-2733 (1999).

[27] J. E. Taylor and D. M. Kulich. Oxidative Pyrolyses of Selected Hydrocarbons Using Wall-Less Reactor. Acs Symposium Series, (32), 72-83 (1976).

[28] M. Niclause, R. Martin, A. Combes and M. Dzierzyn. La Pyrolyse Du Propane Et De Lisopentane Influence De Traces Doxygene Et Effets De Parois. Canadian Journal of Chemistry, 43(5), 1120 (1965).

[29] J. E. Blakemore, J. R. Barker and W. H. Corcoran. Pyrolysis of n-Butane and Effect of Trace Quantities of Oxygen. Industrial \& Engineering Chemistry Fundamentals, 12(12), 147-155 (1973).

[30] A. Pantazidis and C. Mirodatos. Mechanistic approach of the oxidative dehydrogenation of propane over $\mathrm{VMgO}$ catalysts by in situ spectroscopic and kinetic techniques. 11th International Congress on Catalysis - 40th Anniversary, 101, 1029-1038 (1996).

[31] A. Pantazidis, S. A. Bucholz, H. W. Zanthoff, Y. Schuurman and C. Mirodatos. A TAP reactor investigation of the oxidative dehydrogenation of propane over a $\mathrm{V}-\mathrm{Mg}-\mathrm{O}$ catalyst. Catalysis Today, 40(2-3), 207-214 (1998).

[32] S. Pietrzyk, M. L. O. M. Mahmoud, T. Rembeczky, R. Bechara, M. Czernicki and $\mathrm{N}$. Fatah. Oxydehydrogenation of propane on $\mathrm{NiMoO}_{4}$ catalyst under transient and steady-state conditions. Dynamics of Surfaces and Reaction Kinetics in Heterogeneous Catalysis, 109, 263-271 (1997). 


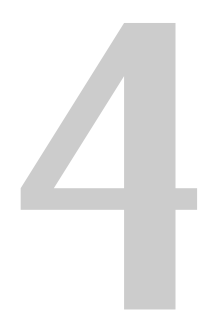

\section{Modeling of a packed bed membrane reactor for the ODHP}

In this chapter a conceptual study of a packed bed membrane reactor for the ODHP is performed. A one dimensional, multi-compartment, multi-component, pseudo-homogeneous, non-isothermal packed bed membrane reactor model was developed for a tube-in-tube configuration. The performance of a reactor for the catalyzed ODHP was simulated for the cases of premixed and distributed oxygen feeding, where the reactants composition, flow rates and extent and manner of dilution were varied. The results of these detailed numerical simulations indeed showed and quantified an improved selectivity to propylene and lower yields of by-products when applying distributive oxygen dosing. 



\subsection{Introduction}

7 He ADVANCEMENT OF MEMBRANES made with a variety of inorganic materials has opened up the opportunity to apply the inorganic and catalytic membrane reactor for many new applications over a much wider range of operating conditions. [1-5] In recent years also the modeling of (catalytic) membrane reactors has progressed significantly. [6-11] In some cases, these models were aimed to complement ongoing experimental studies, sometimes the goals were much more ambitious and the modeling effort was directed towards better understanding of the prevailing phenomena (e.g. 2D flow profiles and extent of concentration polarization, see Tiemersma et al. [12]) and the general design of catalytic membrane reactors or packed bed membrane reactors.

The modeling of membrane reactors for their application in partial oxidation processes has also been studied earlier [13-16], e.g. for the cases of multi-stage dosing in a membrane reactor cascade [17] with a high oxygen over hydrocarbon ratio, or for hydrocarbon partial oxidation process aiming at acrolein production [18]. In this work, a one dimensional, multi-compartment, multi-component, pseudo-homogeneous, nonisothermal reactor model for the ODHP in a packed bed membrane reactor (PBMR) over a $\mathrm{Ga}_{2} \mathrm{O}_{3} / \mathrm{MoO}_{3}$ catalyst is developed, to assess and quantify the benefits of distributive oxygen feeding via a porous membrane, in comparison to the performance of a packed bed reactor with a premixed reactants feed.

The general model assumptions and governing equations will be given in the next sections, followed by a discussion of the effects of the design and process parameters on the reactor performance (propylene yield at a specified propane conversion and radial temperature profiles).

\subsection{General model assumptions}

The packed bed membrane reactor model is based on the following assumptions:

\section{Tube-in-tube reactor configuration (with either premixed or distributed feed)}

A schematic of the packed bed catalytic membrane reactor configuration considered in this work for the ODHP is shown in Figure 4.1. It is a tube-in-tube configuration, with catalyst positioned at the tube side, while oxygen is dosed via a co-currently fed stream to the shell side (annular space) through a porous membrane.

The performance of the packed bed membrane reactor with this tube-in-tube configuration with distributive oxygen feeding via the porous membrane is compared with the performance of a tubular fixed bed reactor with premixed feed. 


\section{Chapter 4}

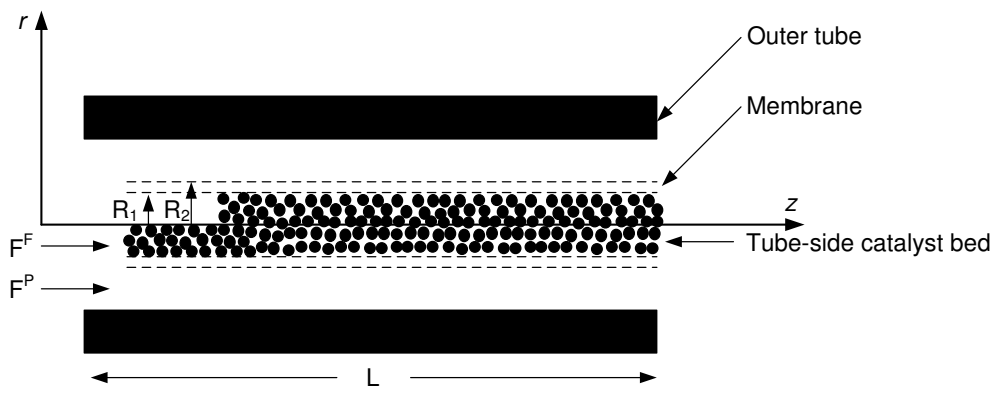

Figure 4.1: Schematic of a membrane reactor used in a generalized packed bed catalytic membrane reactor model

\section{Plug flow with superimposed axial dispersion}

For both compartments, i.e. membrane shell and tube side, plug-flow with superimposed axial dispersion is assumed. A simple, frequently used rule to assess whether axial dispersion effects can be neglected is $L / d_{p}>30$. Mears $[19,20]$ derived a more accurate criterion for the case of single $n$-th order reaction.

$$
\frac{L}{d_{p}}>\frac{20 n D_{a x}}{d_{p} u_{s}} \ln \frac{C_{\text {inlet }}}{C_{\text {outlet }}}
$$

If equation 4.1 holds, the deviation from plug flow is less than $5 \%$.

In the model developed in this research, axial dispersion was included, however its importance was found to be negligible, since the ratio $L / d_{p}$ is much higher than 30 and also the criterion mentioned in equation 4.1 is satisfied.

3. 1D non-isothermal, adiabatic model (i.e. no heat losses, no radial temperature profiles)

To be able to assess whether the $1 \mathrm{D}$ model is sufficient for describing the oxidative dehydrogenation of propane in the selected reactor configuration, the modified Thiele modulus concept developed by Kürten et al. [14] and van Sint Annaland et al. [15, 16], given in equation 4.2 was applied.

$$
\phi=\frac{d_{p}}{4} \sqrt{\frac{\frac{n_{1}+1}{2} \eta_{1} k_{1}\langle c\rangle^{n_{1}-1}+\frac{n_{2}+1}{2} \eta_{2} k_{2}\langle c\rangle^{n_{2}-1}}{D_{\text {rad }}}}
$$

where the radial dispersion coefficient, $D_{\text {rad }}$, is calculated based on expression proposed by Specchia et al. [21] 


$$
D_{\text {rad }}=\frac{d_{p} v_{g}}{8.65\left(1+19.4\left(\frac{d_{p}}{2 r_{i}}\right)^{2}\right)}
$$

Substituting values in equations 4.2 and 4.3 showed that for the catalyst particle size and reactor geometry used in this work, the bed effectiveness factor, $\eta$, is very close to one (Thiele modulus $\approx 0.03$ ). The effectiveness factor was calculated using

$$
\eta=\frac{1}{\phi} \frac{I_{1}(2 \phi)}{I_{0}(2 \phi)}
$$

which is valid for cylindrical geometry (see, for example, Rawlings and Ekerdt [22]), where $I_{0}$ and $I_{1}$ represent modified Bessel's functions. Concluding, a $1 \mathrm{D}$ approach is justified.

\section{Mass/heat transfer between compartments accounted for by overall mass/heat transfer coefficients from the bulk of the catalyst bed to the wall}

Heat transfer between the shell and tube side and the membrane itself is described by overall heat transfer coefficients $h^{P}$ and $h^{F}$, respectively, taken from transport phenomena and reactor design textbooks. It is assumed that the external concentration and temperature gradients between the fluid phase and the catalyst phase and the internal temperature gradients in the catalyst for the tube and shell side are negligible, as well as concentration gradients between shell/tube side and membrane itself.

\section{Pseudo-homogeneous model}

The concentration gradients in the catalyst particles are taken into account through a particle effectiveness factor, which was however close to 1 in this work.

In the same time, it was necessary to prove if the catalyst particles are isothermal or not. Anderson [23] applied the perturbation approach to derive a criterion to check the absence of temperature gradients inside catalyst particles. The reaction is assumed to follow an Arrhenius temperature dependence. For quasi-isothermal behavior, the observed rate $\mathcal{R}$ must not differ from the rate that would prevail at constant temperature by more than an acceptable amount of $5 \%$. The resulting criterion, in terms of Damköhler's number involving heat transport by conduction is

$$
\frac{\left|\Delta H_{r}\right| \mathcal{R} d_{p}^{2}}{4 \lambda_{s} T_{s}}<0.75 \frac{T_{s} R_{g}}{E}
$$

where $\left|\Delta H_{r}\right|$ is the absolute value of the heat of reaction, $\mathcal{R}$ is the reaction rate, $\lambda_{s}$ is the thermal conductivity of the particle, $E$ is the true activation energy (data on activation energy can be found in [24-26]), $R_{g}$ is the gas constant and $T_{s}$ is the absolute temperature 
at the catalyst surface. This criterion is valid whether diffusional limitations exist in the particle or not. By substituting values in equation 4.5 it was confirmed that the catalyst particles are practically isothermal, so that pseudo-homogeneous approach is valid for the cases examined.

\section{Porous membrane where the transport is dominated by Knudsen flow}

The various reactant and product species are assumed to diffuse through the membrane independently from each other, while their diffusivity is not a function of pressure. This indirectly assumes that the prevailing mechanism of diffusion is Knudsen diffusion, which is indeed the case in this experimental study [11, 27-29]. If other transport mechanisms, such as bulk and surface diffusion and viscous flow are present, they could in principle be easily incorporated into the model.

\subsection{Description of the PBMR model}

In the following subsections, the model equations of the PBMR model for the ODHP over a $\mathrm{Ga}_{2} \mathrm{O}_{3} / \mathrm{MoO}_{3}$ catalyst will be presented and the numerical solution method shortly outlined. Details on the selected reactor design and operating conditions are also presented.

\subsubsection{Model equations}

The governing model equations along with the appropriate (Danckwert's type) boundary conditions have been summarized in Table 4.1, representing component mass and energy balances augmented with the differential Ergun equation for the pressure drop over the fixed bed. Note that the accumulation terms are included in the description, since the simulations were always started with the reactor initially at a uniform temperature, filled with an inert gas and subsequently progressed in time, until the steady state solution was obtained.

Constitutive equations for the transport parameters and physical properties can be found in Appendix A and B, respectively.

\subsubsection{Kinetics}

As discussed before (see section 3.6 at page 58) the most important reactions in the oxidative dehydrogenation of propane and their rates can be written as

$$
\begin{array}{ll}
\mathrm{C}_{3} \mathrm{H}_{8}+\frac{1}{2} \mathrm{O}_{2} \longrightarrow \mathrm{C}_{3} \mathrm{H}_{6}+\mathrm{H}_{2} \mathrm{O} & r_{1}=k_{1} p_{\mathrm{C}_{3}}^{m_{1}} p_{\mathrm{O}_{2}}^{n_{1}} \\
\mathrm{C}_{3} \mathrm{H}_{8}+\frac{1}{2}(3 \mathrm{x}+4) \mathrm{O}_{2} \longrightarrow 3 \mathrm{CO}_{\mathrm{x}}+4 \mathrm{H}_{2} \mathrm{O} & r_{2}=k_{2} p_{\mathrm{C}_{3}}^{m_{2}} p_{\mathrm{O}_{2}}^{n_{2}} \\
\mathrm{C}_{3} \mathrm{H}_{6}+\frac{1}{2}(3 \mathrm{x}+3) \mathrm{O}_{2} \longrightarrow 3 \mathrm{CO}_{\mathrm{x}}+3 \mathrm{H}_{2} \mathrm{O} & r_{3}=k_{3} p_{\mathrm{C}_{3}}^{m_{3}}=p_{\mathrm{O}_{2}}^{n_{3}}
\end{array}
$$


Table 4.1: The governing equations: plug flow with superimposed axial dispersion model

\begin{tabular}{lll}
\hline Component mass balance: & $\frac{\partial}{\partial t}\left(\epsilon \rho_{g} \omega_{i}\right)=-\frac{\partial}{\partial z}\left(\epsilon \rho_{g} u_{z} \omega_{j}\right)+\frac{\partial}{\partial z}\left(\rho_{g} D_{j} \frac{\partial \omega_{j}}{\partial z}\right)+S_{r, j}+\Phi_{m, j}$ \\
Boundary conditions: & Inlet $(z=0) \quad-\left.\left(D_{j} \rho_{g}\right) \frac{\partial \omega_{j}}{\partial z}\right|_{z=0}+\left.\left(u_{z} \rho_{g} \epsilon \omega_{j}\right)\right|_{z=0}=\frac{\Phi_{m, j}}{A_{\text {reactor }}}$ \\
& Outlet $\left.(z=L) \quad \frac{\partial \omega_{j}}{\partial z}\right|_{z=L}=0$ \\
The source term $S_{r, j}:$ & $S_{r, j}=(1-\epsilon) \rho_{s} M_{j} \sum_{i=1}^{n r} v_{i j} r_{i} \quad$ for $\quad j=1,2, \ldots, n c \quad$ and $\quad i=1,2, \ldots, n r$ \\
Energy balance: & $\left(\epsilon \rho_{g} c_{p, g}+(1-\epsilon) \rho_{s} c_{p, s}\right) \frac{\partial T}{\partial t}=-c_{p, g} \frac{\partial}{\partial z}\left(\epsilon \rho_{g} u_{z} T\right)+\frac{\partial}{\partial z}\left(\lambda \frac{\partial T}{\partial z}\right)+S_{h}$ \\
The source term, $S_{h}:$ & $S_{h}=(1-\epsilon) \rho_{s} \sum_{i=1}^{n r} r_{i} \Delta H_{i} \quad$ for $\quad i=1,2, \ldots, n r$ \\
Boundary conditions: & Inlet $(z=0) \quad-\left.\lambda \frac{\partial T}{\partial z}\right|_{z=0}+\left.\left(u_{z} \rho_{g} \epsilon c_{p, g} T\right)\right|_{z=0}=\frac{c_{p, g} T_{0} \Phi_{m}}{A_{r e a c t o r}}$ \\
& Outlet $\left.(z=L) \quad \frac{\partial T}{\partial z}\right|_{z=L}=0$ \\
Total momentum balance equation: & $\frac{\partial p}{\partial z}+\beta \rho_{g} u_{z}=\left.0 \quad p\right|_{z=0}=p_{0}$ \\
Friction coefficient: & $\beta=150 \frac{(1-\epsilon)^{2}}{\epsilon^{3}} \frac{\mu_{g}}{\rho_{g} d_{p}^{2}}+1.75 \frac{1-\epsilon}{\epsilon^{3}} \frac{\epsilon \bar{u}_{z}}{d_{p}}$ \\
\hline
\end{tabular}




\section{$76 \quad$ Chapter 4}

where the corresponding kinetic coefficients have been experimentally determined in a micro-catalytic fixed bed reactor operated under differential reactor conditions. These coefficients have been listed in Table 3.2.

\subsubsection{Membrane flux}

The overall flux of component $j$ through the porous membrane, $\Phi_{m, j}\left(\mathrm{in} \mathrm{kg} / \mathrm{m}^{2} \cdot \mathrm{s}\right.$ ), is related to the cross-sectional mass flow rate as follows:

$$
\Phi_{m, j}=\dot{F}_{j}^{P} \frac{S_{P}}{S_{m}}=\dot{F}_{j}^{P} \frac{\frac{\left(D^{2}-d^{2}\right) \pi}{4}}{(d+w) \pi L}=\dot{F}_{j}^{P} \frac{D^{2}-d^{2}}{4(d+w) L}
$$

where $d, D$ and $w$ represent internal and external tube diameter and the wall thickness, respectively.

Expressed in this way, it is easy to compare the amount of oxygen added to the reactor through the membrane with the corresponding amount in the case of premixed reactants flow.

Due to to the permeation of oxygen from the shell side of the reactor through the membrane to the tube side, the flow rates in these compartments change. The total flow rate in the tube side equals

$$
\dot{F}^{F}=\dot{F}_{0}^{F}+\dot{F}_{m}^{F}
$$

where the term $\dot{F}_{m}^{F}$ represents a flow increase due to oxygen permeation, and is expressed as

$$
\dot{F}_{m}^{F}=\Phi_{m} \frac{S_{m}}{S_{F}}=\Phi_{m} \frac{(d+w) \pi L}{\frac{\pi d^{2}}{4}}=4 \Phi_{m} \frac{(d+w) L}{d^{2}}
$$

Simultaneously, the flow in the shell side decreases:

$$
\dot{F}^{P}=\dot{F}_{0}^{P}-\dot{F}_{m}^{P}
$$

where, similar as in equation 4.10 , the factor describing the flow rate change is given as

$$
\dot{F}_{m}^{P}=\Phi_{m} \frac{S_{m}}{S_{P}}=\Phi_{m} \frac{(d+w) \pi L}{\frac{\left(D^{2}-d^{2}\right) \pi}{4}}=4 \Phi_{m} \frac{(d+w) L}{D^{2}-d^{2}}
$$

\subsubsection{Numerical solution}

Solving convection-dominated partial differential equations (PDEs) in intrinsically instationary chemical reactors such as packed bed membrane reactors can be a computationally quite demanding task. One reason for this is the presence of very steep gradients 
in the temperature and concentration profiles at different locations. The computational effort is greatly reduced with higher-order discretization schemes for the convection terms and with an automatic, local grid adaptation. In this research, WENO schemes (see Smit et al. [30]) are used for the convection terms, while a local grid adaptation technique uses the smoothness indicators and interpolation polynomials of the WENO schemes. With this grid adaptation technique, the number of grid cells required to accurately capture steep gradients can be greatly reduced, thereby enormously reducing computation times.

\section{Time integration}

Time integration in this work is carried out using the third-order accurate L-stable singly diagonal implicit Runge-Kutta (SDIRK) scheme, following Alexander [31]. This scheme was selected because it is implicit so that very small steps due to stability problems of the convection, conduction and reaction terms can be avoided. Furthermore, with this scheme only a system of linear equations in the spatial domain has to be solved, which is carried out with an efficient banded matrix solver. Time-step adaptation is also carried out according to Alexander [31]. The tolerance used for the iterations and the time-step adaptation, is spatially averaged and is chosen sufficiently small. Because of the non-linear source terms in the equations an iterative solution method (Newton-Rhapson) is used. Since also the WENO scheme is non-linear, the convection term is discretized implicitly with the Upwind scheme and then iteratively corrected (semi-implicitly) with the WENO scheme (i.e., deferred correction), following Ferziger and Perić [32]. The steady state situations were obtained by time-marching from an initial condition (reactor temperature uniform, filled with inert gas).

\subsubsection{Model settings}

For a simulation of a partial oxidation reaction system with a premixed reactants flow, the dimensions of the tubular reactor were specified in a way that they correspond to the dimensions of an experimentally used reactor (see chapter 5). The diameter was set to $8 \mathrm{~mm}$ and length to $300 \mathrm{~mm}$, where $250 \mathrm{~mm}$ was the effective (reactive section) length. The wall thickness was set to $1.5 \mathrm{~mm}$. Physical properties of the reactor construction material were also taken into account in the energy balance.

The simulation of a partial oxidation system with a distributed oxygen feed was performed similarly to the simulation of the premixed reactants flow system. The system consists of two co-axial tubes, as shown in Figure 4.2, where the inner tube has a porous (alumina) membrane section, which enables oxygen permeation at a given rate. The reactor length was set to $260 \mathrm{~mm}$, while the membrane length was $250 \mathrm{~mm}$.

Other default model settings for the process and operation parameters have been listed in Table 4.2. 


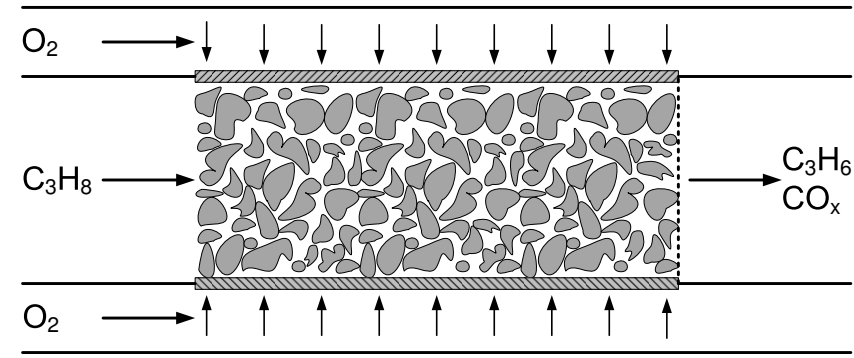

Figure 4.2: Schematic of the reaction section of the packed bed membrane reactor with distributed oxygen feed.

\subsection{Results and discussion}

\subsubsection{Premixed vs. distributive oxygen feeding}

First, the extent of axial temperature profiles in the fixed bed with premixed feed and in the packed bed membrane reactor with distributive feed through a porous membrane has been compared for the base case settings listed in Table 4.2. In Figure 4.3 the axial temperature profiles for adiabatically operated reactors with and without distributive feeding are shown. Due to the difference in heat generation by different reactions and their occurrence along the reactor length, the axial temperature profiles for the premixed feed and for the distributed feed of oxygen have a different shape. In case of premixed reactants flow, the concentration of reactants is highest at the beginning of the reactor. Higher reaction order in oxygen for the side reactions of the hydrocarbons combustion and their corresponding heat production cause an increase in the temperature close to the reactor inlet. Towards the end of the reactor, where oxygen concentration is lower and the main reaction is dominant, the temperature is lower. In the case of the packed bed membrane reactor, where oxygen is fed distributively, at the inlet of the reactor, the main reaction prevails and the temperature rise is slow. Closer to the end of the reactor, the ratio $\mathrm{C}_{3} \mathrm{H}_{8}: \mathrm{O}_{2}$ becomes higher, promoting side (combustion) reactions. Despite this fact, the amount of heat produced in combustion reactions is low since the oxygen concentration is low along the entire reactor. As a consequence, the adiabatic temperature rise becomes smaller.

The profiles also clearly show that for the selected conditions in this work the cooling of the product stream with the inert gas flow through the shell side is already sufficient to

Table 4.2: Usual values for the model parameters

\begin{tabular}{llll}
\hline $\mathrm{D}$ & $0.014 \mathrm{~m}$ & $\mathrm{~d} / \mathrm{w}$ & $0.008 / 0.0015 \mathrm{~m}$ \\
$\mathrm{~L}$ & $0.05-1 \mathrm{~m}$ & $\mathrm{~F}_{\text {tot }}$ & $85 \mathrm{ml} / \mathrm{min}$ \\
$\mathrm{Y}_{\mathrm{N}_{2} / \mathrm{C}_{3} \mathrm{H}_{8} / \mathrm{O}_{2}}$, premixed & $6: 3: 1$ & $\mathrm{Y}_{\mathrm{N}_{2} / \mathrm{C}_{3} \mathrm{H}_{8}}$, distributed & $6: 3$ \\
\hline
\end{tabular}




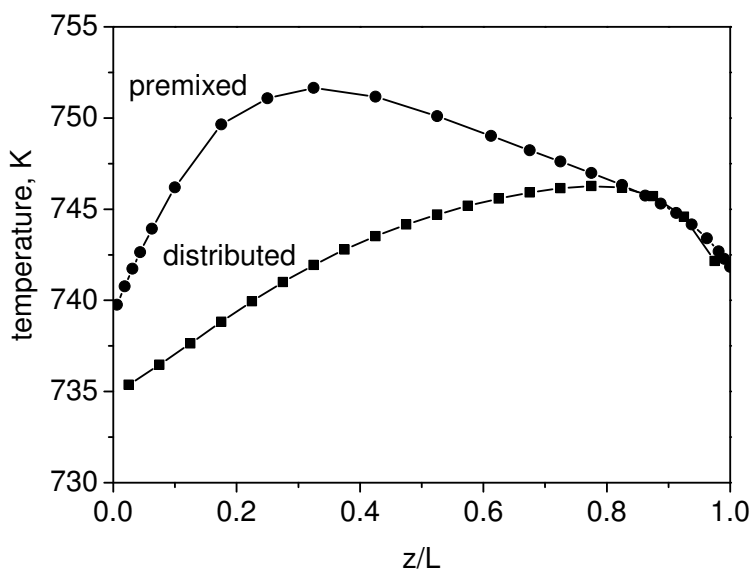

Figure 4.3: Comparison of axial temperature profiles for the cases of premixed feed $(\bullet)$ and with distributed oxygen feed (-). $F_{\text {tot }}=43 \mathrm{ml} / \mathrm{min}, \mathrm{N}_{2}: \mathrm{C}_{3} \mathrm{H}_{8}: \mathrm{O}_{2}=5: 3: 2$

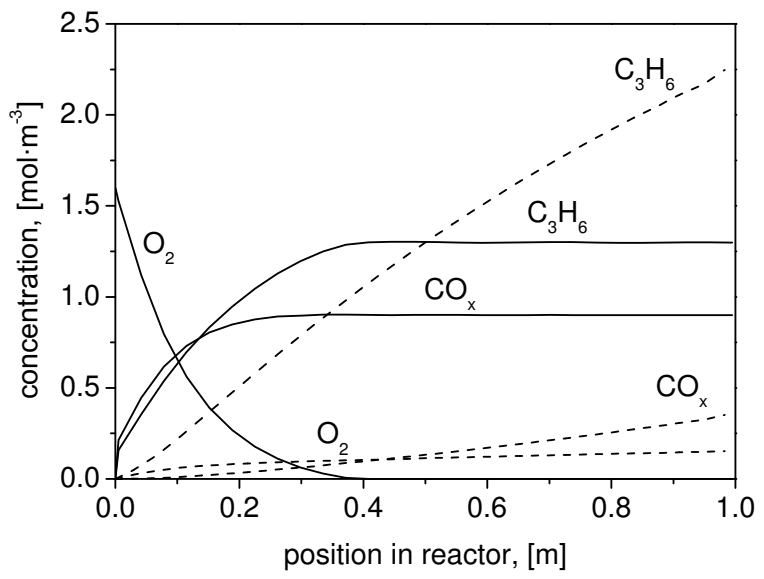

Figure 4.4: Comparison of axial concentration profiles for the cases of premixed feed (solid lines) and with distributed oxygen feed (dashed lines). Operating conditions as given in Table 4.2, except for the flow rate, which in this case was set to $F_{\text {tot }}=30 \mathrm{ml} / \mathrm{min}$ 
approach almost isothermal conditions. Therefore, for the rest of this chapter an isothermal operation mode was used.

Subsequently, the conversion of propane and oxygen and the selectivity to propylene were compared for the cases of premixed reactants flow and distributive oxygen feeding. As it can be discerned from Figure 4.4, for a system with premixed reactants flow, the maximum concentration (i.e. yield) of propylene is always reached at the end of the reactor.

Since oxygen is being competitively consumed by both main reaction and side reactions which have a higher apparent order in oxygen, the waste products are being formed at a high rate at the beginning of the reactor, which leads to a relatively low selectivity to propylene. Moving towards the outlet of the reactor, the ratio propane/oxygen becomes higher, which enhances the main reaction of propylene formation. However, the amount of oxygen already wasted in side reactions is high, so the increase in the propylene concentration is rather low.

If the same amount of oxygen is now fed distributively, keeping the same reactor length, total volumetric flow rate and propane inlet concentration, the oxygen concentration in the tube side becomes low and relatively constant over the reactor length. This leads to a significantly increased yield of propylene, while the yield of waste products is much lower than with premixed feed.

For the system with premixed reactants flow, the oxygen conversion is rapid and complete. The maximum propylene yield $(9.4 \%)$ is at the conditions investigated $\left(\mathrm{N}_{2} / \mathrm{C}_{3} \mathrm{H}_{8} / \mathrm{O}_{2}\right.$ $=6: 3: 1, \mathrm{~F}_{\text {tot }}=30 \mathrm{ml} / \mathrm{min}$ ) obtained already at $z=0.36 \mathrm{~m}$. In contrast, for the packed bed membrane reactor case, the propylene yield can be increased at the same total propane and oxygen flow rate fed by increasing the reactor and membrane length and decreasing the membrane permeability. For the parameters listed in Table 4.2, the effect of the total reactor length (and corresponding membrane permeability) on the propane and oxygen conversion and selectivity is plotted in Figure 4.5.

\subsubsection{Distributive oxygen feeding: Influence of the reactor length}

Increasing the reactor length at the same overall oxygen flow rate decreases the oxygen concentration and increases the propane conversion and selectivity to propylene. The increase in propane conversion is the consequence of the fact that the reactions whose stoichiometry require more oxygen also have a high order in oxygen; a low oxygen concentration suppresses these reactions and enhances the main reaction of propylene formation, where (only) 0.5 moles of oxygen is required per mole of propane. This also leads to an increase of the selectivity to propylene, which, in the theoretical case where $L \rightarrow \infty$ can reach values close to 1 . From Figure 4.5 can be concluded that the propylene yield can be increased to $15.5 \%$ or even $24.6 \%$ at the expense of increasing the reactor length to $0.5 \mathrm{~m}$ or $1 \mathrm{~m}$ respectively. 


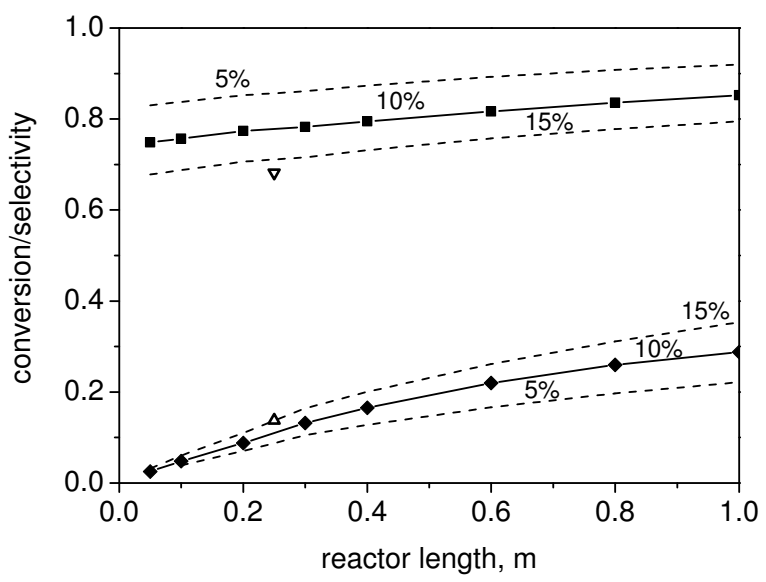

(a)

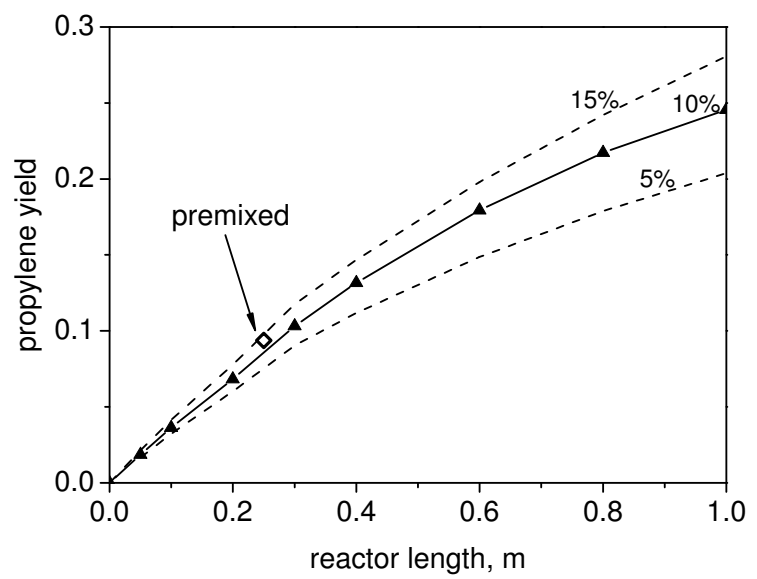

(b)

Figure 4.5: Influence of reactor length change on performance of ODHP (30\% of propane, flow rate $F_{\text {tot }}=85 \mathrm{ml} / \mathrm{min}$, oxygen inlet concentration indicated). (a) conversion/selectivity ( $\bullet$ propane conversion, - selectivity to propylene, $\Delta$ propane conversion (premixed), $\nabla$ selectivity to propylene (premixed)) (b) yield of propylene $\diamond$ (premixed feeding), yield of propylene $\Delta$ (distributed oxygen feeding) 


\section{Chapter 4}

\subsubsection{Influence of the oxygen concentration}

\section{Yields of main products}

Change of the oxygen concentration while keeping the reactor length constant may also contribute to a better utilization of the reactants' stream in the reactor for the ODHP. An increase in oxygen concentration (fraction of propane in the feed kept at $30 \%$ ) led to an increase in the yield of propylene, but also in the yield of carbon oxides. As can be discerned from Figure 4.6, for the case of premixed feed the increase in the propylene yield becomes smaller for higher propane conversions, so that the maximum propylene yield of $10.3 \%$ is reached at a propane conversion of $25.3 \%$.

This may be attributed to secondary reactions of propylene combustion, but also to the prominent reactions of propane combustion, which also become important at higher oxygen feed concentrations. Therefore, the yield of $\mathrm{CO}_{\mathrm{x}}$ rises faster with higher oxygen concentrations and reaches $18.9 \%$ at a propane conversion of $30.4 \%$. However, for high propane conversions and large propylene yields, the oxygen concentration needs to be high, which is highly undesired, because of a high risk of explosion at these propane/oxygen concentration ratios, which was already discussed at page 53 and schematically shown in Figure 3.8.

For the distributed oxygen feed, the propylene yield at the same conditions as for the premixed feed (volumetric flow rate $85 \mathrm{ml} / \mathrm{min}$, propane feed concentration $30 \%$ ) is sig-

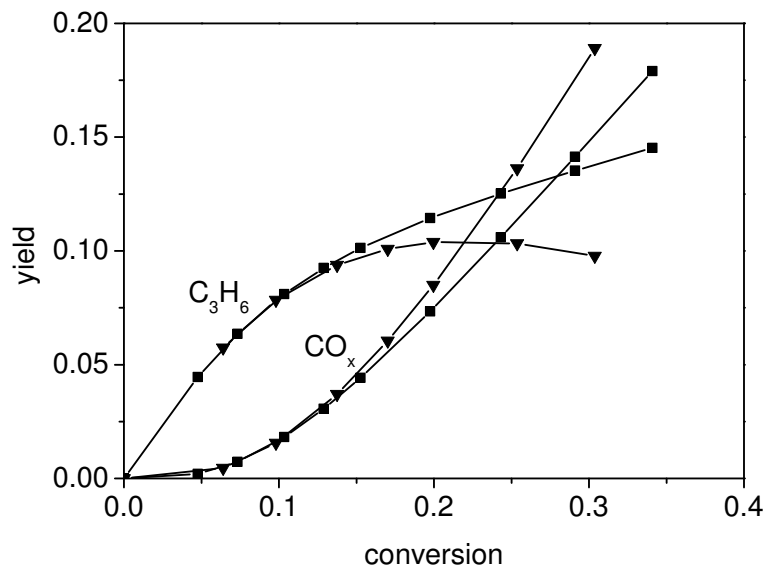

Figure 4.6: Yield of propylene and side products in the catalyzed ODHP at $733 \mathrm{~K}$ in the reactor

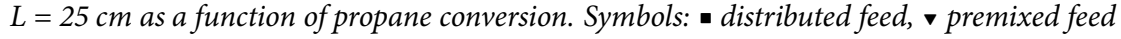


nificantly higher and for propane conversion of $34 \%$ reaches $14.5 \%$. Thus, much higher propylene yields can be achieved at much higher propane conversions. This again demonstrates the superiority of distributed oxygen feed over premixed feed for the process of oxidative dehydrogenation of propane.

\section{Influence on conversion and selectivity}

An increase of the oxygen concentration was beneficial to increase the propane conversion, since at the low temperatures considered in this work $(733 \mathrm{~K})$ cracking processes are absent.

As can be seen from Figure 4.7, showing the propane conversion and $\mathrm{C}_{3} \mathrm{H}_{6}$ and $\mathrm{CO}_{\mathrm{x}}$ selectivity as a function of the oxygen content in the overall feed, a larger increase of propane conversion occurs for relatively low concentrations of oxygen. This results mainly from the fact that the reaction of propane and oxygen in which propylene is formed requires 2 moles of propane per mole of oxygen, in contrast to the reaction of propane combustion (see equations 3.8 and 3.9) where per mole of oxygen only $0.29\left(0.2\right.$ in case of $\left.\mathrm{CO}_{2}\right)$ moles of propane is needed. At higher oxygen concentrations, combustion of propane becomes dominant, so the increase in the propane conversion at higher $\mathrm{O}_{2}$ concentrations becomes lower.

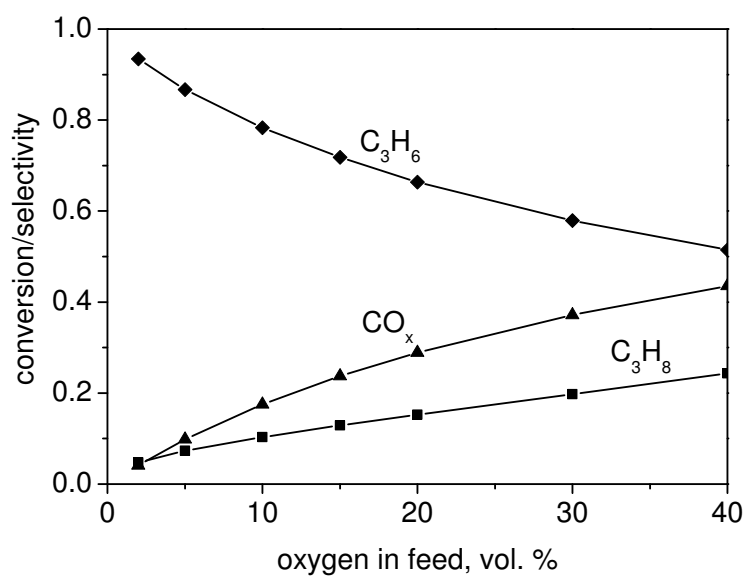

Figure 4.7: Conversion of propane and selectivities to propylene and carbon oxides as a function of oxygen content in the feed. $\left(x_{\mathrm{C}_{3} \mathrm{H}_{8}}=30 \%, T=733 \mathrm{~K}, L=25 \mathrm{~cm}\right)$ 


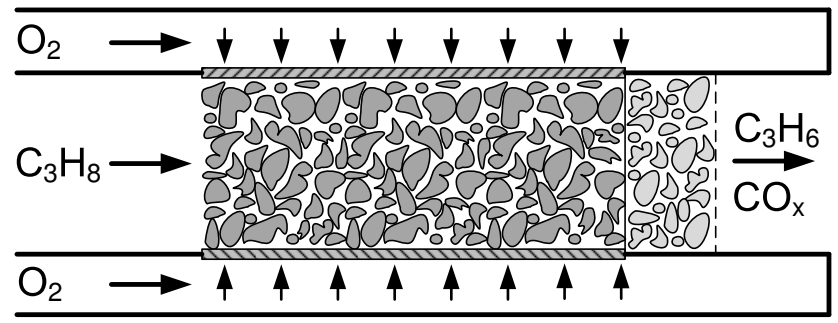

Figure 4.8: Additional catalyst bed placed after the end of porous section of the membrane reactor in order to assure complete oxygen conversion.

Although the oxygen conversion is high, it is not yet complete. The reason for this is that at the end of membrane section there is still some oxygen entering reactor, while in the tube side the catalyst bed ends at the same position. Therefore, the catalyst bed should be extended somewhat behind the end of the membrane section of the reactor, as shown in Figure 4.8. This will allow full utilization of the oxygen supplied, hence, the propylene yield could be slightly further increased, but the effect is relatively small here.

\subsubsection{Dilution effects}

Additional simulations have been performed with the hydrocarbon reactant feed stream diluted with nitrogen, so that the change in contact time when varying the overall feed composition was compensated for. The results for yields of propylene and $\mathrm{CO}_{\mathrm{x}}$ are displayed in Figure 4.9. An increase in the hydrocarbon feed concentration also results in a larger contact time of propane at the same overall $\mathrm{C}_{3} \mathrm{H}_{8} / \mathrm{O}_{2}$ feed ratio, which results in the yield increase for both, propylene and carbon monoxide. However, this approach may be misleading, for here the contact time of propane changes with the change of its inlet concentration. Therefore, the change in selectivity to propylene should be examined at a constant propane conversion. Indeed, when inspecting the conversion-selectivity plot shown in Figure 4.10, it can be noticed that for certain propane conversion, a (slightly) higher selectivity to propylene is achieved in the case of a less diluted feed. With these trends for propane conversion and selectivity to propylene, it can be concluded that the best performance should be expected for higher hydrocarbon feed concentrations.

\subsubsection{Shell vs. tube side dilution}

In order to maintain the contact time in the reactor constant, when varying the oxygen inlet concentration, a certain amount of dilutant (helium or nitrogen) had to be added to the stream. In the case of premixed reactants, the stream can be diluted by co-feed of 


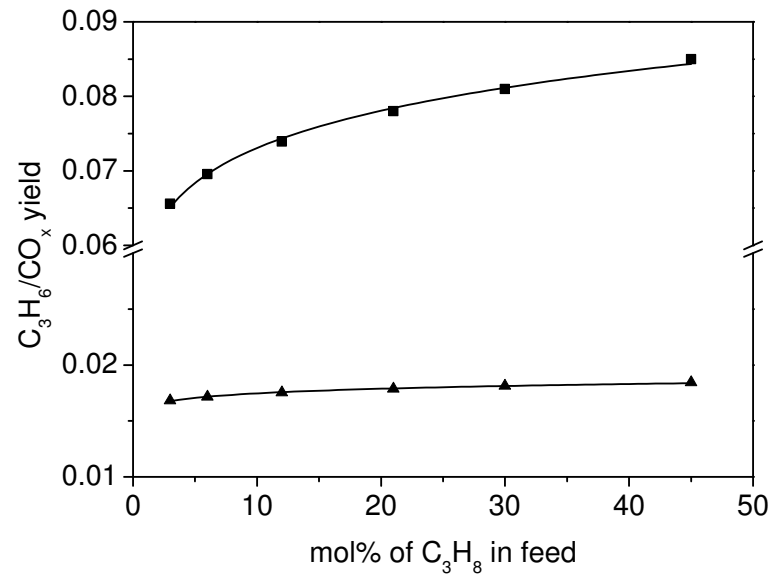

Figure 4.9: Effects of feed dilution with nitrogen. Feed consists of propane and oxygen in molar ratio 3:1 with addition of nitrogen up to the total volumetric flow rate of $85 \mathrm{ml} / \mathrm{min}$. Symbols: - yield of propylene, $\Delta$ yield of $\mathrm{CO}_{x}$

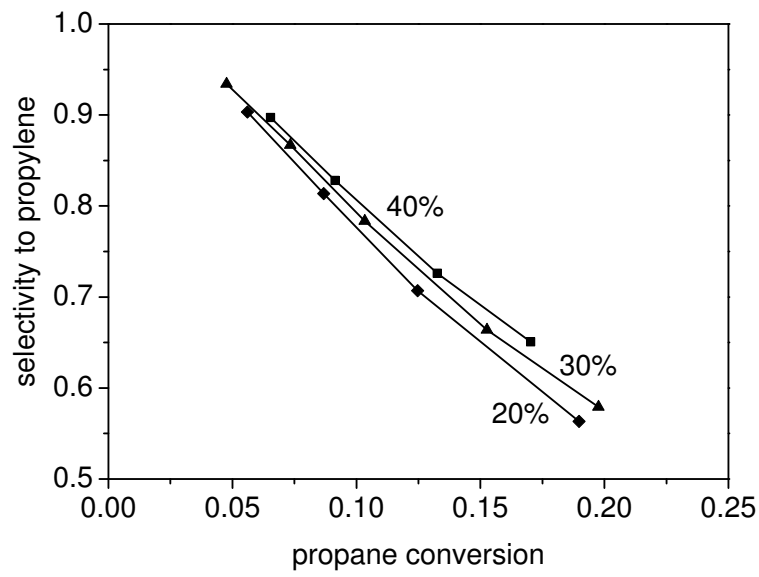

Figure 4.10: Dilution effects: selectivity to propylene as a function of propane conversion for different hydrocarbon feed concentration at $733 \mathrm{~K}$. 
dilutant. However, in the membrane reactor, there are two possibilities, to dilute the tube side flow, or to dilute shell side flow. In Figure 4.11 results for both of these cases are shown.

As can be seen, in the case of shell side dilution, a higher selectivity to propylene can be achieved for a given conversion, if compared to the case of tube side dilution. Diluted shell side stream contributes to the faster flow increase in the tube side and, effectively, lowering the rate of oxygen permeation. Due to this lower oxygen concentration, the selectivity to propylene becomes somewhat higher.

Apart from its beneficial role in increasing the selectivity to propylene, shell side dilution has another important feature: when adding a dilutant, while keeping the amount of oxygen fed constant, the membrane fluxes increased, which led to an increase in total transmembrane pressure difference. This reduces the extent of back-permeation of species present in the tube side of the reactor. From an experimental point of view, this is a very valuable result, firstly because it allows a broader range of experimental conditions in respect to feed composition (high level of back-permeation and bypassing easily possible when diluting tube side stream!) and secondly because it drastically reduces the possibility of the formation of explosive mixtures in the shell side.

\subsubsection{Axial oxygen feed profile - linearly decreasing or constant?}

In the study thus far, the oxygen feed flux through the membrane was constant along the reactor. For further optimization, it was explored if it is possible to obtain higher

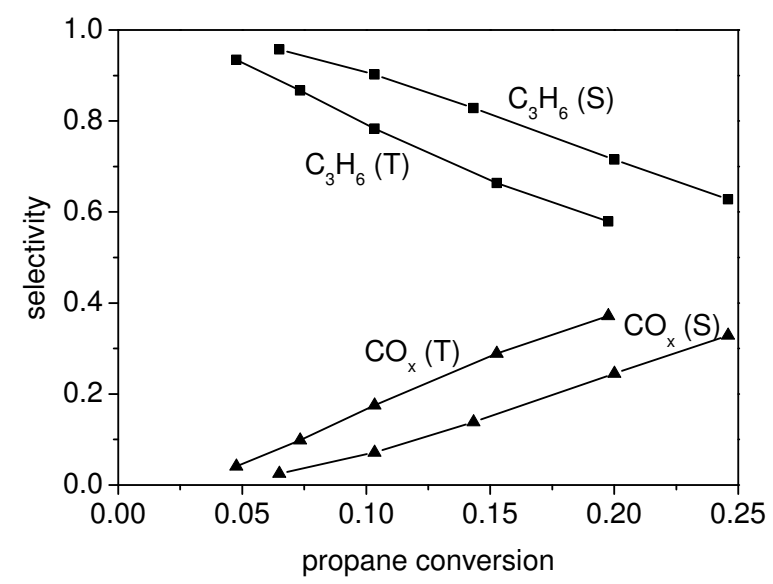

Figure 4.11: Comparison of dilution effects from shell (S) and tube (T) side. Selectivities to propylene and carbon oxides as a function of conversion in the $25 \mathrm{~cm}$ long reactor with total flow of $85 \mathrm{ml} / \mathrm{min}$. Symbols: - propylene, $\triangle \mathrm{CO}_{x}$ 
selectivities to propylene using a different axial oxygen feed profile. Since the propane concentration in the reactor decreases and the key for a high propylene yield is a large propane to oxygen ratio, the first case to be examined is the axially linearly decreasing oxygen membrane flux profile.

Experimentally, this could be achieved by altering the membrane properties along the axial direction, or by applying a fixed bed of particles in the shell side, so that the pressure drop over the bed decreases the pressure difference over the membrane.

In case of a constant oxygen feed flux, the concentration of oxygen along the reactor can be described as

$$
\Phi_{m, \mathrm{O}_{2}}^{\prime \prime}=k_{1}
$$

where the total amount of oxygen fed to the tube side is

$$
Q_{\mathrm{O}_{2}}=\pi d \int_{a}^{b} k_{1} d x=\left.k_{1} x\right|_{a} ^{b}=k_{1}(b-a) \pi d
$$

Similarly, for the case of a linearly decreasing oxygen feed flux can be written

$$
\Phi^{\prime \prime}{ }_{m, \mathrm{O}_{2}}=k_{2}\left(1-\frac{x-a}{b-a}\right)=k_{2}\left(\frac{b-x}{b-a}\right) \quad \text { so that } \quad Q_{O_{2}}=\pi d \frac{1}{2} k_{2}(b-a)
$$

To be able to compare these two cases, the amounts of oxygen fed should be identical. From this condition it follows that $k_{2}=2 k_{1}$ (see Figure 4.12), which means that at the beginning, for $x=a$ the oxygen membrane flux is twice as high as the corresponding oxygen membrane flux for the case with a constant oxygen flux.

If we now compare the results for these two cases (see Figure 4.13), we can see that the linearly decreasing oxygen concentration profile does not help increasing the selectivity to propylene. Instead, for a given propane conversion, the selectivity to propylene is actually slightly higher if the oxygen feed flux is constant. For the case of a linearly decreasing

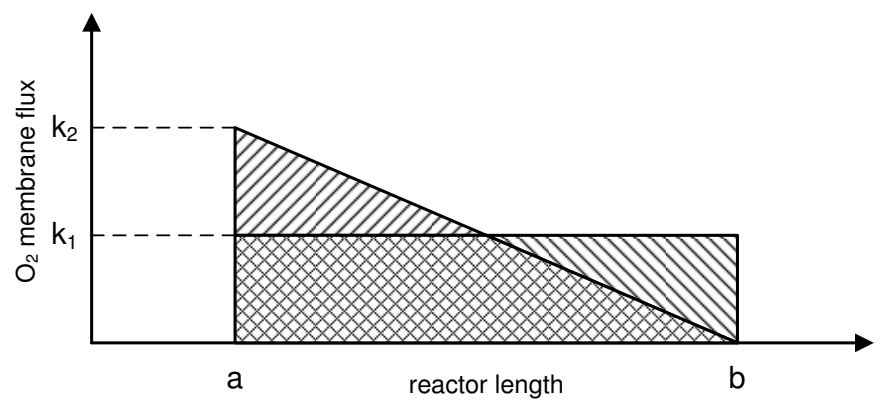

Figure 4.12: Schematic of an oxygen feed profiles: membrane section is situated between $a$ and $b$, while the reactor can contain inert sections before and/or after the membrane 


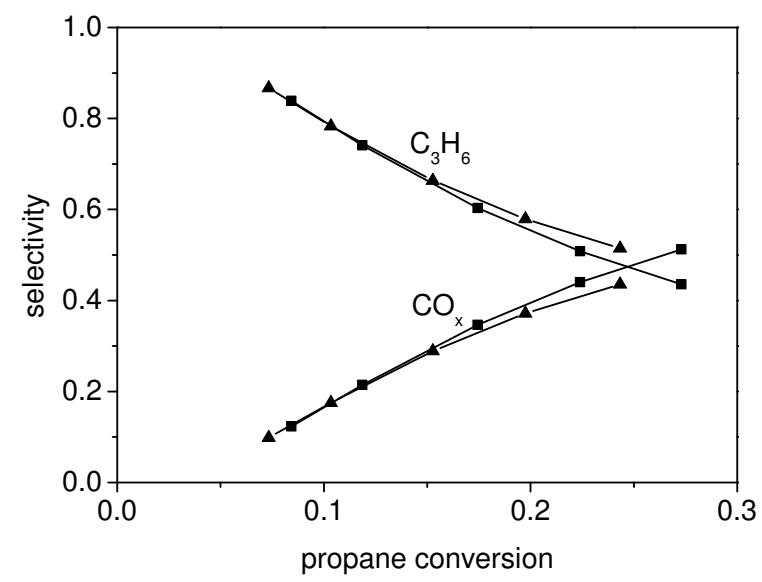

Figure 4.13: Linearly decreasing versus constant oxygen feed profile alongside the reactor. Selectivities to propylene and carbon oxides as a function of conversion in the $25 \mathrm{~cm}$ long reactor with total flow of $85 \mathrm{ml} / \mathrm{min}$ Symbols: $\boldsymbol{\bullet}$ constant, $\Delta$ linear

oxygen feed flux, at the beginning of the membrane section, the oxygen concentration is relatively high and therefore the selectivity to side products is very high.

Moving further along the reactor length, the lower oxygen concentration leads to an increase of the selectivity to propylene, however, the amount of already formed carbon oxides is large, so that the overall performance of such an oxygen feed concentration profile is actually worse in comparison to the case with a constant oxygen feed flux through the membrane. When oxygen is fed with the same rate along the entire membrane length, at the beginning of the membrane section, the propane to oxygen ratio is high, enabling high selectivity to propylene. Along the reactor this ratio becomes slightly lower, but the amount of propylene formed close to the inlet of the membrane section is large, so even this unfavorable situation does not significantly affect the overall performance.

Concluding, little or no benefit is to be expected from optimizing the axial oxygen membrane flux profile.

\subsubsection{Effects of volumetric flow rate}

The total flow in the system has been altered in order to examine which flow rates provide the maximum yield of desired product. In Table 4.3 one can see that the increase of the total flow of reactants unfortunately leads to a decrease in the propane conversion, but remarkably also to a decrease in the selectivity to propylene and in the same time to an 
Table 4.3: Conversion of propane and selectivities to propylene and carbon oxides as a function of the total volumetric flow rate in the membrane reactor.

\begin{tabular}{lccc}
\hline flow, $\times 42.5 \mathrm{ml} / \mathrm{min}$ & conversion & selectivity to $\mathrm{C}_{3} \mathrm{H}_{6}$ & selectivity to $\mathrm{CO}_{\mathrm{x}}$ \\
\hline 1 & 0.179 & 0.81 & 0.15 \\
2 & 0.103 & 0.78 & 0.18 \\
4 & 0.056 & 0.77 & 0.19 \\
8 & 0.029 & 0.76 & 0.20 \\
16 & 0.015 & 0.75 & 0.21 \\
\hline
\end{tabular}

increase in the selectivity to carbon oxides. To be able to understand this, it is necessary to see how the oxygen axial concentration profiles look like. If the total volumetric flow rate is increased, the contact time becomes smaller and therefore the propane conversion decreases. Simultaneously, more oxygen is supplied through the membrane, so the oxygen concentration along the reactor length actually increases (see Figure 4.14), instead of being constant.

Taking into account that the side reactions show a higher reaction order in oxygen compared to main reaction, it becomes then obvious that an increase in the selectivity towards $\mathrm{CO}_{\mathrm{x}}$ is observed. Therefore, the selectivity to propylene decreases from $81 \%$ to $75 \%$

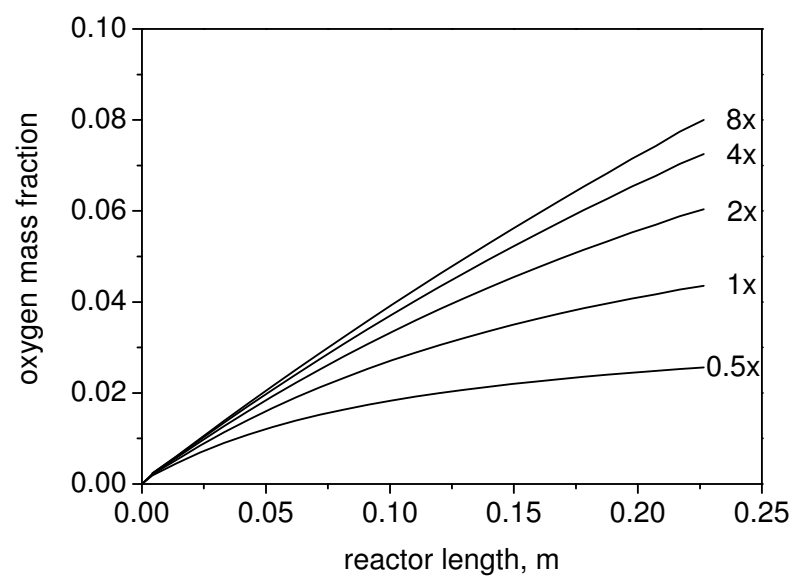

Figure 4.14: Axial profiles of oxygen for different flow rates in the packed bed membrane reactor for the oxidative dehydrogenation of propane. The flow is expressed as multiple of a flow rate for the base case of $42.5 \mathrm{ml} / \mathrm{min}$, feed composition $\mathrm{N}_{2}: \mathrm{C}_{3} \mathrm{H}_{8}: \mathrm{O}_{2}=6: 3: 1$. 
for a flow rate change from 21 to $340 \mathrm{ml} / \mathrm{min}$, while at the same time the selectivity to $\mathrm{CO}_{\mathrm{x}}$ increases from 15 to $21 \%$ in the membrane reactor of $25 \mathrm{~cm}$ in length at the temperature level of $733 \mathrm{~K}$.

Concluding, the membrane flow has to be tuned in such a way to match the reaction kinetics.

\subsection{Conclusions}

This chapter deals with numerical model simulations to quantify benefits of distributive oxygen feeding for the oxidative dehydrogenation of propane over a $\mathrm{Ga}_{2} \mathrm{O}_{3} / \mathrm{MoO}_{3}$ based catalyst using the experimentally determined kinetic data. First, a packed bed reactor with premixed reactants flow was simulated, and the results were compared with simulations of a packed bed membrane reactor with a distributed oxygen feed. The decrease in the oxygen concentration, achieved by distributive feeding through the membrane was found to be very beneficial for the propylene yield. Increasing the reactor length at the same overall oxygen feed flow rate can even further increase the propylene yield (at the cost of additional capital investments).

The results have also shown that the low extent of dilution combined with dilution of the shell side (oxygen) feed improve the overall process performance, where the membrane flux has to be tuned to match the reaction kinetics.

Hence, a packed bed membrane reactor concept is a promising alternative in comparison to the conventional propylene production processes, as well as if compared with the packed bed reactor with premixed reactants feed.

\section{Nomenclature}

\section{Symbols}

$A_{j}$

$B$

$B_{j}$

$c_{j}$

$C_{j}$

$C_{p}$

$d$

$d_{p}$
Constant in the correlations for $\eta_{j, g}$ and $\lambda_{j, g}$

Parameter in the model of Zehner and Schlünder [33]

Constant in the correlations for $\eta_{j, g}$ and $\lambda_{j, g}$

Concentration of species $j, \mathrm{~mol} / \mathrm{m}^{3}$

Constant in the correlations for $\eta_{j, g}$ and $\lambda_{j, g}$

Heat capacity, J/kg.K

Inner (tube) diameter

Particle diameter, $\mathrm{m}$ 
$d_{t}$

D

$D_{j}$

$D_{a x}$

$D_{\text {eff }}$

$e_{p}$

$e_{\text {wall }}$

$E_{a}$

$E_{j}$

$\dot{F}_{m}^{P}$

$\dot{F}_{m}^{F}$

$H_{j}$

$\Delta H_{r}$

$k_{g}$

$k_{i}$

$L_{\text {mem }}$

$L_{\text {reactor }}$

M

$M_{j}$

$\mathrm{Nu}$

p

$p_{j}$

$P e_{a x}$

$\mathrm{Pr}$

$r_{j}$

$r_{i}$

$r_{o}$

$r_{j}, \mathcal{R}$

$R_{g}$

Re

$S$

$S_{F}$
Tube diameter, $\mathrm{m}$

Outer (tube) diameter

Constant in the correlations for $\eta_{j, g}$ and $\lambda_{j, g}$

Axial dispersion coefficient, $\mathrm{m}^{2} / \mathrm{s}$

Effective diffusivity, $\mathrm{m}^{2} / \mathrm{s}$

Emissivity of a particle

Emissivity of the wall

Activation energy, J/mol

Constant in the correlations for $\eta_{j, g}$ and $\lambda_{j, g}$

Shell side flux, $\mathrm{kg} / \mathrm{m}^{2} \cdot \mathrm{s}$

Tube side flux, $\mathrm{kg} / \mathrm{m}^{2} \cdot \mathrm{s}$

Enthalpy of species $j, \mathrm{~J} / \mathrm{mol}$

Reaction heat, $\mathrm{J} / \mathrm{mol}$

Gas to particle mass transfer coefficient, $\mathrm{m} / \mathrm{s}$

Coefficient in the reaction kinetic equation

Length membrane, $\mathrm{m}$

Length of the reactor, $m$

Parameter in the model of Zehner and Schlünder [33]

Molar weight of species $j, \mathrm{~kg} / \mathrm{mol}$

Nusselt number, $\alpha_{g-s} d_{p} / \lambda_{g}$

Pressure, $\mathrm{Pa}$

Partial pressure of species $j, \mathrm{~Pa}$

Péclet number for axial heat dispersion, $\rho_{g} v_{g} d_{p} C_{p, g} / \lambda_{a x}$

Prandtl number, $C_{p, g} \eta_{g} / \lambda_{g}$

Reaction rate of species $j, \mathrm{~mol} / \mathrm{m}^{3} \cdot \mathrm{s}, \mathrm{mol} / \mathrm{g}_{\mathrm{cat}} \cdot \mathrm{s}$

Tube radius, inner, $m$

Tube radius, outer, $\mathrm{m}$

Reaction rate, $\mathrm{mol} / \mathrm{m}^{3} \cdot \mathrm{s}$

Gas constant, $8.314 \mathrm{~J} / \mathrm{mol} \cdot \mathrm{K}$

Reynolds number, $\rho_{g} v_{g} d_{p} / \eta_{g}$

Selectivity

Inner tube cross-sectional surface area, $\mathrm{m}^{2}$ 
$S_{P}$

$S_{m}$

Sc

$t$

$T$

$\Delta T_{a d}$

$u$

$w$

$w_{j}$

$x_{j}$

$z$

\section{Greek symbols}

$\alpha_{b e d-w a l l}$
$\epsilon$
$\eta$
$\kappa_{r}$
$\kappa_{s}$
$\lambda_{(a x)}$
$\lambda_{b e d}$
$\lambda_{r}$
$\lambda_{r, s}$
$v_{j}$
$v_{j}$
$\rho$
$\rho_{b u l k}$
$\sigma$
$\Phi_{m}$
$\varphi$
$\varphi_{j, k}^{\eta}$
$\varphi_{j, k}^{\lambda}$

Outer tube cross-sectional surface area, $\mathrm{m}^{2}$

Membrane surface area, $\mathrm{m}^{2}$

Schmidt number, $\eta_{g} / \rho_{g} / D$

time, $s$

Temperature, $\mathrm{K}$

Adiabatic temperature rise, $\mathrm{K}$

Superficial velocity, $\mathrm{m} / \mathrm{s}$

Wall thickness, $\mathrm{m}$

Weight fraction of species $j$

Mole fraction of species $j$

Spatial coordinate, $\mathrm{m}$

Overall wall to bed heat transfer coefficient, $\mathrm{J} / \mathrm{m}^{2} \cdot \mathrm{K} \cdot \mathrm{s}$

Porosity

Particle effectiveness factor, -, Viscosity, $\mathrm{kg} / \mathrm{m} \cdot \mathrm{s}$

Parameter in the model of Zehner and Schlünder [33]

Parameter in the model of Zehner and Schlünder [33]

(Axial) thermal conductivity, J/m.K.s

Thermal conductivity of a packed bed, $\mathrm{J} / \mathrm{m} \cdot \mathrm{K} \cdot \mathrm{s}$

Parameter in the model of Zehner and Schlünder [33]

Parameter in the model of Zehner and Schlünder [33]

Molar volume of species $j$

Stoichiometric coefficient of the component $j$

Density, $\mathrm{kg} / \mathrm{m}^{3}$

Bulk density, $\mathrm{kg} / \mathrm{m}^{3}$

Stefan-Boltzmann constant, $5.67 \cdot 10^{-8} \mathrm{~W} / \mathrm{m}^{2} \cdot \mathrm{K}^{4}$

Flux through membrane, $\mathrm{kg} / \mathrm{m}^{2} \cdot \mathrm{s}$

Thiele modulus

Parameter used in a mixture viscosity calculus

Parameter used in a mixture thermal conductivity calculus 


\section{Superscripts and subscripts}

0

$P$

F

sup

\author{
Initial \\ Outer (permeate) side \\ Inner (flow) side \\ superficial
}

\section{References}

[1] H. P. Hsieh. Inorganic Membranes. AIChE Symposium Series, 84(261), 1-18 (1988).

[2] H. P. Hsieh. Inorganic Membrane Reactors - A Review. AIChE Symposium Series, 85(268), 53-67 (1989).

[3] H. P. Hsieh. Inorganic Membrane Reactors. Catalysis Reviews - Science and Engineering, 33(1-2), 1-70 (1991).

[4] J. N. Armor. Catalysis with permselective inorganic membranes. Applied catalysis, 49(1), 1-25 (1989).

[5] S. Ilias and R. Govind. Development of High Temperature Membranes for Membrane Reactor: An Overview. AIChE Symposium Series, 85(268), 18-25 (1989).

[6] W. N. Gill, E. Ruckenstein and H. P. Hsieh. Homogeneous Models for Porous Catalysts and Tubular Reactors with Heterogeneous Reactions. Chemical Engineering Science, 30(7), 685-694 (1975).

[7] N. Itoh. A Membrane Reactor Using Palladium. AIChE Journal, 33(9), 1576-1578 (1987).

[8] J. Shu, B. P. A. Grandjean and S. Kaliaguine. Methane Steam Reforming in Asymmetric Pd-Ag and Pd-Ag/Porous Ss Membrane Reactors. Applied Catalysis A - General, 119(2), 305-325 (1994).

[9] G. Barbieri, V. Violante, F. P. DiMaio, A. Criscuoli and E. Drioli. Methane steam reforming analysis in a palladium-based catalytic membrane reactor. Industrial \& Engineering Chemistry Research, 36(8), 3369-3374 (1997).

[10] J. S. Oklany, K. Hou and R. Hughes. A simulative comparison of dense and microporous membrane reactors for the steam reforming of methane. Applied Catalysis A - General, 170(1), 13-22 (1998).

[11] T. T. Tsotsis, A. M. Champagnie, S. P. Vasileiadis, Z. D. Ziaka and R. G. Minet. Packed-Bed Catalytic Membrane Reactors. Chemical Engineering Science, 47(9-11), 2903-2908 (1992).

[12] T. P. Tiemersma, C. S. Patil, M. van Sint Annaland and J. A. M. Kuipers. Modelling of packed bed membrane reactors for autothermal production of ultrapure hydrogen. Chemical Engineering Science, 61(5), 1602-1616 (2006). 
[13] U. Kürten, M. van Sint Annaland and J. A. M. Kuipers. Oxygen distribution in packed-bed membrane reactors for partial oxidations: Effect of the radial porosity profiles on the product selectivity. Industrial \& Engineering Chemistry Research, 43(16), 4753-4760 (2004).

[14] U. Kürten, M. van Sint Annaland and J. A. M. Kuipers. Oxygen distribution in packed bed membrane reactors for partial oxidation systems and the effect on the product selectivity. International Journal of Chemical Reaction Engineering, 2(A24), $1-24$ (2004).

[15] M. van Sint Annaland, U. Kürten and J. A. M. Kuipers. Effect of mass-transport limitations on the performance of a packed bed membrane reactor for partial oxidations. Intraparticle mass transport. Industrial \& Engineering Chemistry Research, 46(23), 7513-7523 (2007).

[16] M. van Sint Annaland, U. Kürten and J. A. M. Kuipers. Effect of mass-transport limitations on the performance of a packed bed membrane reactor for partial oxidations. Transport from the membrane to the packed bed. Industrial \& Engineering Chemistry Research, 46(23), 7524-7534 (2007).

[17] C. Hamel, A. Tóta, F. Klose, E. Tsotsas and A. Seidel-Morgenstern. Analysis of single and multi-stage membrane reactors for the oxidation of short-chain alkanes Simulation study and pilot scale experiments. Chemical Engineering Research and Design, 86(7), 753-764 (2008).

[18] C. M. O’Neill and E. E. Wolf. Yield Improvements in Membrane Reactors for Partial Oxidation Reactions. Industrial \& Engineering Chemistry Research, 45(8), 26972706 (2006).

[19] D. E. Mears. Diagnostic Criteria for Heat Transport Limitations in Fixed Bed Reactors. Journal of Catalysis, 20(2), 127-131 (1971).

[20] D. E. Mears. Role of Axial Dispersion in Trickle-Flow Laboratory Reactors. Chemical Engineering Science, 26(9), 1361-1365 (1971).

[21] V. Specchia, G. Baldi and S. Sicardi. Heat-Transfer in Packed-Bed Reactors with One Phase Flow. Chemical Engineering Communications, 4(2-3), 361-380 (1980).

[22] J. B. Rawlings and J. G. Ekerdt. Chemical Reactor Analysis and Design Fundamentals, chapter 7. Nob Hill Pub. (2002).

[23] J. B. Anderson. A Criterion for Isothermal Behaviour of a Catalyst Pellet. Chemical Engineering Science, 18(2), 147-148 (1963).

[24] M. M. Barsan and F. C. Thyrion. Kinetic study of oxidative dehydrogenation of propane over Ni-Co molybdate catalyst. Catalysis Today, 81(2), 159-170 (2003).

[25] K. D. Chen, A. T. Bell and E. Iglesia. Kinetics and mechanism of oxidative dehydrogenation of propane on vanadium, molybdenum, and tungsten oxides. Journal of Physical Chemistry B, 104(6), 1292-1299 (2000). 
[26] A. Bottino, G. Capannelli, A. Comite, S. Storace and R. Di Felice. Kinetic investigations on the oxidehydrogenation of propane over vanadium supported on gamma$\mathrm{Al}_{2} \mathrm{O}_{3}$. Chemical Engineering Journal, 94(1), 11-18 (2003).

[27] T. Okubo, K. Haruta, K. Kusakabe, S. Morooka, H. Anzai and S. Akiyama. Equilibrium Shift of Dehydrogenation at Short Space-Time with Hollow Fiber Ceramic Membrane. Industrial \& Engineering Chemistry Research, 30(4), 614-616 (1991).

[28] H. J. Sloot, G. F. Versteeg and W. P. M. van Swaaij. A Nonpermselective Membrane Reactor for Chemical Processes Normally Requiring Strict Stoichiometric Feed Rates of Reactants. Chemical Engineering Science, 45(8), 2415-2421 (1990).

[29] T. J. Stanley and J. A. Quinn. Phase-Transfer Catalysis in a Membrane Reactor. Chemical Engineering Science, 42(10), 2313-2324 (1987).

[30] J. Smit, M. van Sint Annaland and J. A. M. Kuipers. Grid adaptation with WENO schemes for non-uniform grids to solve convection-dominated partial differential equations. Chemical Engineering Science, 60(10), 2609-2619 (2005).

[31] R. Alexander. Diagonally Implicit Runge-Kutta Methods for Stiff Odes. Siam Journal on Numerical Analysis, 14(6), 1006-1021 (1977).

[32] J. H. Ferziger and M. Perić. Computational Methods for Fluid Dynamics. SpringerVerlag, Berlin, 2 edition (2001).

[33] P. Zehner and E. U. Schlünder. Wärmeleitfähigkeit von Schüttingen bei Mässigen Temperaturen. Chemie Ingenieur Technik, 42(14), 933-941 (1970).

[34] E. Tsotsas and E. U. Schlünder. On Axial-Dispersion in Packed-Beds with FluidFlow. Chemical Engineering and Processing, 24(1), 15-31 (1988).

[35] A. G. Dixon and D. L. Creswell. Theoretical prediction of effective heat-transfer parameters in packed-beds. AIChE Journal, 25(4), 663 (1979).

[36] T. E. Daubert and R. P. Danner. Data Compilation Tables of Properties of Pure Compounds. American Institute of Chemical Engineers, New York (1985).

[37] R. C. Reid, J. M. Prausnitz and B. E. Poling. The Properties of Gases and Liquids. McGraw-Hill, Inc., New York (1987). 
$96 \quad$ Chapter 4

\section{A Transport parameters}

\section{A.1 Axial mass dispersion}

Effective dispersion of mass in the reactor is, according to Zehner and Schlünder [33] and Tsotsas and Schlünder [34] defined as

$$
D_{z, j}=(1-\sqrt{1-\epsilon}) D_{j}^{m}+\frac{u d_{p}}{2}
$$

\section{A.2 Axial heat dispersion}

The same authors $[33,34]$ suggest the following relation for the effective dispersion of energy

$$
\frac{\lambda_{z}}{\lambda_{g}}=\frac{\lambda_{b e d, 0}}{\lambda_{g}}+\frac{P e_{x}}{K_{\infty} f\left(D_{t} / d_{p}\right)}=\frac{\lambda_{b e d, 0}}{\lambda_{g}}+\frac{P e_{x}}{2}
$$

where $\lambda_{b e d, 0}$ is given as

$$
\begin{gathered}
\frac{\lambda_{\text {bed }, 0}}{\lambda_{g}}=(1-\sqrt{1-\epsilon})\left(1+\frac{\lambda_{\text {rad }}}{\lambda_{g}}\right)+\sqrt{1-\epsilon}\left\{\frac { 2 } { 1 - \frac { \lambda _ { g } } { \lambda _ { \text { cat } } } B } \left[\frac{\left(1-\frac{\lambda_{g}}{\lambda_{\text {cat }}}\right) B}{\left(1-\frac{\lambda_{g}}{\lambda_{\text {cat }}} B\right)^{2}} \ln \frac{\lambda_{\text {cat }}}{\lambda_{g} B}\right.\right. \\
\left.\left.-\frac{B+1}{2}-\frac{B-1}{1-\frac{\lambda_{g}}{\lambda_{\text {cat }}} B}\right]+\frac{1}{\frac{\lambda_{g}}{\lambda_{\text {rad }}}+\frac{\lambda_{g}}{\lambda_{\text {cat }}}}\right\}
\end{gathered}
$$

and $\lambda_{\text {rad }}, P e_{x}$ and coefficients $B$ and $C$ defined as

$$
\lambda_{\text {rad }}=\frac{0.23}{\frac{2}{\epsilon_{\text {rad }}}-1}\left(\frac{T}{100}\right)^{3} d_{p}, \quad P e_{x}=\frac{u_{\text {sup }} \rho_{g} c_{p, g}}{\lambda_{g}} X_{F}, \quad B=\left(\frac{1-\epsilon}{\epsilon}\right)^{\frac{10}{9}}, \quad C=1.4
$$

\section{A.3 Wall-to-bed transfer}

The closure equations for the wall-to-bed heat transfer is summarized in Table 4.4 
Table 4.4: Wall-to-bed heat transfer coefficient calculation, as proposed by Dixon and Creswell [35]

\begin{tabular}{|c|c|c|c|}
\hline 1 & $\begin{array}{lll}1 & r_{i} P e_{r} & B i+3\end{array}$ & \multirow{2}{*}{$B i$} & $r_{i} N u_{w} P e_{e r}$ \\
\hline$\alpha_{\text {bed-wall }}$ & $\overline{\frac{N u_{w} \lambda_{g}}{d_{p}}+\alpha_{r a d}}+\overline{3 \operatorname{RePr} \lambda_{g}} \overline{B i+4}$ & & $=\overline{d_{p} \operatorname{Re} P r}$ \\
\hline$B i_{f}$ & $=\frac{r_{i} N u_{w f} P e_{r f}}{d_{p} \operatorname{RePr}}$ & $B i_{s}$ & $=2.41+0.156\left(\frac{2 r_{i}}{d_{p}}-1\right)^{2}$ \\
\hline \multirow{3}{*}{$P e_{e r}$} & 1 & \multirow{3}{*}{$N u_{w}$} & $=\frac{B i_{s} d_{p} \operatorname{Re} P r}{}$ \\
\hline & $1-\frac{\left(B i_{s}+4\right)}{1}+\frac{\lambda_{\text {bed }}}{1}$ & & $\overline{r_{i} P e_{e r}}$ \\
\hline & $\overline{P e_{r f} B i_{s}} \overline{\left(\frac{8}{N_{f}}+\frac{B i_{f}+4}{B i_{f}}\right)} \overline{\lambda_{g} \operatorname{RePr}}$ & & \\
\hline $\mathrm{Nu}$ & $\begin{array}{l}=\left(7-10 \epsilon_{g}+5 \epsilon_{g}^{2}\right)\left(1+0.7 \operatorname{Re}^{0.2} \operatorname{Pr}^{1 / 3}\right) \\
+\left(1.33-2.4 \epsilon_{g}+1.2 \epsilon_{g}^{2}\right) \operatorname{Re}^{0.7} \operatorname{Pr}^{1 / 3}\end{array}$ & $N u_{w f}$ & $=\left(1-\frac{d_{p}}{2 r_{i}}\right) R e^{0.6} \operatorname{Pr}^{1 / 3}$ \\
\hline \multirow{2}{*}{$N_{f}$} & $=15(1-\epsilon)\left(2 r_{i}\right)^{2} \underline{P e_{r f}}-1$ & \multirow{2}{*}{$\alpha_{\text {rad }}$} & $4 \sigma T^{3}$ \\
\hline & $=1 . J\left(1-\epsilon_{g}\right)\left(\overline{d_{p}}\right) \overline{\operatorname{RePr}} \frac{1}{\frac{1}{N u}+\frac{\lambda_{g}}{10 \lambda_{s}}}$ & & $\overline{\frac{1}{e_{\text {wall }}}+\frac{1}{e_{p}}-1}$ \\
\hline
\end{tabular}




\section{B Physical properties}

The equations used to compare the physical properties of a gas mixture as a function of the pure component data is shortly summarized below.

\section{B.1 Viscosity}

According to the book of Daubert and Danner [36], viscosity of the components can be calculated as

$$
\eta_{j, g}=\frac{A_{j} T^{B_{j}}}{1+\frac{C_{j}}{T}+\frac{D_{j}}{T^{2}}}
$$

where the values for the coefficients $A_{j}, B_{j}, C_{j}$ and $D_{j}$ are given in Table 4.5

Table 4.5: Coefficients in equation 4.21, used in calculation of the component viscosity, according to Daubert and Danner [36]

\begin{tabular}{lcccc}
\hline component & $A_{j}$ & $B_{j}$ & $C_{j}$ & $D_{j}$ \\
\hline $\mathrm{CO}$ & $1.1127 \cdot 10^{-6}$ & $5.3380 \cdot 10^{-1}$ & $9.4700 \cdot 10^{1}$ & 0 \\
$\mathrm{CO}_{2}$ & $2.1480 \cdot 10^{-6}$ & $4.6000 \cdot 10^{-1}$ & $2.9000 \cdot 10^{2}$ & 0 \\
$\mathrm{H}_{2} \mathrm{O}$ & $6.1839 \cdot 10^{-7}$ & $6.7779 \cdot 10^{-1}$ & $8.4723 \cdot 10^{2}$ & $-7.3930 \cdot 10^{4}$ \\
$\mathrm{He}$ & $3.2530 \cdot 10^{-7}$ & $7.1620 \cdot 10^{-1}$ & $-9.6000 \cdot 10^{0}$ & $1.0700 \cdot 10^{2}$ \\
$\mathrm{~N}_{2}$ & $7.6320 \cdot 10^{-7}$ & $5.8823 \cdot 10^{-1}$ & $6.7750 \cdot 10^{1}$ & 0 \\
$\mathrm{C}_{3} \mathrm{H}_{8}$ & $2.4993 \cdot 10^{-7}$ & $6.8612 \cdot 10^{-1}$ & $1.7934 \cdot 10^{2}$ & $-8.2546 \cdot 10^{3}$ \\
$\mathrm{C}_{3} \mathrm{H}_{6}$ & $8.7900 \cdot 10^{-6}$ & $2.3200 \cdot 10^{-1}$ & $8.0000 \cdot 10^{2}$ & $1.2000 \cdot 10^{4}$ \\
$\mathrm{C}_{2} \mathrm{H}_{6}$ & $2.5906 \cdot 10^{-7}$ & $6.7988 \cdot 10^{-1}$ & $9.8902 \cdot 10^{1}$ & 0 \\
$\mathrm{C}_{2} \mathrm{H}_{4}$ & $2.0789 \cdot 10^{-6}$ & $4.1630 \cdot 10^{-1}$ & $3.5270 \cdot 10^{2}$ & 0 \\
$\mathrm{CH}_{4}$ & $5.2546 \cdot 10^{-7}$ & $5.9006 \cdot 10^{-1}$ & $1.0567 \cdot 10^{2}$ & 0 \\
$\mathrm{O}_{2}$ & $8.0380 \cdot 10^{-7}$ & $6.0478 \cdot 10^{-1}$ & $7.0300 \cdot 10^{1}$ & 0 \\
\hline
\end{tabular}

For the viscosity properties of gas mixtures, according to the same source, the following equation should be used:

$$
\eta_{g}=\sum_{j=1}^{N} \frac{x_{j, g} \eta_{j, g}}{\sum_{k=1}^{N} x_{k, g} \varphi_{j, k}^{\eta}}
$$

where $\varphi_{j, k}^{\eta}$ is given as 


$$
\varphi_{j, k}^{\eta}=\frac{\left(1+\sqrt{\frac{\eta_{j}}{\eta_{k}}}\left(\frac{M_{k}}{M_{j}}\right)^{0.25}\right)^{2}}{\sqrt{8+8 \frac{M_{j}}{M_{k}}}}
$$

\section{B.2 Thermal conductivity}

In a membrane reactor, where the solid catalyst is placed in the tube and/or shell side, a thermal conductivity properties of the solid phase may drastically influence the overall reaction process. Therefore, a specification for both, solid phase and gas phase thermal conductivity is given here.

\section{Packed bed thermal conductivity}

For the solid phase thermal conductivity, Zehner and Schlünder [33] suggested the following correlation:

$$
\lambda_{\text {bed }}=\lambda_{r, s} \sqrt{1-\epsilon_{g}}+\lambda_{g}\left(1-\sqrt{1-\epsilon_{g}}\right)\left(1+\epsilon_{g} \kappa_{r}\right)
$$

where $\lambda_{r, s}$ is given as

$$
\lambda_{r, s}=\frac{2 \lambda_{g}}{M}\left(\frac{B\left(\kappa_{s}+\kappa_{r}-1\right)}{M^{2} \kappa_{s}} \ln \left(\kappa_{s}+\frac{\kappa_{r}}{B}\right)+\frac{(B+1)}{2 B}\left(\kappa_{r}-B\right)-\frac{B-1}{M}\right)
$$

while the coefficients appearing in equation 4.25 are represented with following expressions:

$$
M=\frac{\kappa_{s}+\kappa_{r}-B}{\kappa_{s}}, \quad B=1.25\left(\frac{1-\epsilon_{g}}{\epsilon_{g}}\right)^{\frac{10}{9}}, \quad \kappa_{s(r)}=\frac{\lambda_{s(r)}}{\lambda_{g}}, \quad \lambda_{r}=\frac{4 e_{p}}{2-e_{p}} \sigma T^{3} d_{p}
$$

\section{Gas phase thermal conductivity}

Similarly as for component viscosity, an expression for the component thermal conductivity is, according to Daubert and Danner [36] given in the form of an equation with quadratic dependency on temperature.

$$
\lambda_{j, g}=\frac{A_{j} T^{B_{j}}}{1+\frac{C_{j}}{T}+\frac{D_{j}}{T^{2}}}
$$


Coefficients in the previous equation are given in Table 4.6

Table 4.6: Coefficients in equation 4.27, used in calculation of the component thermal conductivity, according to Daubert and Danner [36]

\begin{tabular}{lcrrc}
\hline component & \multicolumn{1}{c}{$A_{j}$} & \multicolumn{1}{c}{$B_{j}$} & \multicolumn{1}{c}{$C_{j}$} & \multicolumn{1}{c}{$D_{j}$} \\
\hline $\mathrm{CO}$ & $8.3900 \cdot 10^{-4}$ & $6.4090 \cdot 10^{-1}$ & $8.6050 \cdot 10^{1}$ & 0 \\
$\mathrm{CO}_{2}$ & $3.6900 \cdot 10^{0}$ & $-3.8380 \cdot 10^{-1}$ & $9.6400 \cdot 10^{2}$ & $1.8600 \cdot 10^{6}$ \\
$\mathrm{H}_{2} \mathrm{O}$ & $2.1606 \cdot 10^{-3}$ & $7.6839 \cdot 10^{-1}$ & $3.9405 \cdot 10^{3}$ & $-4.4534 \cdot 10^{5}$ \\
$\mathrm{He}$ & $8.5900 \cdot 10^{-4}$ & $8.5930 \cdot 10^{-1}$ & $-9.5700 \cdot 10^{1}$ & $6.0000 \cdot 10^{3}$ \\
$\mathrm{~N}_{2}$ & $3.5100 \cdot 10^{-4}$ & $7.6520 \cdot 10^{-1}$ & $2.5767 \cdot 10^{1}$ & 0 \\
$\mathrm{C}_{3} \mathrm{H}_{8}$ & $-1.1200 \cdot 10^{0}$ & $1.0972 \cdot 10^{-1}$ & $-9.8346 \cdot 10^{3}$ & $-7.5358 \cdot 10^{6}$ \\
$\mathrm{C}_{3} \mathrm{H}_{6}$ & $2.2390 \cdot 10^{-5}$ & $1.2928 \cdot 10^{0}$ & $3.1214 \cdot 10^{2}$ & 0 \\
$\mathrm{C}_{2} \mathrm{H}_{6}$ & $7.3869 \cdot 10^{-5}$ & $1.1689 \cdot 10^{0}$ & $5.0073 \cdot 10^{2}$ & 0 \\
$\mathrm{C}_{2} \mathrm{H}_{4}$ & $1.7440 \cdot 10^{-5}$ & $1.3680 \cdot 10^{0}$ & $4.3930 \cdot 10^{2}$ & $-3.8700 \cdot 10^{4}$ \\
$\mathrm{CH}_{4}$ & $6.3252 \cdot 10^{3}$ & $4.3041 \cdot 10^{-1}$ & $7.7040 \cdot 10^{8}$ & $-3.8725 \cdot 10^{10}$ \\
$\mathrm{O}_{2}$ & $4.9430 \cdot 10^{-4}$ & $7.3400 \cdot 10^{-1}$ & $7.0000 \cdot 10^{1}$ & 0 \\
\hline
\end{tabular}

The method of Wilke, as suggested by Reid et al. [37] was used to calculate the mixture thermal conductivity, following the equation 4.28

$$
\lambda_{g}=\sum_{j=1}^{N} \frac{x_{j, g} \lambda_{j, g}}{\sum_{k=1}^{N} x_{k, g} \varphi_{j, k}^{\lambda}}
$$

Coefficient $\varphi_{j, k}^{\lambda}$ is further given as

$$
\varphi_{j, k}^{\lambda}=\frac{\left(1+\sqrt{\frac{\lambda_{j}}{\lambda_{k}}}\left(\frac{M_{k}}{M_{j}}\right)^{0.25}\right)^{2}}{\sqrt{8+8 \frac{M_{j}}{M_{k}}}}
$$




\section{B.3 Heat capacity}

Component heat capacity was obtained via equation

$$
C_{p, j}=\frac{1}{1000 M_{j}}\left[A_{j}+B_{j}\left(\frac{C_{j}}{T \sinh \frac{C_{j}}{T}}\right)^{2}+D_{j}\left(\frac{E_{j}}{T \cosh \frac{E_{j}}{T}}\right)^{2}\right]
$$

as proposed by Daubert and Danner [36], while the corresponding coefficients are listed in Table 4.7

Table 4.7: Coefficients in equation 4.30, used in calculation of the component heat capacity, according to Daubert and Danner [36]

\begin{tabular}{lccccc}
\hline component & $A_{j}$ & $B_{j}$ & $C_{j}$ & $D_{j}$ & $E_{j}$ \\
\hline $\mathrm{CO}$ & $2.9108 \cdot 10^{4}$ & $8.7730 \cdot 10^{3}$ & $3.0851 \cdot 10^{3}$ & $8.4553 \cdot 10^{3}$ & $1.5382 \cdot 10^{3}$ \\
$\mathrm{CO}_{2}$ & $2.9370 \cdot 10^{4}$ & $3.4540 \cdot 10^{4}$ & $-1.4280 \cdot 10^{3}$ & $2.6400 \cdot 10^{4}$ & $5.8800 \cdot 10^{2}$ \\
$\mathrm{H}_{2} \mathrm{O}$ & $3.3363 \cdot 10^{4}$ & $2.6790 \cdot 10^{4}$ & $2.6105 \cdot 10^{3}$ & $8.8960 \cdot 10^{3}$ & $1.1690 \cdot 10^{3}$ \\
$\mathrm{He}$ & $2.0786 \cdot 10^{4}$ & 0 & 0 & 0 & 0 \\
$\mathrm{~N}_{2}$ & $2.9105 \cdot 10^{4}$ & $8.6149 \cdot 10^{3}$ & $1.7016 \cdot 10^{3}$ & $1.0347 \cdot 10^{2}$ & $9.0979 \cdot 10^{2}$ \\
$\mathrm{C}_{3} \mathrm{H}_{8}$ & $5.1920 \cdot 10^{4}$ & $1.9245 \cdot 10^{5}$ & $1.6265 \cdot 10^{3}$ & $1.1680 \cdot 10^{5}$ & $7.2360 \cdot 10^{2}$ \\
$\mathrm{C}_{3} \mathrm{H}_{6}$ & $4.1300 \cdot 10^{4}$ & $1.5250 \cdot 10^{5}$ & $1.3520 \cdot 10^{3}$ & $7.4400 \cdot 10^{4}$ & $5.7800 \cdot 10^{2}$ \\
$\mathrm{C}_{2} \mathrm{H}_{6}$ & $4.0326 \cdot 10^{4}$ & $1.3422 \cdot 10^{5}$ & $1.6555 \cdot 10^{3}$ & $7.3223 \cdot 10^{4}$ & $7.5287 \cdot 10^{2}$ \\
$\mathrm{C}_{2} \mathrm{H}_{4}$ & $3.3380 \cdot 10^{4}$ & $9.4790 \cdot 10^{4}$ & $1.5960 \cdot 10^{3}$ & $5.5100 \cdot 10^{4}$ & $7.4080 \cdot 10^{2}$ \\
$\mathrm{CH}_{4}$ & $3.3298 \cdot 10^{4}$ & $7.9933 \cdot 10^{4}$ & $2.0869 \cdot 10^{3}$ & $4.1602 \cdot 10^{4}$ & $9.9196 \cdot 10^{2}$ \\
$\mathrm{O}_{2}$ & $2.9103 \cdot 10^{4}$ & $1.0040 \cdot 10^{4}$ & $2.5265 \cdot 10^{3}$ & $9.3560 \cdot 10^{3}$ & $1.1538 \cdot 10^{3}$ \\
\hline
\end{tabular}

For the mixture heat capacity, an equation given below was used.

$$
C_{p, g}=\sum_{j=1}^{N} w_{j, g} C_{p, j, g}
$$




\section{B.4 Diffusion coefficients}

The estimation of molar diffusion coefficients was done using the Fuller's method [37]:

$$
D_{j, k}=\frac{1}{\sqrt{\frac{2000}{\frac{1}{M_{j}}+\frac{1}{M_{k}}}} p\left(v_{j}^{1 / 3}+v_{k}^{1 / 3}\right)^{2}}
$$

Molar volumes for certain compounds are mentioned in Table 4.8

Table 4.8: Molar volumes of the components, according to Reid et al. [37]

\begin{tabular}{lclc}
\hline component & $v$ & component & $v$ \\
\hline $\mathrm{CO}$ & 18.00 & $\mathrm{C}_{3} \mathrm{H}_{6}$ & 61.56 \\
$\mathrm{CO}_{2}$ & 26.90 & $\mathrm{C}_{2} \mathrm{H}_{6}$ & 45.66 \\
$\mathrm{H}_{2} \mathrm{O}$ & 13.10 & $\mathrm{C}_{2} \mathrm{H}_{4}$ & 41.04 \\
$\mathrm{~N}_{2}$ & 18.50 & $\mathrm{CH}_{4}$ & 25.14 \\
$\mathrm{C}_{3} \mathrm{H}_{8}$ & 66.18 & $\mathrm{O}_{2}$ & 16.30 \\
$\mathrm{He}$ & 2.67 & $\mathrm{H}_{2}$ & 6.12 \\
\hline
\end{tabular}




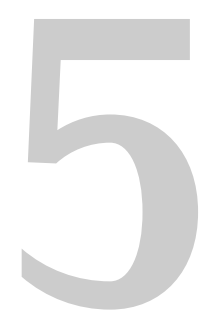

\section{Experimental demonstration of ODHP in a packed bed membrane reactor}

An experimental demonstration of the ODHP in a lab scale packed bed membrane reactor has been performed. Experiments were carried out with both premixed and distributed oxygen feed and compared, and the influence of the gas composition, flow rate and the extent of dilution was investigated. The results revealed that, in comparison with conventional reactor concepts for the ODHP (fixed bed with premixed reactants feed), a significantly higher propylene yield can be achieved at higher propane conversions in a packed bed membrane reactor. 



\subsection{Introduction}

$\mathrm{M}$

EMBRANE REACTORS ATTRACT A LOT OF ATTENTION of many scientists all over the world during the last two decades, for their wide application possibilities. They are mostly used in biotechnology $[1,2]$ and in the separation/filtration processes [3-5], but the promising features of a reaction system with catalytically active or inert membranes are also explored in heterogeneously catalyzed gas phase reactions in order to improve already existing conventional production processes, such as the production of formaldehyde and methanol from methane $[6,7]$, or the oxidative dehydrogenation of ethane $[8,9]$. Here the potential of a membrane reactor has been examined for the possible application in the process of oxidative dehydrogenation of propane (ODHP).

\subsection{Objectives}

An experimental demonstration of yield improvement of propylene by distributive oxygen feeding via a porous membrane and comparison with results from numerical model simulations (see chapter 4) are the main objectives of this part of the study. The experimental setup and operation are described in the following section, followed by a discussion of the results from the experimental study on the performance of ODHP in a packed bed reactor using both premixed feeding and distributive oxygen feeding. The effects of the inlet gas composition, reactants flow rate and the extent and way of dilution will also be discussed.

\subsection{Experimental}

For the experimental validation of the numerical results presented in the previous chapter, an experimental setup was constructed, equipped with a single membrane tube of desired characteristics in terms of mechanical and physical properties.

\subsubsection{Setup and operation}

The experimental setup used for the experiments described in this chapter is schematically shown in Figure 5.1. Propane enters the tube side of the reactor (R1) through a pipeline equipped with mass flow controller MFC2. If distributive feed of oxygen is used, the three way valve V2 is set in the position such that the stream is directed towards the shell side of the reactor. For operation with premixed reactants, this valve directs the stream to the junction point in front of valve V3. The three way valve V3 is used to allow bypassing the reactor to analyze the feed composition on a gas chromatograph GC. Nitrogen can either be added to the shell or tube side, by setting valve V1 into the desired position. With the design presented, it is possible to have the following setup configurations: 


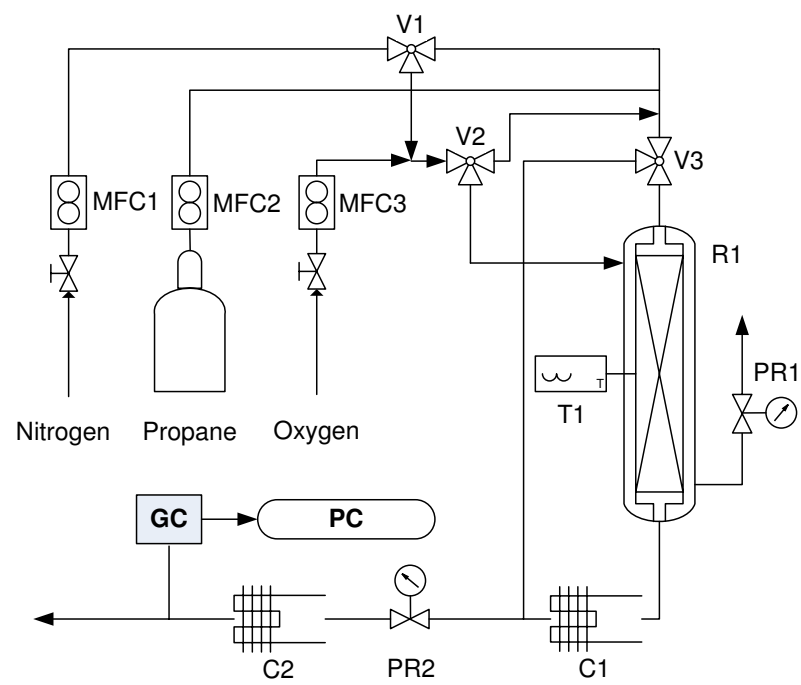

Figure 5.1: Schematic overview of the experimental setup used: R1 - Reactor, MFC1-3-Mass flow controllers, $\mathrm{T1}$ - Temperature controller, C1-2 - Condensers, PR1-2 - Pressure regulator, V1-3 Three-way valves, GC - Gas chromatograph

1. premixed reactants (dense tube installed instead of porous membrane)

2. distributed feed (porous membrane tube installed)

- dilution of oxygen feed (shell side dilution by nitrogen)

- dilution of propane feed (tube side dilution by nitrogen)

3. bypass of the reactor (to analyze feed composition)

After cooling to room temperature and removing condensed water from the stream (C1), the reaction products were analyzed using a Varian MicroGC 4900. A molsieve $5 \AA$ column was used for the detection of oxygen, nitrogen, methane and carbon monoxide, while a $\mathrm{Al}_{2} \mathrm{O}_{3} / \mathrm{KCl}$ column measured the ethane, ethylene, propane and propylene concentrations. Thermal conductivity detectors were attached to both columns and absolute concentrations were obtained from the chromatogram peaks. The relative accuracy of the gas concentrations measured with the chromatograph was within $2 \%$ and it was regularly checked by analyzing a gas mixture of known composition.

A thermocouple was inserted in the catalyst bed, inside the membrane tube. Pressure indicators were placed at the inlets of both tube and shell side of the reactor and the difference between the pressures was in all the cases positive $\left(p_{\text {shell }}-p_{\text {tube }}>0\right)$. This ensures that the back-permeation is minimized and that no bypassing of the tube side stream can occur. 


\subsubsection{Membrane properties}

The membrane used in this research is a porous alumina $\left(\mathrm{Al}_{2} \mathrm{O}_{3}+5-10 \% \mathrm{SiO}_{2}\right)$ with an internal diameter of $8 \mathrm{~mm}$. The results of an XRD measurement on the material composition are shown in Figure 5.2. Squares represent the characteristic peaks for $\mathrm{Al}_{2} \mathrm{O}_{3}$, obtained from the database of The International Centre for Diffraction Data (ICDD). Silicium dioxide peaks are almost invisible here.

Together with XRD measurements, SEM photographs of a cross section of the membrane tube were made. Figures 5.3(a) and 5.3(b) show the material under low (500x) and high (2000x) magnification. It can also be seen that the pores are typically a few micrometers in diameter.

\subsubsection{Membrane fluxes}

One of the important characterization routines in membrane related operations using porous membranes is certainly the characterization of the membrane permeability as a function of the transmembrane pressure drop. The permeation can be expressed either in moles or in (milli)liters of substance permeating through a unit of membrane area per unit of time and correlated to the pressure difference between the feed and permeate side of the membrane.

In this particular case, when no membrane layer is applied on a porous support (inside or outside), but the entire wall acts as a membrane/distributor, the permeability can be related to both, inner and outer diameter. Here, all the fluxes are calculated based on the outer tube diameter.

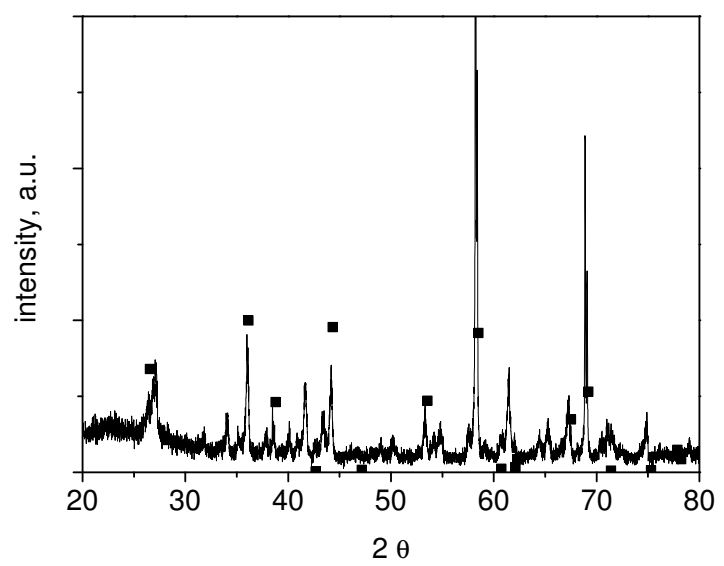

Figure 5.2: XRD pattern of the membrane tube material 


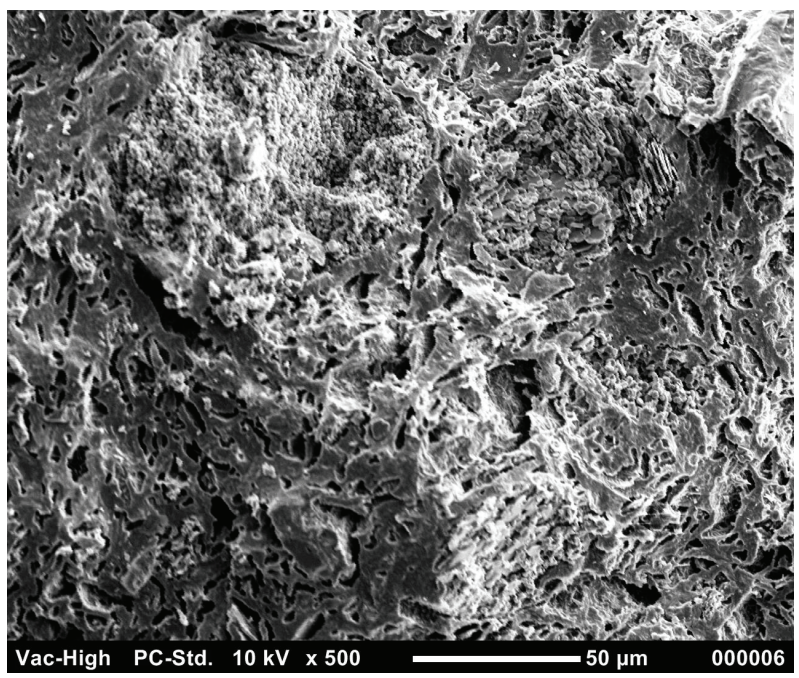

(a)

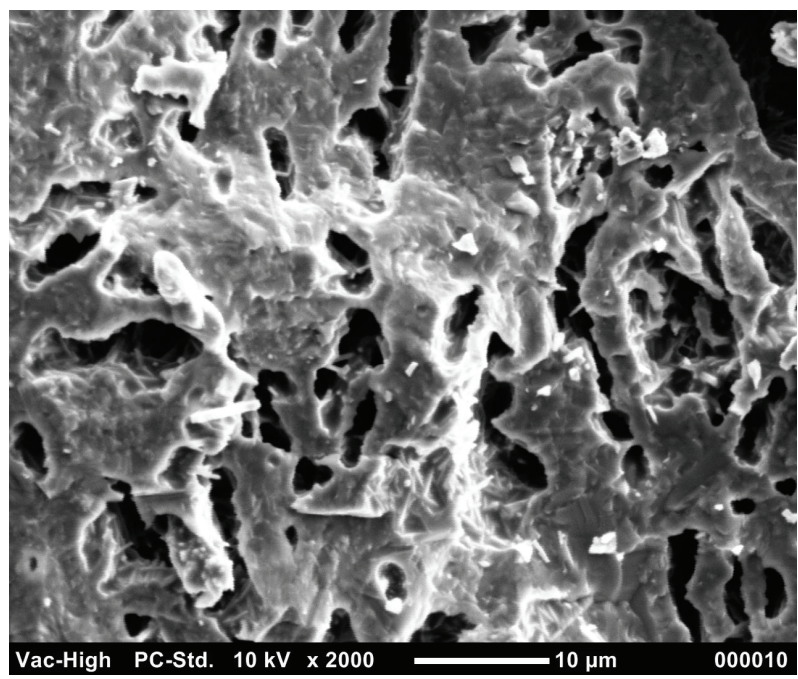

(b)

Figure 5.3: SEM photo of a cross section of the membrane: (a) low magnification (500x) (b) high magnification (2000x) 
The porous alumina tube used in the membrane reactor in this case was $42 \mathrm{~cm}$ in length, equal to the length of the reactor. The flow through this membrane was examined as a function of the transmembrane pressure difference at room temperature (see Figure 5.4). However, only the part of this tube which was located in the oven $(25 \mathrm{~cm}$, middle part of the tube), was permeable. The remaining of the tube was made non-permeable. There are two routes to achieve this: either by cutting the tube to the desired permeable length and then extending it with dense tubes at either end to the length required by the size of the reactor, or by sealing the top and bottom sections of the membrane tube. The first approach includes combining (ceramic) materials of different physical properties, which then causes accumulation of stresses at the connection points. This leads to an easy breakage of such a tube and therefore this approach was not used here. Instead, top and bottom sections were sealed, for this solution avoids high stresses in the material and it is from a technical point of view much easier to be achieved. In order to prove that the sealing is satisfactory, flux measurements were done with and without sealing of the bottom and top sections of the membrane and the dependency of the permeation on the transmembrane pressure difference is plotted in Figure 5.4. As can be deduced from the fitted functions through the measured data points, sealing successfully prevents permeation in the top and bottom section of the tube, even at pressure levels which are far beyond those used in the subsequent ODHP experiments.

Since the ODHP reactions will be carried out at a temperature of $733 \mathrm{~K}$, it was also necessary to examine the membrane fluxes over the temperature range from $298 \mathrm{~K}$ until $773 \mathrm{~K}$. Results from these experiments, presented in Figure 5.5, show that the highest flux is obtained for a temperature of $298 \mathrm{~K}$ and at large transmembrane pressure differences. As the temperature was increased, the flux of oxygen (expressed in $\mathrm{mol} /\left(\mathrm{m}^{2} \cdot \mathrm{s}\right)$ ) for the same $\Delta \mathrm{p}$ decreased. If the flux is compared at $\Delta \mathrm{p}=1.3 \mathrm{bar}$, it can be seen that the decrease is about $65 \%$.

\subsubsection{Back-permeation}

The extent of back-permeation of propane from the tube side of the membrane reactor to the shell side due to the concentration difference has also been examined. The gas stream to the tube side consisted of pure nitrogen, and to the shell side pure oxygen was fed. The oxygen flow rate was set to $200 \mathrm{ml} / \mathrm{min}$ (all volumetric flow rates mentioned in this chapter are in normal milliliters per minute), while the transmembrane pressure difference was regulated by the valve at the outlet of the shell side. It is also important to mention that in these experiments the shell side was open ended.

From Figure 5.6 it can be clearly seen that the back-permeation is very significant at lower nitrogen flow rates and at higher operating temperatures. An increase of the flow rate to the tube side increases the amount of nitrogen found in the shell side, however, if this is quantified as percentage of nitrogen (initially) present in the tube side, the extent of back-permeation actually reduces. It is also noticeable that the operating temperature sig- 


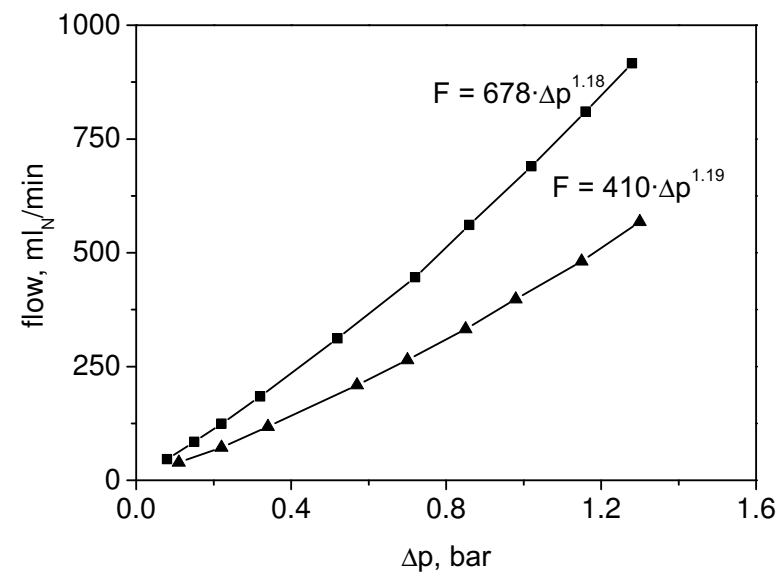

Figure 5.4: Membrane permeability as a function of the transmembrane pressure drop at $298 \mathrm{~K}$. The lower curve represents the permeability of the tube with sealed ends and thus permeable only for a length of $25 \mathrm{~cm}$, while the other curve is obtained from the permeability measurements with the entire, unsealed, $42 \mathrm{~cm}$ long, porous alumina tube.

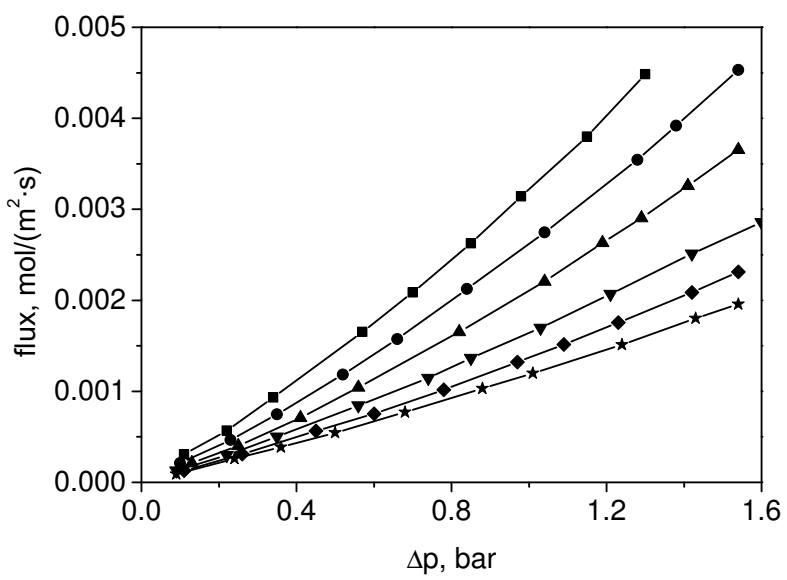

Figure 5.5: Membrane flux as a function of temperature. Symbols: $\bullet 298 \mathrm{~K}, \bullet 373 \mathrm{~K}, \boldsymbol{4} 473 \mathrm{~K}, \boldsymbol{\nabla} 573 \mathrm{~K}$, - $673 \mathrm{~K}, \star 773 \mathrm{~K}$ (tube side feed: pure $\mathrm{N}_{2}$; shell side feed: pure $\mathrm{O}_{2}$ ) 


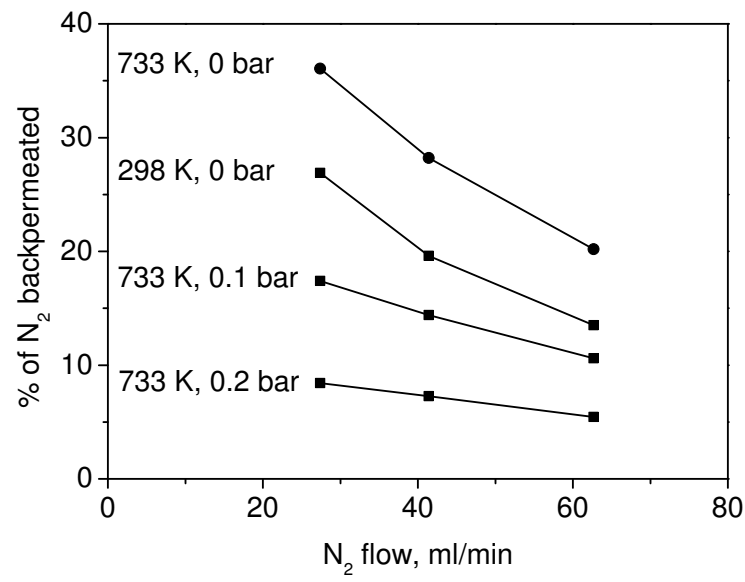

Figure 5.6: Back-permeation: percentage of nitrogen back-permeated as a function of tube side flow rate at two temperature levels.

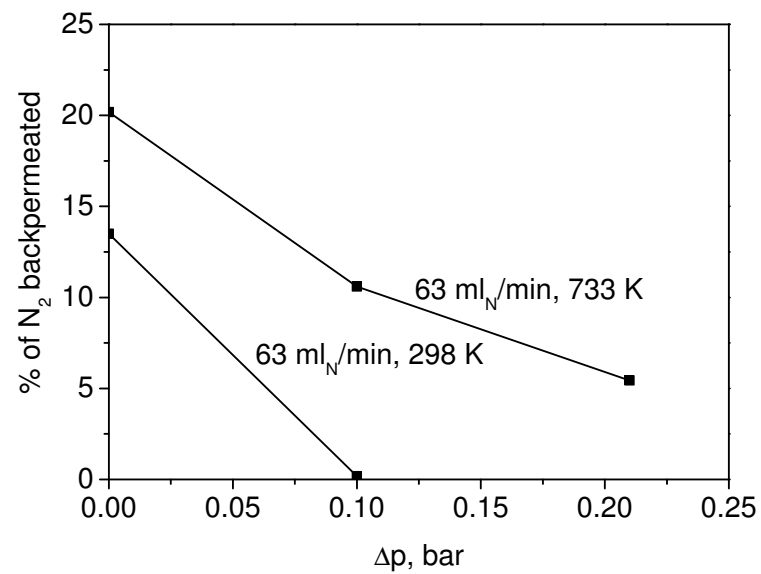

Figure 5.7: Extent of back-permeation of nitrogen as a function of transmembrane pressure difference at different temperatures. Shell side feed: $200 \mathrm{ml} / \mathrm{min} \mathrm{O}_{2}$; tube side feed: $63 \mathrm{ml} / \mathrm{min} \mathrm{N}_{2}$. 
nificantly affects the extent of back-permeation: back-permeation at $733 \mathrm{~K}$ is significantly higher in comparison to back-permeation at $298 \mathrm{~K}$, which can be attributed to the lower permeability of the membrane at high temperatures.

The transmembrane pressure difference also has a significant impact on the extent of back-permeation. As shown in Figure 5.7, increasing the transmembrane pressure difference to 0.2 bar at $733 \mathrm{~K}$ leads to a decrease of the percentage of nitrogen back-permeated from 20.2 to $5.4 \%$. At the same time, at a lower temperature level, even a difference of 0.1 bar leads to virtual absence of back-permeation.

\subsubsection{Reproducibility}

In order to ensure that the experimental results are reliable, several reproducibility tests were performed. Both reactor setups (with premixed as well as with distributed oxygen feed) were examined. The experimental series were done in the way that between repeating two identical experiments (i.e. with identical setpoints with respect to all process parameters) a number of other experiments was performed. The results from these tests can be found in Figure 5.8 and Figure 5.10. From these graphs it can be clearly concluded that the overall reproducibility in both cases is quite good.

\subsection{Results and discussion}

\subsubsection{Premixed feed}

The experiments with premixed reactants were performed in the experimental setup using a dense alumina tube (see subsection 5.3.1). To be able to compare the results from these experiments and the experiments in the membrane reactor discussed later, the identical amount of catalyst was used. In Figure 5.8 the results of two experimental series for two different inlet flow rates are given. In these experiments the total volumetric flow rate (thus also the contact time) as well as the propane inlet concentration were kept constant, while the oxygen inlet concentration was varied. In order to maintain the same flow rate for different oxygen concentrations, the inlet stream was diluted with nitrogen.

As expected, the propylene selectivity decreases strongly with increasing propane conversion. For low propane conversions, the experimentally obtained selectivities are in a very good agreement with the conversion-selectivity curve obtained from numerical simulations, indicated with the dashed lines. Moving towards higher conversions, the calculated selectivity to propylene is slightly higher in comparison to the experimentally obtained values. This could be attributed to possible formation of acrolein at lower propane over oxygen ratios (see Davies and Taylor [10,11]), since this reaction has not been included in the model.

Decreasing the inlet flow rate, the selectivity to propylene increases, when compared 


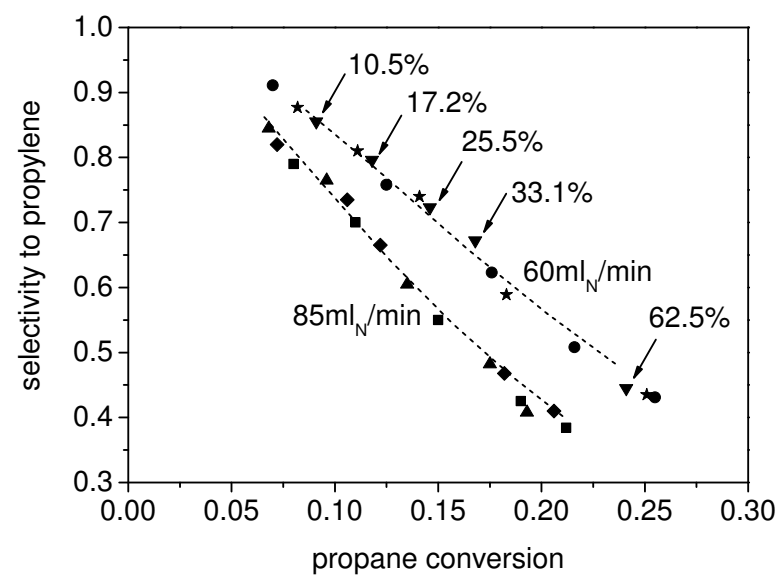

Figure 5.8: Premixed reactants flow: reproducibility tests and influence of the oxygen inlet concentration for two different (total) flow rates at $733 \mathrm{~K}$. For one series the oxygen inlet concentration is indicated.

at the same propane conversion. The explanation for this result can be found by examining the oxygen concentration levels for these two cases.

The amount of oxygen needed for achieving a certain propane conversion differs for different contact times; higher flow rates mean shorter contact times and therefore more oxygen is needed to reach a certain conversion, in which case the propane/oxygen ratio is lower, which favors side reactions and explains the observed lower selectivity to propylene.

\subsubsection{Distributed oxygen feed}

Similar to the cases with premixed reactants feed, experiments with distributed feed of oxygen were performed. Dilution of the feed stream was used to keep the overall contact time unchanged, when the concentration of one of the reactants was varied. In case of distributed oxygen feed, there are two possibilities, either to dilute the shell side stream (oxygen), or to dilute the propane feed in the tube side of the reactor. In chapter 4, these two cases were also investigated.

\section{Tube side dilution}

Experimental examination of the ODHP was performed in the reactor setup described previously with the porous alumina membrane tube installed. The membrane tube was 
inserted in the steel tube with a diameter of $25 \mathrm{~mm}$, so that oxygen was fed via the annular space (closed end!), while propane and nitrogen were fed through the tube side of the membrane reactor.

Having in mind that the oxygen concentration was targeted to be low, the pressure difference between the shell and tube side was also kept low. The addition of nitrogen in the tube side contributed to a slight increase of the pressure difference over the catalyst bed, thereby decreasing the pressure difference between the shell and tube side of the reactor.

In these experiments, the contact time was kept constant, while the oxygen concentration was altered, comparable to the experiments where the shell side stream was diluted. The effects of the inlet composition variation are shown in Figure 5.9.

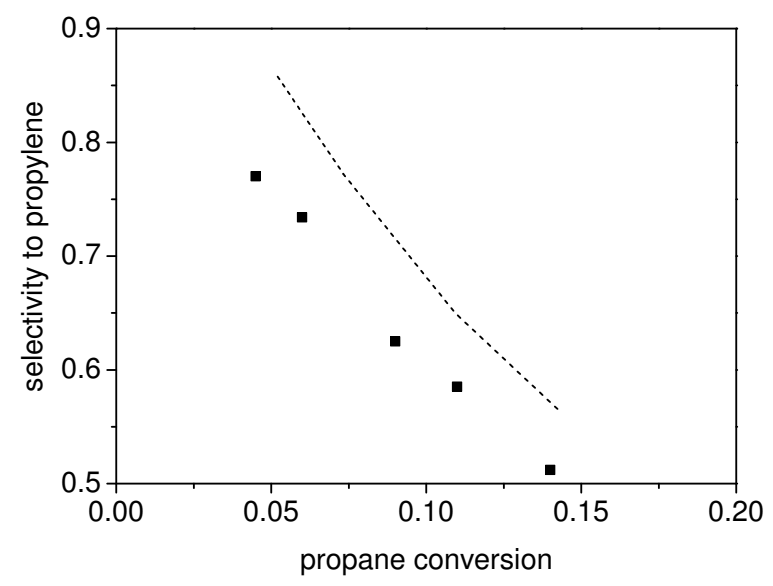

Figure 5.9: Selectivity to propylene as a function of the propane conversion: back-permeation imposes serious problems in the system where the tube side stream was diluted. Reaction composition contained $30 \%$ of propane, while the contact time was kept constant by adjustment of inert $\left(\mathrm{N}_{2}\right)$.

Unlike the experiments with dilution from the shell side, discussed later, these experimental results showed much larger deviations from the numerically predicted values for the conversion and selectivity. Even at low conversions, the difference was reasonably large. For a given propane conversion, the selectivity to propylene was overpredicted. At higher conversions, this difference becomes somewhat lower, however, still a large amount of propane is involved in side reactions. This is most likely caused by the relatively high extent of propane back-permeation to the shell side of the membrane reactor. Propane which back-permeates to the shell side of the reactor can also react with oxygen present there and form $\mathrm{CO}_{\mathrm{x}}$. Although the rate of the gas phase reaction of propane with oxygen 
at moderate temperatures, such as in this work used $(733 \mathrm{~K})$ is low, one should keep in mind the following:

1. The oven heats the steel shell side of the reactor, so the the membrane tube is heated indirectly by convective heat transport. As a consequence, the temperature in the shell side is somewhat higher than $733 \mathrm{~K}$.

2. The annular space is confined by the alumina membrane and by the steel reactor wall. Steel, under these conditions, may act as a catalyst for propane oxidation, while alumina remains inert, especially having in mind that its temperature is lower and close to $733 \mathrm{~K}$.

Thus, the low transmembrane pressure difference and the low amount of oxygen fed can explain why the experimental results obtained were in large discrepancy with the model. Of course, the model could be extended to include back-permeation effects. However, industrial reactors should be operated such that back-permeation effects are negligible. In this work, this was achieved via shell side dilution.

\section{Shell side dilution}

In previous experiments, the reactants stream was diluted from the tube side. The other possibility, dilution from the shell side, was examined as well.

Experiments were performed where the oxygen concentration was varied (at constant contact time) as well as where the total flow rate was varied, while the feed composition was kept constant. The influence of the oxygen concentration on the performance of the packed bed membrane reactor is shown in Figure 5.10, together with results of similar experiments in the packed bed reactor with premixed reactants.

A significantly higher propylene selectivity can be achieved with distributive oxygen feeding, especially at higher propane conversions. As can be clearly seen, the experimentally determined selectivity to propylene agrees well with results obtained from numerical model simulations, however for somewhat higher conversions (obviously obtained at high oxygen concentrations!), the experimentally obtained selectivity tends to be slightly smaller than predicted. A possible explanation for this is formation of acrolein [10, 11], as mentioned earlier, which was not included in the modeling. Acrolein is formed at propane to oxygen ratios close, or lower than one, which was generally avoided, firstly because of the low selectivity to propylene and secondly because operation at these conditions falls within the explosion limits of the propane/oxygen mixture. Moreover, it can be concluded that the reproducibility of the experiments in the membrane reactor is quite good.

Another series of experiments was carried out where the total flow rate of reactants was varied, while keeping the inlet composition unchanged. These experiments were performed with a feed composition $\mathrm{N}_{2}: \mathrm{C}_{3} \mathrm{H}_{8}: \mathrm{O}_{2}=6: 3: 1$, while the total volumetric flow rate 


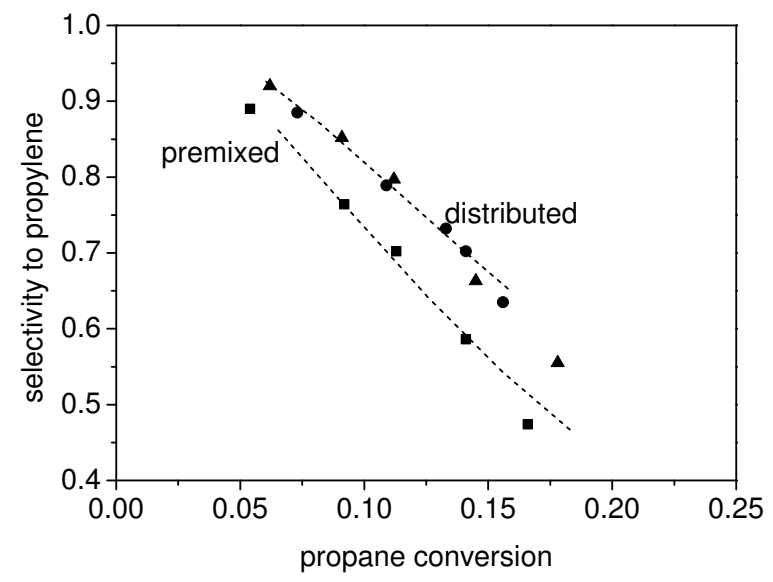

Figure 5.10: Comparison of the performance of a packed bed reactor with premixed feed and a packed bed membrane reactor with distributed oxygen feed. Influence of the oxygen inlet concentration at constant contact time at $733 \mathrm{~K}$. Volumetric flow rate for both systems was kept at $85 \mathrm{ml} / \mathrm{min}$.

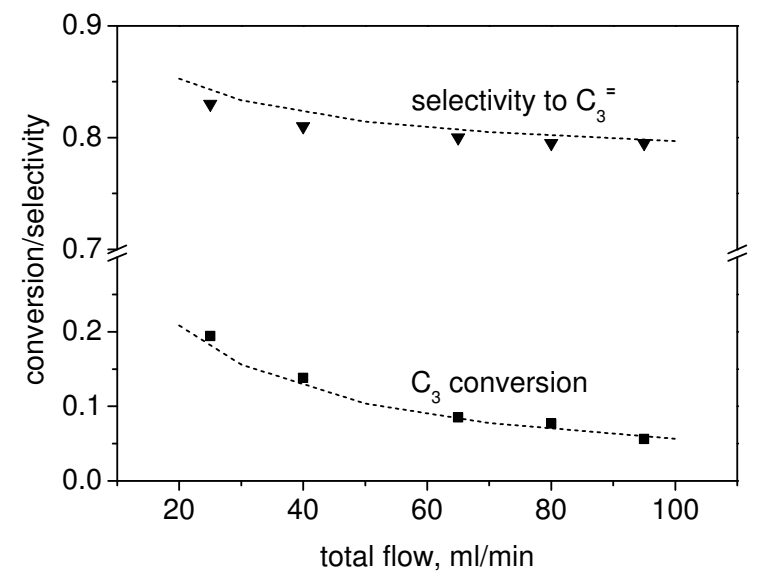

Figure 5.11: The influence of the total volumetric flow rate on the propane conversion and propylene selectivity at constant inlet composition in the PBMR $\left(\mathrm{N}_{2}: \mathrm{C}_{3} \mathrm{H}_{8}: \mathrm{O}_{2}=6: 3: 1\right)$. 
was varied between 25 and $95 \mathrm{ml} / \mathrm{min}$. Results from these experiments are depicted in Figure 5.11. Again, the experimental results compare well with the numerical simulations.

The selectivity to propylene at lower flow rates is slightly lower than expected from the simulation study. A possible explanation of this is the following: low (total) flow rate means low flow rate of propane in the tube side, but also low flow rate of oxygen in the shell side of the reactor. As a consequence, this low flow rate in the shell side corresponds to a lower transmembrane pressure, which increases the extent of back-permeation somewhat. Therefore the conversion at the low flow rates is slightly overpredicted, since propane can also react in the shell side, while the selectivity to propylene is somewhat underpredicted. For the higher flow rates, the transmembrane pressure difference is higher, so that backpermeation is negligible and the numerical simulations compare very well with the experimental results.

\section{Influence of inert addition}

The influence of different hydrocarbon concentrations was also examined experimentally. The overall concentration of propane in the first case was set to $20 \%$ of the total volumetric flow rate $(50 \mathrm{ml} / \mathrm{min})$ and the different conversions/selectivities were obtained by variation of the oxygen feed concentration. In the second case, the concentration of propane was set to $40 \%$.

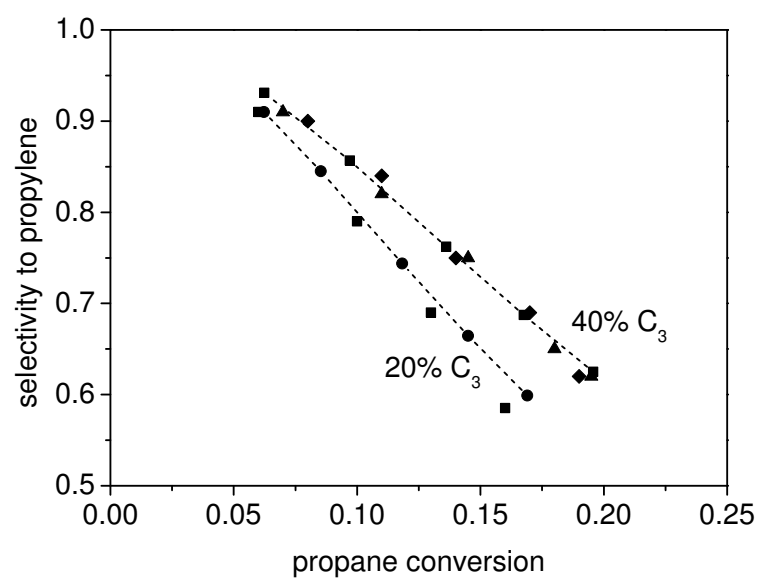

Figure 5.12: Influence of inert addition on the performance of membrane reactor. Flow rate constant, $50 \mathrm{ml} / \mathrm{min}, \mathrm{C}_{3} \mathrm{H}_{8}$ concentration $20(40) \%$. 
The experimentally obtained results, shown together with curves obtained from numerical simulations (see Figure 5.12) show clearly that a better performance is achieved without dilution. Lower reactants concentrations reduce the reaction rate, thus requiring a higher oxygen concentration to obtain the same propane conversion with a corresponding decrease in the propylene selectivity.

\subsection{Conclusions}

In this chapter an experimental study was presented on the performance of the oxidative dehydrogenation of propane in a packed bed reactor with premixed reactants and a packed bed membrane reactor where oxygen was fed distributively. The influences of the flow rate, inlet composition and dilution were experimentally examined and compared with the results obtained from numerical model simulations. It was experimentally demonstrated that significantly higher propylene yields can be achieved in a packed bed membrane reactor with distributive oxygen feed.

The results from the experiments where the inlet composition was altered compared very well with the simulation results, which also holds for the experiments with shell side dilution where the total volumetric flow rate was varied. Only for the case of tube side dilution larger discrepancies were found, where it has been shown that back-permeation significantly decreased the overall performance of the membrane reactor, which was not accounted for in the modeling.

At the end, it can be concluded that the propylene yields obtained in the packed bed membrane reactor are indeed significantly higher at higher propane conversions, compared to those obtained in the reactor with no distributive oxygen feeding and that the packed bed membrane reactor can outperform conventional reactors which are currently in industrial use.

\section{References}

[1] M. K. H. Liew, A. G. Fane and P. L. Rogers. Applicability of continuous membrane bioreactor in production of phenylacetylcarbinol. Journal of Chemical Technology and Biotechnology, 64(2), 200-206 (1995).

[2] B. Bibal, Y. Vayssier, G. Goma and A. Pareilleux. High-concentration cultivation of Lactococcus cremoris in a cell-recycle reactor. Biotechnology and Bioengineering, 37(8), 746-754 (1991).

[3] J. A. Scott, D. J. Neilson, W. Liu and P. N. Boon. A dual function membrane bioreactor system for enhanced aerobic remediation of high-strength industrial waste. Water Science and Technology, 38(4-5), 413-420 (1998). 
[4] C. S. F. Ragona and E. R. Hall. Parallel operation of ultrafiltration and aerobic membrane bioreactor treatment systems for mechanical newsprint mill whitewater at $55^{\circ} \mathrm{C}$. Water Science and Technology, 38(4-5), 307-314 (1998).

[5] E. Tardieu, A. Grasmick, V. Geaugey and J. Manem. Influence of hydrodynamics on fouling velocity in a recirculated MBR for wastewater treatment. Journal of Membrane Science, 156(1), 131-140 (1999).

[6] G. Lu, S. Shen and R. Wang. Direct oxidation of methane to methanol at atmospheric pressure in CMR and RSCMR. Catalysis Today, 30(1-3), 41-48 (1996).

[7] Q. Liu, J. Rogut, B. Chen, J. L. Falconer and R. D. Noble. Improved methanol yield from methane oxidation in a non-isothermal reactor. Fuel, 75(15), 1748-1754 (1996).

[8] E. López, E. Heracleous, A. A. Lemonidou and D. O. Borio. Study of a multitubular fixed-bed reactor for ethylene production via ethane oxidative dehydrogenation. Chemical Engineering Journal, 145(2), 308-315 (2008).

[9] C. Hamel, A. Tóta, F. Klose, E. Tsotsas and A. Seidel-Morgenstern. Analysis of single and multi-stage membrane reactors for the oxidation of short-chain alkanes Simulation study and pilot scale experiments. Chemical Engineering Research and Design, 86(7), 753-764 (2008).

[10] T. Davies and S. H. Taylor. The oxidative dehydrogenation of propane using galliummolybdenum oxide-based catalysts. Journal of Molecular Catalysis A: Chemical, 220(1), 77-84 (2004).

[11] T. Davies and S. H. Taylor. The oxidative dehydrogenation of propane using galliummolybdenum based catalyst. Catalysis Letters, 93(3-4), 151-154 (2004). 



\section{Summary}

The limitations of current processes for propylene production and the strong increase in the demand for propylene over the past decade made the oxidative dehydrogenation of propane (ODHP) an attractive alternative direct production route for propylene. Its significant advantages over currently applied dehydrogenation processes, are:

- The conversion of propane in ODHP is not limited by the thermodynamic equilibrium,

- ODH is exothermic and has therefore a benefit over classic dehydrogenation processes, which are endothermic processes requiring costly heat supply at high temperature levels,

- Coke formation is prevented,

- High propylene to ethylene ratio is obtained,

- Operation is possible at moderate temperature levels of about $500^{\circ} \mathrm{C}$,

making this process very attractive for a possible future industrial application.

The research on ODHP reported in the literature can be divided into two categories. One direction focuses on the design of the catalysts which partially oxidize alkanes to olefins, with yields comparable to those obtained with current technologies for propylene production. The other direction focuses on different reactor configurations and nonconventional reactor operation (cyclic feeding of reactants, for example) which can outperform the "traditional" reactor configurations and their operation.

In this thesis, the main research effort was in the direction of how a sophisticated reactor design can improve the propylene yield in the ODHP process and to quantify this.

First, a literature survey was performed, to investigate which are the best catalyst systems and best operating conditions that result in the largest propylene yield. This was accompanied by an investigation of different proposed reactor concepts. Packed bed reactors with premixed and distributed oxygen feed, as well as reactors using fluidized bed technology were discussed. Research on process conditions showed that the oxidative dehydrogenation of propane can be performed at moderate temperature levels. This is a 
large benefit in terms of energy utilization, in comparison to more conventional dehydrogenation processes. Operation at atmospheric, or close-to-atmospheric pressure was also reported to give optimal results. This was then further used to select the conditions for the experimental work. It was also found for this research the combination of $\mathrm{Ga}_{2} \mathrm{O}_{3}$ and $\mathrm{MoO}_{3}$ can be used as a catalyst. The $\mathrm{Ga}_{2} \mathrm{O}_{3} / \mathrm{MoO}_{3}$ catalyst combines good alkane activation properties of $\mathrm{Ga}_{2} \mathrm{O}_{3}$ with the selective oxidation function of $\mathrm{MoO}_{3}$ in a beneficial manner. Also, this catalyst is very easy to prepare, while its performance is quite comparable to the performance of other, much more sophisticated (hence expensive) catalytic systems. However, kinetic data for this specific catalytic system have not been reported in literature. Therefore, for the assessment of the reactor concept, a kinetic study was performed.

In the kinetic study of ODHP over a $\mathrm{Ga}_{2} \mathrm{O}_{3} / \mathrm{MoO}_{3}$ catalyst which followed, the reaction rates were experimentally determined in a catalytic reactor under differential reaction conditions for the catalyzed and non-catalyzed system. It was verified extensively that intrinsic reaction kinetics were determined. The results obtained showed that the reaction orders in oxygen are higher for the side reactions, than for the main reaction, indicating that the distributive oxygen feed via a packed bed membrane reactor can be used to maximize the propylene yield. The reaction system was also studied without the presence of catalyst and again a higher order in oxygen was found for the side reactions. For quantifying the benefit of employing a packed bed membrane reactor with distributive oxygen feed, instead of packed bed reactor with premixed reactants feed, a detailed numerical model was developed. A multi-compartment, multi-component reactor model was developed for a tube-in-tube configuration, where the number of compartments could be varied. If the number of compartments was selected to be one, then the model comprised a single tube reactor with premixed reactants flow. For two compartments, a model of a membrane reactor with distributed feed of reactant(s) was obtained. Using the modified Thiele modulus concept it was verified that a $1 \mathrm{D}$ model description is appropriate. It was also examined (and confirmed) that the catalyst particles are practically isothermal, so that a pseudo-homogeneous approach is valid for the case examined. Using this model, the performance of a reactor for the catalyzed ODHP was simulated for the cases of premixed and distributed oxygen feeding, where the reactants composition, flow rates and extent and manner of dilution were varied. The simulation results demonstrated that large improvements in propylene yield can be achieved via distributive feeding of oxygen.

Finally, a series of experiments were performed in a lab-scale packed bed membrane reactor in order to validate the numerical simulation results. First, an experimental setup was constructed, equipped with a single membrane tube of desired characteristics in terms of mechanical and physical properties. Experiments were carried out with both premixed and distributed oxygen feed and compared, and the influence of the gas composition, flow rate and the extent of dilution was investigated. The extent of back-permeation of propane from the tube side of the membrane reactor to the shell side due to the concentration difference has also been examined. A good match between experimental results and results 
from numerical simulations showed that the model is indeed quite satisfactory to describe the process of the oxidative dehydrogenation of propane. Only for the case of tube side dilution somewhat larger discrepancies between experimental and numerically obtained results were found, caused by back-permeation, which was ignored in the model. Finally, the results demonstrated also that a significantly higher propylene yield can be achieved at higher propane conversions in a packed bed membrane reactor operated at much lower temperatures, outperforming conventional reactor concepts for the ODHP (fixed bed with premixed reactants feed). 



\section{Samenvatting}

Door de limiteringen van de huidige industriële processen voor de productie van propyleen en de toenemende vraag naar propyleen over de laatste tien jaar is de oxidatieve dehydrogenering van propaan (ODHP) een attractief alternatief proces voor de directe productie van propyleen. De voordelen ten opzichte van de hydrogeneringsprocessen die momenteel worden toegepast, zijn:

- De conversie van propaan in het oxidatieve dehydrogeneringsproces is niet gelimiteerd door het thermodynamisch evenwicht,

- Oxidatieve dehydrogenering is exotherm, terwijl de klassieke dehydrogeneringsprocessen endotherm verlopen bij hoge temperaturen. Op hoge kosten voor warmtetoevoer bij hoge temperaturen kan dus worden bespaard,

- Koolstofvorming kan worden voorkomen in het oxidatieve dehydrogeneringsproces,

- Er kan een hoge propyleen/ethyleen product ratio worden verkregen.

- Het oxidatieve dehydrogeneringsproces kan worden uitgevoerd bij gematigde temperaturen van rond de $500^{\circ} \mathrm{C}$.

Deze voordelen maken oxidatieve dehydrogenering een aantrekkelijk alternatief voor industriële propyleen productie.

In de onderzoeksliteratuur naar oxidatieve dehydrogenering zijn twee hoofdstromingen te onderscheiden. Een onderzoekslijn concentreert zich op het ontwerpen van katalysatoren die alkanen partieel oxideren naar olefins met opbrengsten die vergelijkbaar zijn met die in de huidige technologie voor propyleen productie. De andere onderzoekslijn concentreert zich op nieuwe reactor ontwerpen en onconventioneel reactorgebruik (bijvoorbeeld: cyclische reactantentoevoer) ten einde de prestaties van de traditionele reactor configuraties en hun gebruik te kunnen overtreffen.

In dit proefschrift wordt beschreven hoe met een verbeterd reactor concept de propyleen opbrengst kan worden verhoogd met het oxidatieve dehydrogeneringsproces en wordt deze verbetering gekwantificeerd. 
Als eerste is een literatuuronderzoek uitgevoerd naar katalysatoren en reactie condities die een maximale ethyleen productie mogelijk maken. Tegelijkertijd werden verschillende reactorconcepten onderzocht. Zowel gepakte bed reactoren met een voorgemengde of distributieve zuurstof toevoer, als gefluidiseerde bed reactoren worden besproken. Onderzoek naar de proces condities liet zien dat de oxidatieve dehydrogenering van propaan kan worden uitgevoerd bij gematigde temperatuurniveau's, wat een groot voordeel is in termen van energie-efficiëntie in vergelijking met de traditionele dehydrogeneringsprocessen. Bij operatie onder atmosferische of bijna atmosferische druk werden optimale resultaten gevonden. Deze input werd gebruikt voor de selectie van de condities in het experimentele werk beschreven in dit proefschrift. Een combinatie van $\mathrm{Ga}_{2} \mathrm{O}_{3}$ en $\mathrm{MoO}_{3}$ werd gebruikt als katalysator in dit onderzoek. De $\mathrm{Ga}_{2} \mathrm{O}_{3} / \mathrm{MoO}_{3}$ katalysator combineert succesvol de goede alkaan activerings eigenschappen van $\mathrm{Ga}_{2} \mathrm{O}_{3}$ met de selectieve oxidatie eigenschappen van $\mathrm{MoO}_{3}$. Bovendien is deze katalysator gemakkelijk te bereiden, terwijl de prestaties vergelijkbaar zijn met andere, meer verfijndere (en dus duurdere) katalysatoren. Kinetische gegevens voor deze katalysator zijn in de literuur echter niet te vinden. Om deze reden is eerst de reactiekinetiek experimenteel bepaald.

In de kinetische bestudering van de oxidatieve dehydrogenering van propaan met een $\mathrm{Ga}_{2} \mathrm{O}_{3} / \mathrm{MoO}_{3}$ katalysator zijn de reactiesnelheden experimenteel bepaald in een katalytische reactor onder differentiële reactie condities voor het gekatalyseerde en het nietgekatalyeerde systeem. De verkregen resultaten laten zien dat de reactie orde in zuurstof hoger is voor de nevenreacties in vergelijking met de hoofdreactie, wat aangeeft dat distributieve zuurstoftoevoer in een gepakt bed membraan reactor kan worden gebruikt om de propyleen productie te optimaliseren. De reactie is tevens bestudeerd in afwezigheid van de katalysator. Ook in dit geval werd een hogere reactie orde in zuurstof gevonden voor de nevenreacties. Om het voordeel van een gepakt bed membraan reactor met distributieve zuurstoftoevoer ten opzichte van een gepakt bed reactor met voorgemengde reactantentoevoer te kwantificeren, is een gedetailleerd numeriek model ontwikkeld. Een model reactor bestaande uit meerdere componenten en een variabel aantal compartimenten werd ontwikkeld in een buis-in-buis configuratie. Als het aantal compartimenten gelijk is aan één, wordt een enkele buis reactor met voorgemengde reactanten gemodelleerd, terwijl als het aantal compartimenten gelijk is aan twee, een membraan reactor met distributieve reactantentoevoer. Met de gewijzigde Thiele modulus voor 1 dimensionale diffusie werd geverifieerd dat een 1D model beschrijving voor dit systeem geschikt is. Evenzo werd getest (en gevonden) dat de katalysatordeeltjes zich praktisch isotherm gedragen, zo dat in dit geval een pseudo homogene aanpak voldoet. Gebruik maken van dit model werd het gedrag van een reactor tijdens de oxidatieve dehydrogenering van propaan gesimuleerd voor voorgemengde en distributieve zuurstoftoevoer, terwijl de compositie van de reactanten, doorstroomsnelheden en mate en wijze van verdunning werden gevarieerd. De simulatieresultaten lieten zien dat er grote verbeteringen in de propyleen opbrengst kunnen worden behaald met distributieve zuurstoftoevoer. 
Ten einde de resultaten van de numerieke simulaties te valideren werd een serie experimenten uitgevoerd in een gepakt bed membraan reactor op lab schaal. Een experimentele setup werd uitgerust met een enkele membraanbuis met de vereiste fysische en mechanische eigenschappen. Er werden experimenten uitgevoerd met zowel voorgemengde als distributieve zuurstof toevoer en de resultaten werden met elkaar vergeleken. De invloed van de gassamenstelling, doorstroomsnelheid en de mate van verdunning werd onderzocht. Daarnaast is ook de mate van terugdiffusie van propaan van de buiskant van de membraan reactor naar de buitenkant als gevolg van de concentratiegradiënt onderzocht. De goede overeenkomst tussen de experimentele resultaten en de resultaten van de numerieke simulaties toont aan dat het gebruikte model inderdaad geschikt is om de oxidatieve hydrogenering van propaan accuraat te beschrijven. Alleen in het geval van verdunning aan de buiskant werd er een grotere discrepantie tussen de experimenteel en de numeriek verkregen resultaten gevonden. Tot besluit laten deze resultaten zien dat een significant hogere propyleen opbrengst kan worden verkregen bij hogere propaan conversies in een gepakt-bed-membraan reactor, uitgevoerd bij lagere temperaturen vergeleken met conventionele reactor concepten voor de oxidatieve dehydrogenering van propaan (in een gepakt bed met voorgemengde reactanten toevoer). 



\section{Сажетак}

Ограничења постојећих процеса за производњу пропилена, као и велики пораст потражње за пропиленом током протекле деценије, учинили су да оксидативна дехидрогенација пропана (ОДХП) постане занимљив алтернативни начин производње пропилена директним поступком. Значајне предности овог поступка су:

• Конверзија пропана у ОДХП није ограничена термодинамичком равнотежом,

- ОДХ је егзотермна, те је према томе повољнија у односу на класичне дехидрогенационе процесе, који су ендотермни и захтевају скупоцено довођење топлоте на високим температурама,

- Нема настајања кокса,

- Добија се велики однос пропилен/етилен,

- Процес је могућ на умереним температурама од око $500^{\circ} \mathrm{C}$.

Наведене предности чине овај процес врло перспективним за могућу индустријску употребу у будућности.

Истраживања на тему ОДХП, обрађена у литератури, могу да се поделе у две категорије. Један правац истраживања се фокусира на дизајн катализатора који парцијално оксидују алкане до алкена са приносима упоредивим са приносима добијеним користећи технологије за производњу пропилена које су тренутно у употреби. Други правац се фокусира на различите конфигурације реактора, као и неконвенционални рад реактора (циклично довођење реактаната, на пример), који могу да буду знатно бољи у поређењу са „традиционалним” конфигурацијама реактора и њиховим начином рада.

Главни циљ истраживања приказаног у овој тези је испитивање и квантификација утицаја напредног дизајна реактора на повећање приноса пропилена у ОДХП.

Као прво, проучена је литература, да би се истражило који каталитички системи и какви процесни услови резултују највећим приносом пропилена. Ово је било праћено и истраживањем различитих предлаганих реакторских концепата. Разматрани су реактори са пакованим слојем са и без дистрибуисаног довода кисеоника, 
као и реактори са флуидизованим слојем. Истраживање на тему процесних услова је показало да је оксидативна дехидрогенација пропана могућа на умереним температурама, што је свакако од велике користи у смислу искоришћења енергије, у поређењу са конвенционалним поступцима дехидрогенације. У литератури је показано да рад на атмосферском притиску, или притиску блиском атмосферском, даје оптималане резултате. Ово је касније коришћено приликом избора услова за експериментални рад описан у тези. Такође је наведено да би комбинација $\mathrm{Ga}_{2} \mathrm{O}_{3}$ ca $\mathrm{MoO}_{3}$ могла да буде катализатор који би се користио у овом истраживању. Наиме, катализатор $\mathrm{Ga}_{2} \mathrm{O}_{3} / \mathrm{MoO}_{3}$ у себи комбинује добру способност $\mathrm{Ga}_{2} \mathrm{O}_{3}$ за активацију алкана са способношћу $\mathrm{MoO}_{3}$ за селективну оксидацију. Такође, овај катализатор се једноставно прави, док је његов учинак упоредив са учинцима других, сложенијих, (те тиме и скупљих) каталитичких система. На жалост, подаци о кинетици за овај конкретни каталитички систем нису били доступни у литератури, те је за оцену учинка реакторског система било неопходно да се испита и кинетика реакционог система.

Приликом испитивања кинетике ОДХП на катализатору $\mathrm{Ga}_{2} \mathrm{O}_{3} / \mathrm{MoO}_{3}$ која је затим уследила, брзине реакција за катализован и некатализован систем су експериментално одређене у каталитичком реактору, при диференцијалним реакционим условима. Потврђено је на више начина да је одређивана само унутрашња кинетика. Добијени резултати су показали да је ред реакције у односу на кисеоник већи за случај споредних реакција него за главну реакцију, указујући да дистрибуисани довод кисеоника помоћу мембранског реактора са пакованим слојем може да максимизује принос пропилена. Реакциони систем је проучаван и у одсуству катализатора и поново је нађено да је ред реакције у односу на кисеоник већи за споредне реакције. Да би се квантификовале предности употребе мембранског реактора са пакованим слојем, у односу на реактор са пакованим слојем где се реактанти доводе већ претходно помешани, развијен је детаљан нумерички модел. Вишекомпонентни, вишеделни модел реактора је развијен за конфигурацију цев-у-цеви, при чему је могуће мењање броја одељака. Уколико је број одељака једнак јединици, модел представља реактор са једном цеви и унапред помешаним доводом гасова, док у случају да постоје два одељка, модел представља модел мембранског реактора са дистрибуисаним доводом реактан(а)та. Користећи концепт модификованог Тилеовог модула, потврђено је да је једнодимензионални модел задовољавајући. Такође је испитано (и потврђено) да су честице катализатора практично изотермне, тако да је псеудохомогени приступ валидан у испитиваним случајевима. Користећи овај модел, симулиран је рад каталитичког реактора за ОДХП, за случај дистрибуисаног и недистрибуисаног довода кисеоника, при чему је мењан састав реактаната, протоци, као и степен и начин разблажења реакционе смеше. Резултати симулација су показали да је дистрибуисаним довођењем кисеоника могуће остварити значајно повећање приноса пропилена. 
Напослетку, да би се потврдили резултати нумеричких симулација, изведена је серија експеримената на лабораторијском мембранском реактору са пакованим слојем. Претходно је конструисан реактор опремљен мембранском цеви, одговарајућих механичких и физичких особина. Изведени су експерименти како са дистрибуисаним, тако и са недистрибуисаним доводом кисеоника и затим упоређени резултати, а испитани су такође и утицаји састава гасне смеше, промене протока и степена и начина разблажења. Испитиван је и степен повратне пермеације пропана из цеви мембранског реактора у ануларни простор, услед разлике у концентрацији. Добро слагање између експерименталних и резултата нумеричких симулација је показало да је модел заиста задовољавајући за описивање процеса оксидативне дехидрогенације пропана. Нешто веће неслагање експерименталних и теоријских резултата је забележено једино у случају разблаживања реактаната који протичу кроз унутрашњу цев реактора. Ово неслагање је последица занемаривања утицаја повратне пермеације у моделу. Коначно, резултати су такође показали да је у мембранском реактору са пакованим слојем могуће остварити и значајно већи принос пропилена при већој конверзији пропана и на знатно нижој температури, надмашујући притом могућности конвенционалног реактора за ОДХП (реактор са пакованим слојем, код кога се реактанти доводе претходно већ помешани). 



\section{About the author}

Željko Kotanjac was born in Kraljevo (Serbia) on September 25, 1977.

In October 1996, after completing secondary education in Gymnasium (major in natural sciences), he became a student at Faculty of Technology and Metallurgy of Belgrade University, Serbia. As one of the best students, he had an opportunity to do his traineeship in Eka Chemicals (AKZO Nobel) in Bohus, Sweden. After graduation in September 2002, with a thesis titled "Dynamic Holdup In A Three Phase Gas-Solid-Solid Contactors" he continued his studies through a postgraduate research program at the same faculty. In the period 2000-2004, he was also employed as a teaching assistant for the subject "Electronics for chemical engineers".

Being offered a $\mathrm{PhD}$ position at the University of Twente, he came to The Netherlands in February 2004. In the years that followed, he studied a reactor concept for the oxidative dehydrogenation of propane, with this thesis as a result. 
